San Jose State University

SJSU ScholarWorks

Master's Theses

Master's Theses and Graduate Research

1995

\title{
The development of a computer based courseware to teach research methods
}

Laura McEwen

San Jose State University

Follow this and additional works at: https://scholarworks.sjsu.edu/etd_theses

\section{Recommended Citation}

McEwen, Laura, "The development of a computer based courseware to teach research methods" (1995). Master's Theses. 1164.

DOI: https://doi.org/10.31979/etd.a8h8-vyu3

https://scholarworks.sjsu.edu/etd_theses/1164

This Thesis is brought to you for free and open access by the Master's Theses and Graduate Research at SJSU ScholarWorks. It has been accepted for inclusion in Master's Theses by an authorized administrator of SJSU ScholarWorks. For more information, please contact scholarworks@sjsu.edu. 


\section{INFORMATION TO USERS}

This manuscript has been reproduced from the microfilm master. UMI films the text directly from the original or copy submitted. Thus, some thesis and dissertation copies are in typewriter face, while others may be from any type of computer printer.

The quality of this reproduction is dependent upon the quality of the copy submitted. Broken or indistinct print, colored or poor quality illustrations and photographs, print bleedthrough, substandard margins, and improper alignment can adversely affect reproduction.

In the unlikely, event that the author did not send UMI a complete manuscript and there are missing pages, these will be noted. Also, if unauthorized copyright material had to be removed, a note will indicate the deletion.

Oversize materials (e.g., maps, drawings, charts) are reproduced by sectioning the original, beginning at the upper left-hand corner and contimuing from left to right in equal sections with small overlaps. Each original is also photographed in one exposure and is included in reduced form at the back of the book.

Photographs included in the original mamuscript have been reproduced xerographically in this copy. Higher quality $6^{n} \times 9^{n}$ black and white photographic prints are available for any photographs or illustrations appearing in this copy for an additional charge. Contact UMI directly to order.

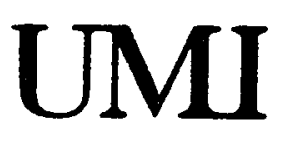

A Bell \& Howell information Company

300 North Zeeb Road. Ann Arbor. MI 48106-1346 USA

313:761-4700 800:521-0600 
THE DEVELOPMENT OF A COMPUTER

BASED COURSEWARE TO TEACH RESEARCH METHODS

\author{
A Thesis \\ Presented to \\ The Faculty of the Department of \\ Nutrition and Food Science \\ San Jose State University \\ In Partial Fulfillment \\ of the Requirements for the Degree \\ Master of Science \\ in Nutritional Science
}

By

Laura McEwen

December, 1995 
UMI Number: 1377255

UMI Microform 1377255

Copyright 1996, by UMI Company. All rights reserved.

This microform edition is protected against unauthorized copying under Title 17, Onited States code.

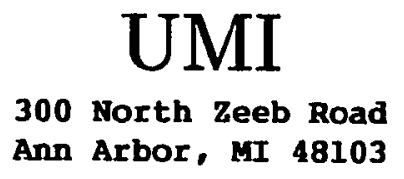




\section{(C)1995}

Laura McEwen

ALI RIGHTS RESERVED 
APPROVED FOR THE DEPARTMENT OF NUTRITION AND FOOD SCIENCE

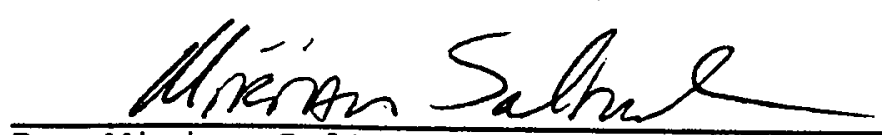

Dr. Miriam Saltmarch, Ph.D., Graduate Advisor Department of Nutrition and Food Science

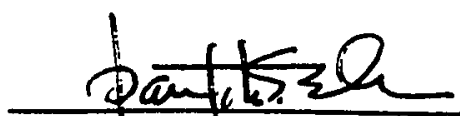

Dr. Fanfilo Belo, Ph.D., Professor

Department of Nutrition and Food Science

Mananas decker

Dr. Kathryn Sucker, PhD., R.D., Professor Department of Nutrition and Food science

APPROVED FOR THE UNIVERSITY

M. Iou Licuardoushi 


\begin{abstract}
THE DEVELOPMENT OF A COMPUTER

BASED COURSEWARE TO TEACH RESEARCH METHODS

by Laura McEwen
\end{abstract}

Research methodology curricula is an important part of the nutrition program at San Jose State University. A preliminary computer based instruction (CBI) courseware on research methodology was developed. The purpose of this study was (1) to evaluate the preliminary CBI courseware modules, (2) to complete development of the courseware modules based on these evaluations, and (3) to evaluate the completely developed courseware modules. Ten students evaluated the preliminary CBI courseware with several methods, including focus groups. The initial evaluation led to the final development which included multicolored text, high-resolution colored graphics, sound, and real-time video segments in approximately 10-14 hours of user interaction. Three groups of students (total $\underline{n}=29$ ) evaluated the final courseware and agreed or strongly agreed that the courseware features were presented in a logical manner and enhanced understanding. 


\section{ACKNOWLEDGMENTS}

I wholeheartedly want to acknowledge my advisor, Dr. Miriam Saltmarch, for her dedication, energy, and support. Without her vision and confidence in me, I could not have completed the courseware or the thesis.

I extend deep thanks and appreciation to Dana Arnold, Vicki Castelli, Meenakshi Hejmadi, and Yvette Rivas whose projects contributed so much to the CBI courseware.

There are numerous people within the San Jose State University community whose willingness to give so freely of their time enriched the CBI courseware; Lucia Karakostios, Jesse Martinez, Gloria Meerscheidt, and Candyce Roberts. A great deal of appreciation goes to Don Perrin and Morning Shu of the Alquist Center for Innovative Learning.

A special note of appreciation to Dr. Belo whose open door policy always provided a calm oasis of good advice, realism, and confidence.

Most of all, I want to thank my husband, Jim Falls, for his incredible support and help on the program. Without his patience and love this project would have never been undertaken. 


\section{PREFACE}

This thesis is written in publication style. The second chapter is written in the journal format according to the style guide for research papers and will be submitted to the Journal on Excellence in College Teaching. The first and third chapters are written according to the guidelines outlined in the Publication Manual of the American Psychological Association, third edition, 1983. 
Table uf Contents

PAGE

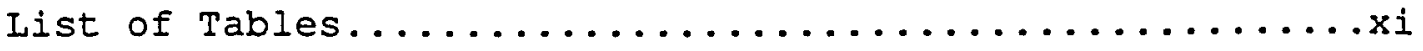
CHAPTER

1 INTRODUCTION AND REVIEW OF THE IITERATURE..........

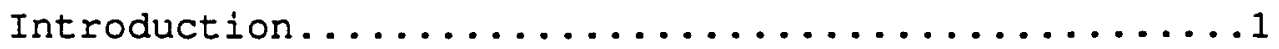

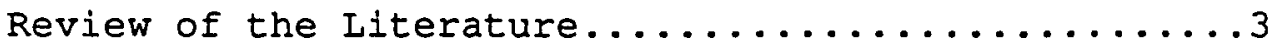

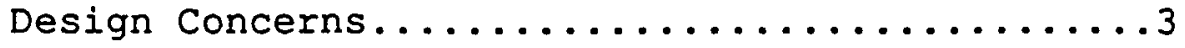

Pedagogical Design Concerns with CBI........3

Specific Design Concerns with CBI Features...4

Text.....................

Pictures and Images...............

Examples......................

Questions......................

Sequence Control.................

Small Group Learning...............

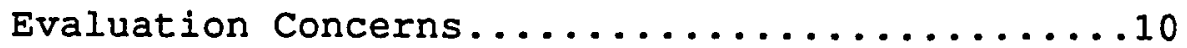

Focus Groups....................10

Conceptual Frame of Reference..........11

Group Interactions...............11

Iikert scale...................11

Summary of Literature Review.............12

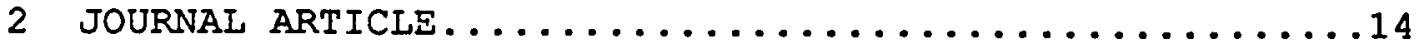

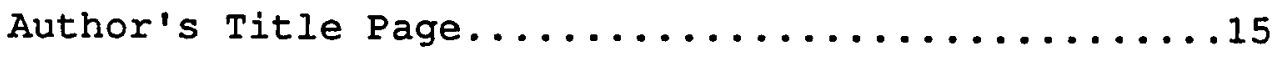




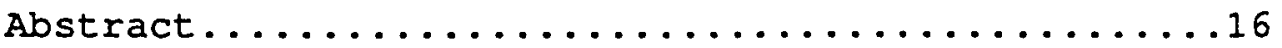

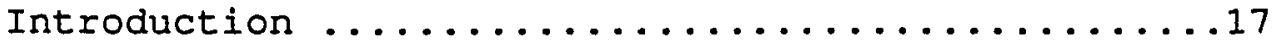

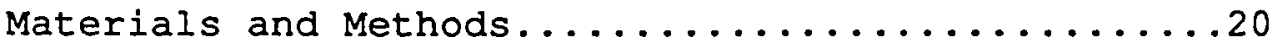

Materials.........................20

Hardware and Software.............20

Questionnaires..................20

Focus Groups and Interviews..........20

Methods..........................21

Evaluation of the Preliminary Courseware..21

Focus Groups.................21

Final Development of the Modules........22

Structure and Text...........22

Images...................22

Audio and video...............23

Final Evaluation of the Modules.........23

Questionnaires and Focus Groups.....23

Results and Discussion...................26

Focus Group Evaluation of the Preliminary

Courseware....................25

Results of the Final Courseware Development....26

Text.........................

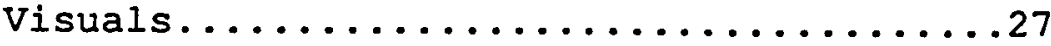

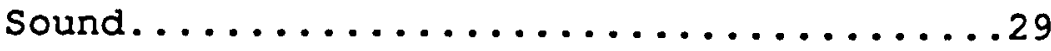




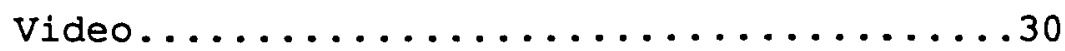

Evaluation of the Final Courseware..........30

Results from the Midway Evaluation......30

Questionnaires...................30

Focus Groups.......................

Results from the Final Evaluation.......32

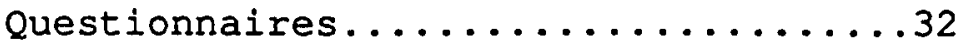

Individual Interviews............34

Results of Final Evaluation from San

Diego State University Students.....35

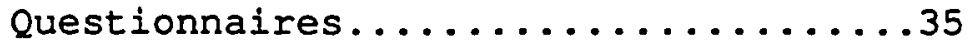

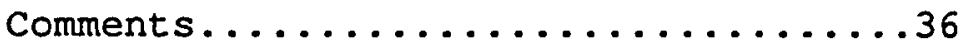

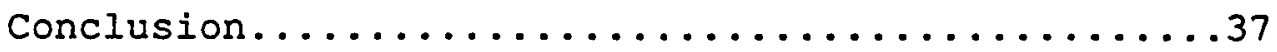

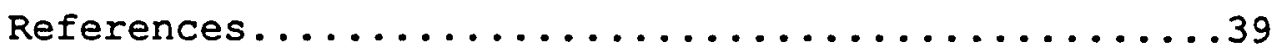

3 CONCLUSIONS AND RECOMMENDATIONS............... 56

4 REFERENCES ........................... 58

5 APPENDICES........................... 62

Appendix A: Questionnaire, Evaluation of the

Preliminary Courseware...............63

Appendix B: Questionnaire, Evaluation of the

Midway Evaluation...................66

Appendix C: Questionnaire, Group Two..........69

Appendix D: Questionnaire, SDSU Students........72

Appendix E: Topic Files with Names...........75 
Appendix F: Module 1: Program Details and

External Files...................78

Appendix G: Module 2: Program Details and

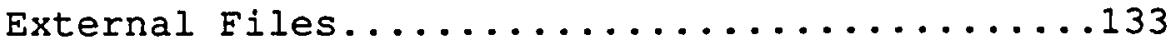

Appendix H: Module 3: Program Details and

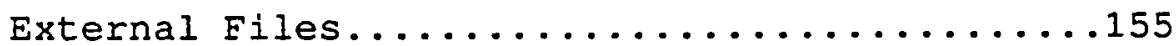

Appendix G: V. Castelli - Master's Project......168 
List of Tables

TABLE

PAGE

1 Hardware and Software....................43

2 Outline for Focus Group Evaluating the Preliminary

Courseware.........................44

3 Subject Content of Three Modules...............45

4 Structure of the Topic sections...............46

5 Focus Groups Results: Evaluation of the Preliminary

Courseware......................47

6 Average Score of Final Evaluation: Midway

Evaluation......................48

7 Average Score of Final Courseware - Group Two

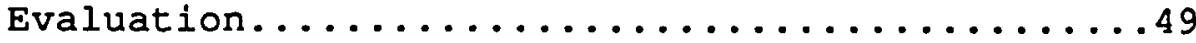

8 Ranking of Attributes Wanted More or Less

Frequently - Group Two Evaluation..........50

9 Ranking of Attributes That Students Identified as

Most or Least Important - Group Two Evaluation..51

10 Summary of Individual Interviews - Group Two

Evaluation.........................52

11 Average Score of Final Courseware - SDSU Evaluation..53

12 Ranking of Attributes Wanted More or Less

Frequently - SDSU Evaluation............54

13 Ranking of Attributes That Students Identified as

Most or Least Important - SDSU Evaluation......55 
CHAPTER 1

INTRODUCTION AND REVIEW OF THE LITERATURE

Introduction

Curricula at the undergraduate level in research methodology are an essential and integral part of the nutrition program at San Jose State University (SJSU) . Research methodology is a knowledge requirement of the American Dietetic Association (ADA, Plan V) for undergraduate dietetic programs. Recently, many ADA Approved Plan IV/V programs have begun to strengthen their research methodology curricula to meet the more stringent requirements on the Registration Exam for dietitians. Consequently, there is increased need for dietitians to be knowledgeable consumers of research information. There is concern that it would be too costly or too difficult to increase the scope of the research methods course.

In a meta-analysis by Kulik and Kulik (1987), it was found that: 1) students generally learned more in classes when they received help from computers, 2) students learned their lessons with less instructional time and, 3) students liked their classes more when they received computer help. Another meta-analysis by Cohen and Dacanay (1992) reported that computer enriched versions of computer based instruction (CBI), such as simulation or interactive video, 
had large positive effects on the effectiveness in education of health professions. Proponents of CBI believe that the computer can simulate real life clinical scenarios in health education settings. (Cohen \& Dacanay, 1992).

Computer based instruction also has the potential to provide quality education in research methodology to undergraduate students in nutrition. This CBI courseware can optimize the amount of material and can act as an adjunct to conventional instructional techniques freeing the instructor to utilize new and more critical thinking forms of instruction. In order to achieve this, it is first necessary to develop CBI courseware. Any development must include an evaluation component to ensure that the courseware adequately addresses student learning needs and preferences. The objectives for this study were (1) to evaluate the preliminary research methodology CBI courseware modules, (2) to complete development of the CBI courseware based on evaluation of the initial courseware, and (3) to evaluate the developed research methodology CBI courseware. 
Review of the Literature

Design Concerns

Pedagogical Design Concerns with CBI

Most of the learning theories associated with

pedagogical CBI courseware are grounded in the cognitive learning theories with emphasis on elements to create metacognition in the learner. According to cognitive theorists, the meaningfulness of information is a primary variable affecting the strength of learning (Hannifin \& Peck, 1988). Theories directly influence how a courseware is designed. Consequently, design is defined as the purposeful organization of presentation stimuli in order to influence how students process information (Hannifin \& Hooper, 1989). The elaboration theory (Reigeluth \& Stein, 1983) provided insight to macro-design elements of $\mathrm{CBI}$. Instruction should begin with an overview and then proceed to more complex ideas that elaborate the primary concept. The progression adds detail, counter-concepts, and finally, abstraction.

Component design theory (Merrill, 1987) proposed that there are different categories of learning. Tasks can be categorized and accomplishments associated with the task can be measured. The main principles state that cognitive structures are consistently associated with learning 
outcome, the learner needs to be navigated through the program, and the learner should have time to practice. The schema theory (Jonassen, 1988) proposed that learning is a reorganization of ideas in semantic memory. The schema, or mental associations about an idea, are restructured and interlinked in the learning process.

Hannifin and Hooper (1989) proposed another cognitive model for CBI design based on three principal foundations in the psychological, instructional, and the technological realms. Specifically, good screen design should cause learners to develop and maintain interest, to promote deep processing, to facilitate engagement between the learner and the lesson content, and to help lesson navigation (Hannifin \& Hooper, 1989).

\section{Specific Design Concerns of CBI Features}

The CBI terminology describes the technology, i.e., the computer, and not the processes made possible by the medium (Higginbotham-Wheat, 1991). Computer based instruction does not have universally defined features. It can be a simple, externally paced, drill-and-practice routine that lasts a few minutes. It can also be an advanced, interactive, simulation that lasts hours. Unfortunately, the literature contains only limited studies showing the effectiveness of specific features within a CBI courseware. 
The literature is also very limited in qualitative studies to identify features that students felt were effective. Although many quantitative studies survey students about their attitudes towards CBI courseware, it rarely defines the attributes that influenced students attitudes.

$\underline{\text { Text }}$

Computer design guidelines recommended that screen text be simple and that there is ample space around the text to decrease the search time for the students and aid in the recognition of important information (Rambally \& Rambally, 1987; Milheim \& Lavix, 1992)

Morrison (1989) and Ross and Morrison (1989) investigated text density in print and $C B I$ media. Text density is amount of context given in the CBI. Results confirmed that low text density in either print or CBI was as effective as high density text. In addition, students tended to prefer the low-density material when given a choice.

\section{Pictures and Images}

The theoretical framework for the effectiveness of pictures is based on the dual-coding theory advanced by Pavio (1986). This theory suggests that there are independent cognitive encoding systems, one visual and one 
verbal. Information is more likely to be remembered if it is encoded in both the verbal and the visual systems. In addition, recall is more likely to occur when the content is easily abstracted to images by the learner. Consequently, any image, such as still pictures, graphs, animation, and perhaps even video, should be expected to aid in the recall of information when it serves to precisely illustrate a concept (Rieber, 1989).

Rieber (1989) established a taxonomy for classifying the uses of animated visuals in CBI instruction. This taxonomy is flexible enough to encompass most any image or graphic in CBI. The six levels are (1) cosmetic, (2) attention gaining, (3) motivation/reinforcement, (4) presentation, (5) conceptualization, and (6) interactive dynamics.

Dwyer (1978) found that pictures facilitated learning in adults when there is sufficient processing time to scan the visual material in search of essential learning cues. If insufficient time is given, students may choose to ignore the visual material and attend to the more familiar printed text. Levin and Lesgold (1978) also found that pictures should be highly related or congruent to the textual material. Unrelated pictures or pictures that are too complex may be distracting. Although the research was not 
performed in computer media, the results are important for CBI designers of courseware that are externally paced or have limited time for students interaction.

Examples

According to the dual coding theory, examples of concepts are more effective if they can be imagined. In addition, there is increasing emphasis on making connections between the learner's existing knowledge structure and new information (Peterson, 1988). When college students were given a choice of examples, such as education, business, sports, or no examples, to their CBI course in education, no significant difference in achievement was found with any of the example choices (Ross, 1990). Even so, the students were very positive about selecting the type of examples. More research is needed to substantiate the effectiveness of custom examples.

\section{Questions}

There is a long teaching tradition for students to answer questions to prove understanding of the material. The quality of the answers often determine the effectiveness of the educational process. In CBI courseware, not unlike traditional learning environments, questions are also important navigational tools or learning cues for students. Interactive $C B I$ relies heavily on questions as an integral 
part of the structure of the courseware, rather just as an evaluation tool.

Shiang and McDaniel (1991) imbedded three types of questions in a CBI: (1) external higher order questions, external lower order questions, and (3) self generated questions. The students were allowed to take notes during the CBI course. The quality and complexity of the student's written responses were correlated to the previous four variables. They found no significant difference between the higher order, lower order, or self generated questions on the quality of the final explanation. They did find that students who elected to take notes produced explanations that were more thoughtful, complex, and complete than students who did not take notes (Shiang \& McDaniel, 1991). Sequence Control

One of the unique features of CBI is the possibility of learner control over the pacing and sequencing of the material. As technology improves, CBI has moved from linear, designer-paced programs to interactive branched programs that are learner-paced. The assumption is that the more control over the instruction the learner has, the greater the learner's motivation. Even so, the research shows varied results on the effectiveness of various type of pacing and sequencing in $\mathrm{CBI}$. 
In some early $\mathrm{CBI}$ research, O'Day, Kulhavy, \& Malczynski (1971) found that a linear format showed higher post-test gains than either a branching or auto-elucidative format in a CBI about the function and structure of the human eye.

Gray (1987) found that a CBI with a branching pattern resulted in significantly higher immediate post test scores than a linear pattern. A week after the post test, there was no significant difference between the two groups when tested a second time. Students who used the linear format had a better attitude toward the CBI. Gray (1987) concluded that too much sequence control may serve to distract the student. With each screen, two complex decisions have to be made; what decision to choose, and then where in the CBI to travel. If the program is linear, only one decision has to be made.

\section{Small Group Learning}

In general, CBI is utilized in pairs or trios of learners, and thus is uniquely different from the traditional lecture learning environment.

Mevarech, Silber, and Fine (1991) found that pairs using drill and practice math programs performed better than students who used it individually. They also found that use 
of the CBI in pairs alleviated math anxiety of low ability students more than the individual CBI treatment.

Other researchers have found that lower ability students responded differently to CBI than did higher ability students. Schlechter (1992) found that for tasks designed for individual performance, lower ability students preferred small group CBI and higher ability students preferred individualized CBI. For small group learning tasks, the opposite preferences occurred (Schlecter, 1992).

\section{Evaluation Concerns}

\section{Focus Groups}

A focus group interview is a qualitative research technique used to obtain data about feelings and opinions of small groups of participants about a given problem, experience, service, or other phenomena (Basch, 1987). Generally, a moderator leads eight to ten participants who do not know each other through an interview that lasts approximately 60 minutes.

Academic institutions are using focus groups as a way to reassess programs and curricula, especially in the face of less government funding (McDermott, 1987; Elliott, Ingersoll, \& Smith, 1984). 


\section{Conceptual Frame of Reference}

The hallmark of focus groups is the explicit use of the group interaction to produce data and insights that would be less accessible without the interaction found in a group (Morgan, 1988). From a psychological perspective, this challenges the participants to bring more ideas into the cognitive realm. The challenge of focus group research is to identify the trends of attitudes and the interrelations so when viewed as a whole, these attributes can be seen to form a system (Crespi, 1965).

\section{Group Interaction}

Fern (1982) found that focus groups of participants who do not know one another generated significantly more ideas than focus groups made up of acquaintances. Although the quality of the ideas was not evaluated, indications are that strangers produce a higher volume of ideas in focus group interviews than acquaintances.

\section{Likert Scale}

The Likert scale was developed by Rensis Likert in 1932, as a simple scale method of attitude measurement. Attitude is defined as expressed opinion. It is understood that only the actual attitude expressed can be measured and that the subjects may be consciously hiding their true 
attitude or that the social pressure of the situation have made them believe what they expressed.

This qualitative method stems from Thurston's Law of Comparative Judgment which proposed the rationale for the placement of psychological stimuli along a continuum independent of any underlying physical order. Since then, it has become a very important method of attitude measurement (Seiler \& Hough, 1970).

\section{Summary of Literature Review}

Although the literature has shown CBI to be effective, the research is less clear regarding which features lead to the effectiveness of the courseware. A simplified text is generally preferred by students and is as effective as more lengthy text. Theoretically, if pictures or images aid the student's ability to imagine the content, learner outcome is improved. Researchers found that pictures facilitate learning if there is sufficient time to mentally process the image and if it is highly related to the text. Custom contexts have not shown to enhance performance, but students are very positive about the concept. In general, CBI rely very heavily on questions, although the effectiveness of questions on learner outcome is still under debate. Sequencing in CBI is changing from linear designercontrolled programs to branched user-controlled media. Even 
so, the linear sequencing was shown to be effective and liked by students. Small group learning with CBI was shown to enhance the outcome of students, especially low aptitude students.

Focus groups started as a qualitative research tool in the social sciences, but are now used in many areas to evaluate media, products, and academic programs. Generally, focus groups consist of eight to ten participants who do not know one another. Research has found that focus groups of strangers produce a higher volume of ideas than acquaintances. 
CHAPTER 2

JOURNAL ARTICLE 
Author's Title Page

THE DEVELOPMENT OF A COMPUTER BASED DIGITAL VIDEO INTERACTIVE COMPUTER COURSEWARE TO

TEACH RESEARCH METHODOLOGY

Laura McEwen, M.S., Miriam Saltmarch, Ph.D., Vicki Castelli, M.S., Kathryn Sucher, Ph.D, R.D., Iucy McProud, Ph.D., R.D., Dana Arnold, M.S., Meenakshi Hejmadi, M.S., Yvette Rivas, M.S. and Jill Ellis, Ph.D. Department of Nutrition and Food Science San Jose State University One Washington Square San Jose, California 95192

For all correspondence, please contact Dr. Miriam Saltmarch, Department of Nutrition and Food Science, San Jose State University, One Washington Square, San Jose, California, $95192,408-924-3118$. 
Abstract

Research methodology curricula is an important part of the nutrition program at San Jose State University. A preliminary computer-based instruction (CBI) courseware on research methodology was developed. The purpose of this study was (1) to evaluate the preliminary CBI courseware modules, (2) to complete the development of the courseware modules based on these evaluations, and (3) to evaluate the developed courseware modules. Ten students evaluated the preliminary CBI courseware with several methods, including focus groups. The initial evaluations led to the final development which included multicolored text, highresolution color graphics, sound, real-time video segments, and extensive multiple choice questions in approximately 1014 hours of user interaction. Three groups of students (total $n=29$ ) evaluated the final courseware and agreed or strongly agreed that the courseware features were presented in a logical manner and enhanced understanding. 
Introduction

Research methodology curricula is an important part of the nutrition program at San Jose State University (SJSU). A preliminary computer based instruction (CBI) courseware was developed to increase the scope of the research methods course. Although the literature has shown $\mathrm{CBI}$ to be effective (Kulik \& Kulik, 1987; Cohen, \& Dacanay, 1992), the cognitive theorists are in less agreement about the pedagogical design of CBI courseware. The elaboration theory (Reigeluth \& Stein, 1983) proposed that instruction should begin with an overview and proceed to more complex issues that elaborate the primary concept. Component design theory (Merrill, 1987) has aided in the micro-design of CBI in that that accomplishments associated with tasks can be measured.

The literature is limited in studies identifying the effective components of CBI. A simplified text is generally preferred by students and is as effective as more lengthy text (Milheim \& Lavix, 1992; Morrison, 1989; Ross \& Morrison, 1989; Rambally \& Rambally, 1987). Theoretically, if pictures or images aid the student's ability to imagine the content, learner outcome is improved (Pavio, 1989). Researchers found that pictures facilitate learning if there is sufficient time to mentally process the image and if it 
is highly related to the text (Hannifin \& Hooper, 1989; Rieber, 1989; Dwyer, 1978; Levin \& Lesgold, 1978). Custom examples have not been shown to enhance performance, but students are very positive about the concept (Peterson, 1988). In general, CBI relies very heavily on questions, although the effectiveness of questions on learner outcome is not been significantly proven (Shiang \& MCDaniel, 1991). Sequencing in $C B I$ is moving from linear designer-paced programs to branched program controlled by the learner. Even so, the linear sequencing was shown to be effective and liked by students (O'Day, Kulhavy, Anderson, \& Malczynski, 1971; Gray, 1987).

Small group learning with CBI was shown to enhance the outcome of students, especially low aptitude students (Mevarech, Silber, \& Fine, 1991; Schlecter, 1992).

Computer based instruction has the potential to provide quality education in research methodology to undergraduate students in nutrition. This CBI courseware can optimize the amount of material and can act as an adjunct to conventional instructional techniques freeing the instructor to utilize new and more critical thinking forms of instruction. In order to achieve this, it is first necessary to develop CBI courseware. Any development must include an evaluation 
component so that the courseware adequately addresses student learning needs.

The objectives for this study were (1) to evaluate preliminary research methodology CBI courseware modules, (2) to complete development of the CBI courseware based on the evaluation of these preliminary modules, and (3) to evaluate the developed research methodology CBI courseware modules. 
Materials and Methods

Materials

Hardware and Software

The CBI courseware was developed on an IBM-PC 486, 25 MHz, clone with two high capacity disc drives 11.2 gigabyte and 500 megabyte) and an Intel ActionMedia II DVI capture and delivery board. The courseware was developed with the authoring multimedia software Authology®, Version 2.0. A full list of the hardware and software used to develop the courseware is presented in Table 1.

Questionnaires

Three groups of students evaluated the CBI courseware with questionnaires that utilized the 5-point Likert scale ( 1 = strongly agree and 5 = strongly disagree), fill-in-theblank questions, and ranking. The questions evaluated the appropriateness and effectiveness of the content, examples, visual images, audio/video segments, test questions, and manner of presentation. The students were also asked to write comments.

Focus Groups and Interviews

Students from each group participated in focus groups or were randomly chosen for individual interviews after completion of the courseware. Questions were prepared in 
advance. The responses were tape recorded with the student's knowledge and analyzed after the session.

Methods

Evaluation of the Preliminary Courseware

Eocus group.

A group of female undergraduate nutrition majors ( $\mathrm{n}=$ 10) who had used the preliminary $C B I$ courseware in the Spring semester, 1993, participated in qualitative and quantitative evaluations of the preliminary courseware (Rivas, 1993; Hejmadi, 1993). These results and the results from two one-hour focus groups provided the direction for the final development of the CBI courseware. The students were informed that their participation in the focus groups was voluntary and their comments would not affect their grade in the class. They were also informed the focus groups were tape recorded. Two graduate students acted as moderators and asked the focus group prepared questions about specific attributes of the CBI (Table 2).

The tape recordings were transcribed and the comments grouped according to common themes in order to achieve a full range of answers to the questions presented. 
Final Development of the Modules

Structure and text.

The courseware was developed in three modules (Table

3). Each topic section in the modules had the same structure (Table 4).

The text from the preliminary courseware was edited to simple sentences or an outline. The text was divided into discrete units for each idea or concept. This separation was emphasized by placing a colored box behind every text segment.

Images.

Custom graphics, icons, and graphs were created with Harvard Graphics, Photostyler, ImagePrep, LUMENA, and a DOS based utility conversion program. Written permission was received to use all images in the courseware. Pictures were subsequently taken of students and staff at San Jose State University. All other images were from the public domain or of immediate family members who gave permission to be included in the courseware. Images were imported from other programs or directly scanned into Photostyler where they were then cropped and enhanced. These images were then exported to Imageprep to be converted and saved as Targa-16 files on the hard drive. All images were then finally converted and compressed to C16 files using a DOS based 
compression utility program and incorporated into the Authology ${ }^{\circledR}$ authoring program.

Audio and video.

The Instructional Resource Center at SJSU supplied music in the public domain. All music was copied from compact disc to video cassette tape. Narration was taped live directly onto video cassette tape. Written permission was received from all individuals whose video images were used in the courseware. Video segments were taped at various locations on the SJSU Campus. The Digital Video Producer software edited, captured, compressed, and saved to disk the audio and video segments which could then be used by the Authology® program.

Einal Evaluation of the Modules

Questionnaires and focus groups.

Three groups of students evaluated the developed CBI courseware with questionnaires, and two of these groups also participated in focus groups or individual interviews. The first group ( $\underline{n}=7$ ) evaluated the course midway through the final development, and the other two groups $(\underline{\mathrm{n}}=17 ; \underline{\mathrm{n}}=5$ ) evaluated the courseware upon its completion.

The first group was composed of female undergraduate students who had previously taken the research methodology course with either the preliminary CBI or the traditional 
classroom lecture (Arnold, 1994). They volunteered in Spring, 1993, to evaluate the courseware midway through its final development in late Fall, 1993. The students viewed the courseware in pairs or trios during three one hour sessions. After each session, they completed the objective Likert scale questionnaire. After the completion of the courseware, the students participated in a one hour focus group led by a graduate student and suggested improvements to the courseware. The students were informed that their participation was voluntary and that the group was tape recorded. The taped responses were evaluated and categorized by type of response.

The second group of female undergraduate nutrition majors were randomly chosen from 33 students enrolled in the research methodology course in the Spring of 1994 (Castelli, 1994). The students were grouped into pairs or trios and used the CBI in weekly one-hour sessions through the rest of the semester. At the end of the courseware, each student filled out the objective likert scale questionnaire to evaluate the courseware. After the completion of the course, six students were randomly chosen for individual taped interviews conducted by a graduate student. All the students were asked to give their overall impressions of the CBI courseware, its strengths and weaknesses, suggestions for 
improvement, and if they would recommend the course to others. The taped responses were evaluated.

The third group was composed of female graduate students from San Diego State University who had previously taken a research methodology course or were currently involved in research. A video tape was made of six topic sections in the CBI courseware. Each student viewed the tape individually during June of 1994, and completed the objective Likert scale questionnaire after each topic section. Due to logistical problems, no one from the SDSU group participated in a focus group or an interview at SJSU. 
Results and Discussion

Focus Group Evaluation of the Preliminary Courseware

Although students indicated they wanted a highly interactive courseware (Table 3), they reacted negatively to the branches and loops used in the preliminary courseware. Even though the return to a linear design runs opposite to the current trends in CBI design, a linear program was shown to be effective 10'Day, Kulhavy \& Malczynski, 1971; Gray, 1987). In addition, the authoring software did not easily support multiple loops or any file larger than 12 panels. Students preferred simple text which was shown to be effective and well liked (Morrison, 1989; Ross \& Morrison, 1989). The students stated that high quality resolution pictures should correlate directly with the text to aid in comprehension. This corresponds to the results of research (Rieber, 1989; Dwyer, 1978; Levin \& Lesgold, 1978). The focus group results showed that examples, video, and pictures should have themes applicable to college aged students. This positive response toward custom examples was also seen by Peterson (1988).

\section{Results of the Final Courseware Development}

Text

The preliminary text was edited to a very simple structure. A simplified text was highly desired by the 
students in preliminary evaluations (Hejmadi, 1993) and the focus group. The literature has shown that simplified text was effective and well-liked (Morrison, 1989; Ross \& Morrison, 1989).

The text was divided into discrete units for each idea or concept. Each text unit had a unique color and was placed on a different colored background to emphasize separation from other text units. The color and separation aided the student's ability to recognize important information (Rambally \& Rambally, 1987; Milheim \& Lavix, 1992).

The text was placed on approximately 380 panels and provided for extensive interaction time, about 10-14 hours. The students in the focus groups indicated the modules were well organized, comprehensive, and clear. Although the literature is limited regarding the effect of CBI length, the CBI courseware provided extensive amounts of information that was not considered excessive by the students (Hejmadi, 1993).

\section{Visuals}

Visual images in the form of pictures, graphs, or icons were added to every panel throughout the CBI. Approximately 300 images were used in the courseware. The students felt the pictures made the modules enjoyable (Hejmadi, 1993). The results of the focus group also indicated the students were 
positive about images. If images help students abstract the concepts to memory, recall is improved (Rieber, 1989).

Clear images of simple concepts with minimal

abstraction were used. Captions were added to every picture for clarification. Generally, the pictures were one-quarter screen or larger in size. Students in the focus group wanted large high-quality pictures that were easily understood and also included captions. Levin \& Lesgold (1978) found that pictures highly congruent to the text were also more effective in learner outcome.

Professionals or students actively engaged in research were common image themes. In addition, pictures of food and people consuming foods in their natural cultural context were other image topics. The focus group results indicated students wanted themes that were "college-aged" or represented "real-life." Ross (1990) found that students were very positive about custom examples, but no significant difference in learning with custom examples was found.

Icons, a special type of visual image, were used as location markers through each topic segment. Each topic subject had its own unique icon. For example, the topic on animal rights in research ethics, a rabbit superimposed on a international warning sign was used. When describing the advantages and disadvantages of a particular research type, 
icons of a "thumb-up" or a "thumb-down" was used. The purpose of the icons was to aid student navigation through the program. The focus group response indicated the students liked headings and other location markers; icons were a natural extension. According to the component theory (Merrill, 1987), students need to be aided in navigation through CBI programs.

Sound

Sound was associated with every panel in the form of music, narration, or radio-style dialog. Over 217 sound tracks were used in the courseware. The focus group results indicated sound was best as a reiteration of the text. There is limited research on the effectiveness of sound in CBI. Consequently, borrowing Rieber's (1989) taxonomy on animated visuals provided guidance for sound features. Sound was used for (1) cosmetic purposes, such as announcing a topic subject; (2) attention gaining, such as using whistles and animal noises; (3) motivation/reinforcement, such as restating the text; (4) presentation, such as talking about features of research; and (5) conceptualization, such as creating radio-style dialog discussing research ethics. In addition, music was used to create a soothing environment. 
$\underline{\text { Video }}$

Nine video segments lasting up to three minutes each were taped at various locations throughout the SJSU campus. The purpose of the video segments was to show male and female researchers involved in a broad spectrum of positive nutrition research roles. The focus group results indicated the students were very positive about video, especially as a means to simulate real-life situations. The literature is limited on the effectiveness of video clips within a CBI courseware. Video, much like graphics, may aid in the student's ability to imagine the content and improve learner outcome (Rieber, 1989).

Evaluation of the Final Courseware

Results from the Midway Evaluation

Questionnaires.

The average score for the seven students across all modules indicated that the students agreed that the CBI courseware was effective in many ways (Arnold, 1994; Table 6). The students felt that visual images made the information more interesting which was predicted, based on earlier focus group guideline of using large bright pictures of actual students and research that correlated with the text. According to Rieber (1989), graphics can be effectively used to arouse and maintain a learner's 
attention during CBI. In addition, good screen design should cause learners to maintain interest in the lesson content (Hannifin and Hooper 1989).

The students agreed that the audiolvideo option enhanced learning. From the written comments it was clear that the students wanted more video, even though some found the video segment of a laporoscopy workshop objectionable and difficult to understand. As with all graphic information, videos must be of high resolution and correlate directly with other information in the course (Rieber, 1989, Dwyer, 1978, Levin \& Lesgold, 1978).

Suggestions for improvement taken from the written comments included increasing the print size and decreasing the amount of technical terminology. Again, students wanted easily understandable text which was known from earlier focus groups and the literature (Morrison, 1989; Ross \& Morrison, 1989). These changes were subsequently included in the final courseware.

Focus groups.

The focus groups confirmed much of the results from the questionnaire (Arnold, 1994). The visual images were positive in many ways. The students felt the pictures and videos reinforced learning and provided a mental pause from reading. The icons helped the students stay organized which 
was an important part of the navigation tools suggested by Merrill (1987).

Suggestions for improvement included adding the ability to move forward and backwards in the courseware. Freedom of movement was viewed positively in earlier focus groups and is the current trend in interactive CBI design. The authoring program could not accommodate bi-directional movement with the large files used in this program. Results from the Final Evaluation

Questionnaires.

The 17 student's average score indicated they agreed that the text, examples, video segments, visual images, and test questions enhanced understanding or were presented in a logical manner (Castelli, 1994; Table 7). These responses were similar to the midway evaluation.

The student's average score indicated that they neither agreed nor disagreed that the CBI was effective for understanding the material. The high standard deviation (1.07) indicated a variety of responses within the group. The comments and interview results showed that there was enough information and examples, but there was inadequate time or opportunity to integrate and fully understand the information. Some students missed the teacher and group interaction found in the class which helped them understand 
material. Others students felt that the material was learned at home after copying the information from the screen. Additionally, many students felt rushed and consequently did not use the multiple choice questions which may have provided them with greater understanding of the material. These results stress the importance that achievement be associated with tasks and that the learner has adequate time to practice (Merrill, 1987).

The students neither agreed nor disagreed that audio (voice) enhanced understanding. The decreased importance of audio was reflected in the ranking of attributes. Audio was ranked second as the attribute wanted less often (Table 8). It was also listed as one of the least important attributes (Table 9). The written comments indicated that some students were distracted when the voice track read the text that was on the screen, especially when the students were taking notes. The response to voice segments contradicts earlier focus group results that recommended the voice segments repeat the text on the screen.

In addition, the written comments indicated that many of the students found the music tracks repetitive and distracting. The earlier focus groups were neutral towards the inclusion of music. Consequently, this may have contributed to the questionnaire results on audio tracks. 
Although the students average score indicated they agreed that video segments enhanced understanding, there was high standard deviation (SD $=1.13$ ). This mixed response toward video was reflected in the attribute ranked as wanted more frequently (rank = 1) and less frequently (rank = 3). Much like the midway evaluation, some students found the video segment on laporoscopy objectionable. Customizing video, like graphics, to the text is highly recommended (Levin \& Lesgold, 1978).

Text was most frequently listed as the most important attribute. Even so, it was also listed as most wanted less frequently. Although students understood the importance of text, it was one of the least desired ways to absorb information. As CBI moves toward more interactivity and incorporates more multi-media, the reliance on text may decrease. These current results stress the importance of simplified text in CBI courseware (Morrison, 1989; Ross and Morrison, 1989).

Individual interviews.

The six students chosen for individual interviews confirmed the results from the questionnaires. The overall impressions of the CBI was that it was a good concept, but there was a desire for more class interaction and more interactivity within the CBI (Table 10). The students liked 
working at their own pace, but some felt there should have been more time available to use the CBI. The strengths of the CBI were clearly in the amount of information, the organization, and the examples. The weaknesses of the CBI included confusion when audio voices said the text on the screen and music that started and stopped abruptly.

The students were generally positive in recommending the CBI class. Three students stated they would recommend the CBI courseware to others and two students said they would conditionally recommended the courseware to others. One student would not recommend the CBI because of the research environment. This would not be a problem when the CBI was presented in a regular classroom.

Results of Final Evaluation from San Diego state students

Questionnaires.

In general, the results from the SDSU students evaluations were more positive than those from the SUSU students. The average score of the five students across all topic segments indicated they strongly agreed the material was presented logically, the content was at an appropriate level, and the examples enhanced understanding (Table 11). The students agreed that the audio, video, visuals, or test questions enhanced understanding or made the information more interesting. 
The SDSU students ranked audio first as the attribute wanted more frequently (Table 12) and fourth as the attribute listed most important (Table 13). The SDSU students were not responsible for the CBI material and most probably did not take notes from the screen. Consequently, they found the audio voices helpful and not a distraction. Research is needed to compare different learning styles in perceived effectiveness. This is important for designers of curriculum or tutorial CBI.

Comments.

The students comments reinforced the data from the questionnaire. In general, all the students commented that the material was logical, easy to follow, and appropriate to their level of understanding. Most students said that the material was a review and some wanted a more in-depth perspective. There was a desire to have more audio. Several students consistently commented that more audio voices were needed to define, describe or explain the material. Consequently, less text would be required. 
Conclusion

The purpose of the study was to evaluate the preliminary CBI courseware, to complete the development of the CBI courseware, and to evaluate the developed courseware. The evaluations of the preliminary courseware indicated the students wanted simple text, high resolution pictures, video, and examples that represented college-aged, real-life research. Although the students liked the idea of a highly interactive program, they reacted negatively to the loops and simple branching features in the preliminary courseware.

The final courseware was developed with these guidelines in a linear, student-controlled progression. Each topic section concluded with multiple choice questions that supplied feedback for each answer. The courseware consisted of approximately 380 multi-colored panels and provided for extensive interaction time, approximately 10-14 hours.

The three groups of students who evaluated the courseware agreed or strongly agreed that the courseware was presented in a logical manner and that text, visual images, examples, and test questions were interesting or enhanced understanding. Although students found the video segments interesting and wanted more of them, other students reacted negatively to the content of one video segment. In addition, 
audio voices that repeated the text on the screen and music that stopped abruptly were seen as distracting to some students. Overall, the positive results from the students evaluations indicated the features of the final CBI courseware modules were considered interesting and enhanced understanding of research methodology. 
REFERENCES

Arnold, D. G. (1994). Critical evaluation of computer courseware in an undergraduate nutrition and dietetics research methodology course. Unpublished master's project, San Jose State University, San Jose, CA. Castelli, V. G. (1994). Evaluation of the effectiveness of computer based instruction (CBI) courseware for teaching research methodology to undergraduate students. Unpublished master's project, San Jose State University, San Jose, CA.

Cohen, P. A., \& Dacanay, L. S. (1992). Computer-based instruction and health professions education: A metaanalysis of outcomes. Evaluations \& The Health Professions, 15(3), 259-281.

Dwyer, F. (1978) . Strategies for improving visual learning. State College, PA: Learning Services. Gray, S. H. (1987). The effect of sequence control on computer assisted learning. Journal of Computer Based Instruction, 14(2), 54-56.

Hannifin, M. J., \& Hooper, S. (1989). An integrated framework for CBI screen design and layout. Computers in Human Behavior, 5, 155-165.

Hejmadi, M. (1993). Development of two computer based instructional modules to teach research methodology in 
nutrition. Unpublished master's project, San Jose State University, San Jose, CA.

Kulik, J. A., \& Kulik, C. C. (1987). Review of recent research literature on computer-based instruction. Contemporary Educational Psychology, 12, 222-230. Levin J., \& Lesgold, A. (1978). On pictures in prose. Educational Communications and Technology Journal, 26 (3), 233-243.

Merrill, M. D. (1987). The new component design theory: Instructional design for courseware authoring. Instructional Science, 16, 19-34.

Mevarech, Z. R., Silber, O., \& Fine, D. (1991). Learning with computers in small groups: Cognitive and affective outcomes. Journal of Educational Computing Research, $\underline{7}(2), 233-243$.

Milheim, W. D., \& Lavix, C. (1992, May/June). Screen design for computer-based training and interactive video: Practical suggestions and overall guidelines. Performance and Instruction, pp. 13-21.

Morrison, G. R. (1989). Reconsidering the research on CBI screen design. Proceedings of Selected Research Papers at the Annual Meeting of the Association for Educational Communications and Technology. (ERIC Document Reproduction Service no. ED 308 829). 
O' Day, E. E., Kulhavy, R. W., Anderson, W., \& Malczynski, R. J. (1971). Programmed instruction: techniques and trends. New York: Appleton-Century-Crofts. Pavio, A. (1986). Mental representations: A dual coding approach. New York: Oxford University Press. Peterson, P. I. (1988). Making instruction meaningful: Lessons from research on cognition and instruction. Educational Psychologist, $23,365-374$.

Rambally, G. K., \& Rambally, R. S. (1987). Human factors in CAI design. Computer Education, 11(2), 149-153.

Rieber, L. P. (1989). A review of animation research in computer-based instruction. Proceedings of Selected Research Papers at the Annual Meeting of the Association for Educational Communications and Technology. (ERIC Document Reproduction Service no. ED 308 832). Reigeluth, C. M., \& Stein, F. S. (1983). The elaboration theory of instruction. In C. M. Reigeluth (Ed.), Instructional Design Theories and Models. Hillsdale, NJ: Erlbaum.

Rivas, Y. (1993). Evaluation of the effectiveness of computer based instruction courseware materials in an undergraduate nutrition and dietetics research methodology course. Unpublished master's project, San Jose State University, San Jose, CA. 
Ross, S. M., \& Morrison, G. R. (1989). Reducing the density of text presentations using alternative control strategies and media. Proceedings of Selected Research Papers at the Annual Meeting of the Association for Educational Communications and Technology. (ERIC Document Reproduction Service no. ED 308 829).

Shiang, C. P., \& McDaniel, E. (1991). Examining the effects of questioning on thinking processes with a computerbased exercise. Journal of Educational Computing Research, $7(2), 203-217$.

Shlecter, T. M. (1992). Students' attitudes toward small group CBI: A question of aptitude. Proceedings of Selected Research and Development Presentations at the Convention of the Association for Educational Communications and Technology and Sponsored by the Research and Theory Division. (ERIC Document Reproduction Service no. ED 348 022). 
Table 1

Hardware and Software Used in the Development of the CBI

Hardware

IBM PC-486 clone with two high capacity disc drives

Intel ActionMedia II DVI capture and delivery board

Summagraphics Summasketch pad, 21-inch pad

Two 14-inch monitors: One sceptor S-VGA and one Mitsubishi Diamond Scan RGB

External CD ROM and Media Kit stereo speakers

Panasonic-AG455 S-VHS camcorder

IVC Vid-Star HR-S8000U digital stereo S-VHS VCR

Software

Authology Multimedia V. 2.0 by CEIT of Santa Clara

LUMENA/DVI by Time Arts Inc. (Version 3.4)

Digital Video Producer (copyright 1990-1991)

Harvard Graphics by Software Publishing, Inc. and Image Mark Software labs (copyright 1991-1992)

Photostyler by U-Lead Systems, Inc. (Version 1.03, copyright 1990-1991)

ImagePrep by Computer Presentations, Inc. (Version 4.0, copyright $1990-1991$ 
Table 2

Outline for Focus Group Evaluating Preliminary Courseware

1. Welcome and review of focus group guidelines

2. What are the highlights of a perfect CBI?

3. What are the most effective examples to use?

4. Why are video games so exciting?

5. What can we do to make this CBI better?

6. What is the role of $\mathrm{CBI}$ in the classroom?

7. Did you get enough information from the CBI?

8. Should you have a CBI partner?

9. What is the ideal environment to use CBI?

10. What makes a good visual image?

11. Why are the pictures from Life Magazine so effective?

12. Why have visual images?

13. What are bad visual images?

14. What makes good audio?

15. When is music appropriate?

16. When is humor appropriate? 
Table 3

Subject Content of the Three Modules

Module I

\begin{tabular}{c} 
Research Definitions \\
True and Quasi Experiment \\
Correlational Research \\
Descriptive Research \\
Epidemiology \\
Survey \\
Historical \\
Case Study \\
Methodological and Program Related \\
Module II \\
Eodule III \\
\hline Ethics and Experimental Errors
\end{tabular}


Table 4

Structure of the Topic sections

Definition of the type of research

Reasons to conduct research

various types of research

Examples of research

How to conduct research

Advantages and disadvantages of the research 
Table 5

Eocus Group Results From Evaluation of Preliminary

Courseware

What is the Ideal Courseware?

* Self paced and repeatable

* Used anytime and any number of times

* Unidirectional movement within the program

* High level of interactivity and feedback

* High level of student/user control

* Examples are simple, depict real life, and specific

* Images correlate directly with text and have high resolution

* Audio should be a male voice and free of accent

* Minimal humor should be used

What Changes Can we Do to Make This CBI Better?

* More Control

* More feedback

* Role playing and "what-if" scenarios 
Table 6

Average Score of Final Courseware - Midway Evaluation

\begin{tabular}{ll}
\hline \multicolumn{1}{c}{ Question } & Mean \\
& \\
\hline & \\
\hline 1. The material was presented logically & 1.6 \\
2. The content was appropriate & 1.7 \\
3. Examples enhanced understanding & 1.7 \\
4. Audio/video option enhanced learning & 2.1 \\
5. Visuals enhanced understanding & 1.8 \\
6. The visual images made the information & 1.5 \\
more interesting & 1.8 \\
8. The test questions helped me test myself & 1.9 \\
9. The text/images/video flowed logically & 1.6 \\
\hline
\end{tabular}

Note: 1 = Strongly agree, 3 = Neither agree nor disagree, and 5 = strongly disagree. 
Table 7

Average Score of Final Courseware - Group Two Evaluation

Question $\quad$ Mean Score SD
Students $(n=17)$

1. The CBI was effective for understanding $\begin{array}{lll}\text { the material for this course } & 2.7 & 1.07\end{array}$

2. The text was presented in a logical manner $1.9 \quad 0.54$

3. The examples enhanced understanding $\quad \begin{array}{ll}1.7 & 0.82\end{array}$

4. The audio (voice) enhanced understanding $\quad 2.9 \quad 0.94$

5. The video segments enhanced understanding $\quad \begin{array}{lll}2.3 & 1.13\end{array}$

6. The visual images enhanced understanding $\quad 2.1 \quad 0.96$

7. The test questions enhanced understanding $2.3 \quad 0.90$

8. The text, audio, video and images flowed $\begin{array}{lll}\text { in a logical manner } & 2.1 & 0.56\end{array}$

Note: 1 = Strongly agree, 3 = Neither agree nor disagree, 5 = strongly disagree. 
Table 8

Ranking of Attributes Wanted More or Less Frequently - Group Two Evaluation

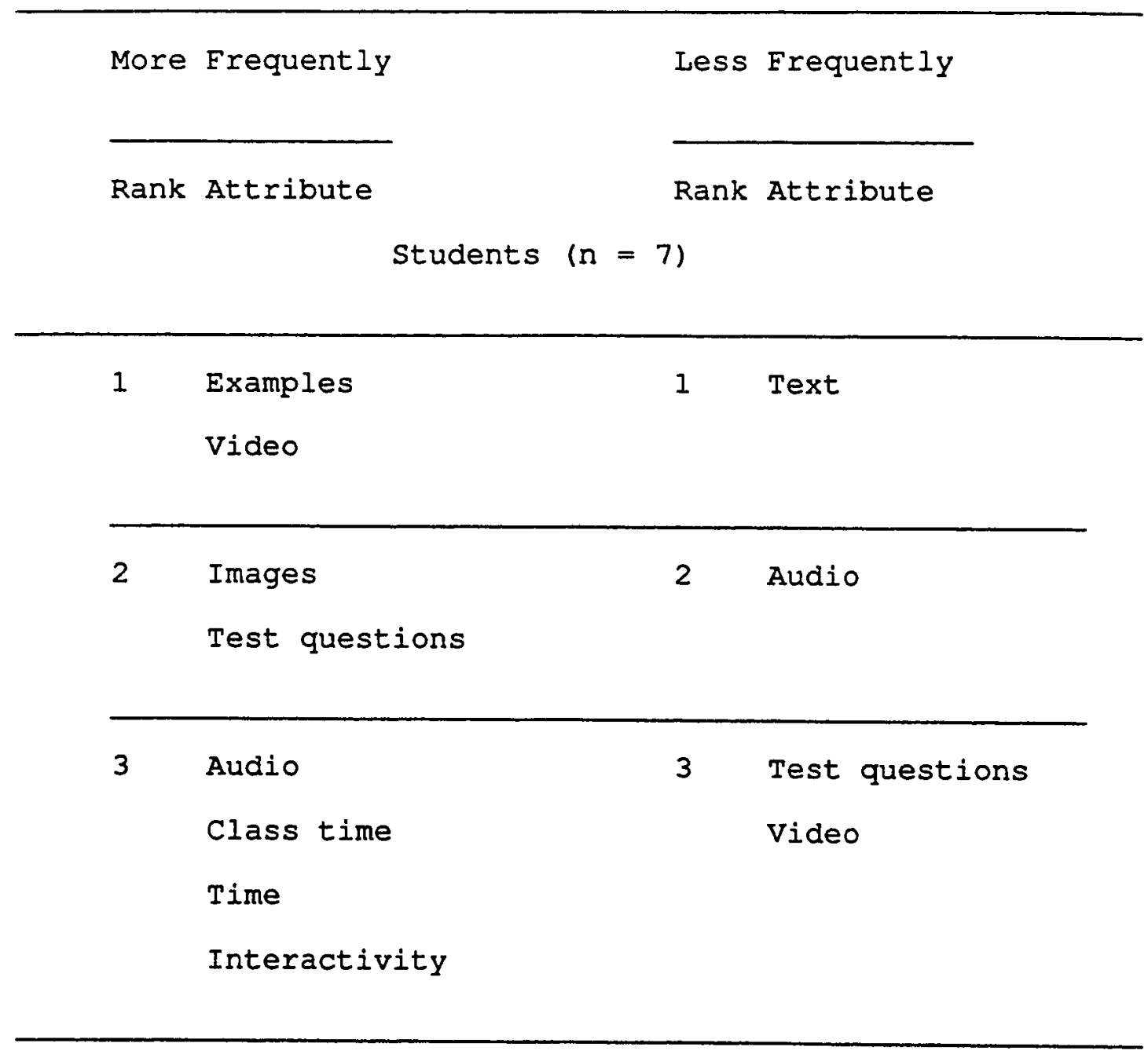

Note: Each student could identify as many attributes as were considered appropriate. 
Table 9

Ranking of Attributes That Students Identified as Most or Least Important - Group Two Evaluation

\begin{tabular}{|c|c|c|c|}
\hline \multirow{2}{*}{$\begin{array}{r}\text { Listed as } 15 \\
\text { Most } \\
\text { Rank }\end{array}$} & \multicolumn{2}{|l|}{ Important } & ed as Least Important \\
\hline & $\begin{array}{l}\text { Attribute } \\
\text { Students ( } \mathrm{n}=\end{array}$ & \multicolumn{2}{|l|}{$\begin{array}{l}\text { Rank } \\
=17)\end{array}$} \\
\hline 1 & Text & 1 & Music \\
\hline 2 & Examples & 2 & Audio \\
\hline 3 & Video & 3 & Video \\
\hline \multirow[t]{2}{*}{4} & Graphics & & Test \\
\hline & Visuals & & Graphics \\
\hline 5 & Test & & Text \\
\hline 6 & Audio & & \\
\hline
\end{tabular}


Table 10

Summary of Individual Interviews - Group Two Evaluation

Strengths

* Consolidates a lot of information. Easy to follow.

* Organized. It had a lot of information.

* It was very through. Lots of examples

* Being able to go back and read everything. Selfpaced.

* The video with audio and going at your own pace.

Weaknesses and Suggestions For Improvements

* There was no class interaction or interaction with an instructor or professor.

* The audio voices should not say what's on the screen. It is too hard to write and listen.

* An written outline of the CBI would be helpful.

* Maybe I would have had more out of it had I not known my partners. It was a given, so we did not discuss the material.

* Longer amount of time allotted so you were not waiting for the people in front of you to finish.

* I did not like the music starting and stopping. It was choppy. 
Table 11

Average Score of Final Courseware - SDSU Evaluation

Question

Mean

$(N=5)$

1. The material was presented logically

1.1

2. The content was appropriate

1.2

3. Examples enhanced understanding

1.4

4. Audio/video option enhanced learning

1.8

5. Visuals enhanced understanding

1.7

6. The visual images made the information

1.6

more interesting

7. The test questions helped me test myself 1.6

8. New terms were explained 1.5

9. The text/images/video flowed logically 1.3

Note: 1 = Strongly agree, 3 = Neither agree nor disagree, and 5 = Strongly disagree. This is a summation of $\mathrm{six}$ different topic sessions. 
Table 12

Ranking of Attributes Wanted More or Less Frequently - SDSU

Evaluation

\begin{tabular}{|c|c|c|c|}
\hline More & Erequently & Less & Frequently \\
\hline Rank & $\begin{array}{l}\text { Attribute } \\
\text { Students }(n=5)\end{array}$ & Rank & Attribute \\
\hline 1 & Audio & 1 & Music \\
\hline 2 & Video & 2 & Text \\
\hline 3 & Test questions & 3 & Examples \\
\hline
\end{tabular}

Note: This is a summation of all the attributes listed on questionnaires evaluating six different topic sessions. Student could identify as many attributes as were considered appropriate. 
Table 13

Ranking of Attributes That Students Identified as Most or

Least Important - SDSU Evaluation

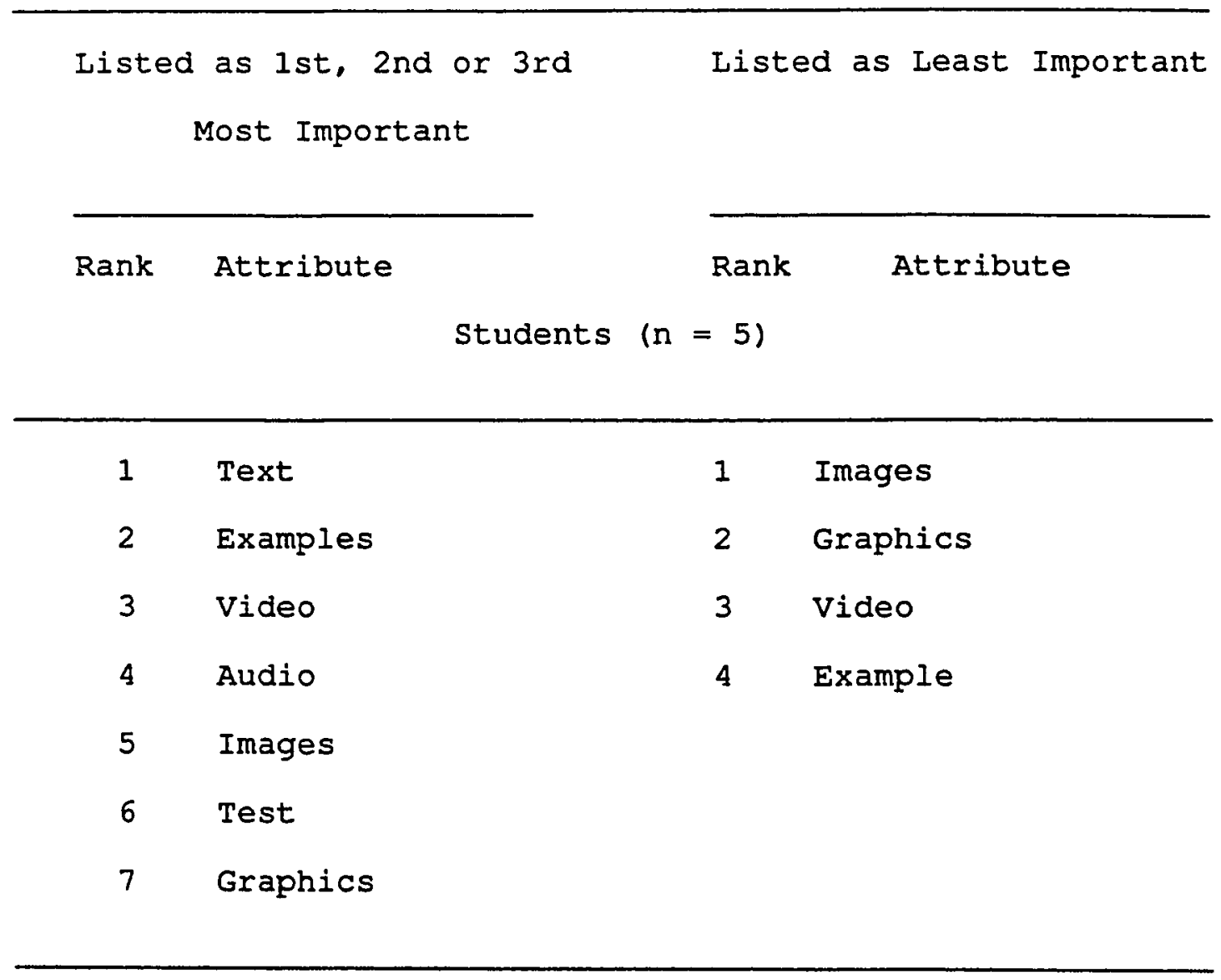

Note: This is a summation of attributes listed on questionnaires evaluating six different topic sections. 
CHAPTER 3

\section{CONCLUSION AND RECOMMENDATIONS}

The purpose of this study was to evaluate the preliminary CBI courseware, to complete the development of the CBI courseware, and to evaluate the developed courseware. The evaluations of the preliminary courseware indicated the students wanted simple text, high resolution pictures, video, and examples that represented college-aged, real-life research. Additional research is still needed to determine the effectiveness of these various features within CBI courseware on learner outcome. The literature supports numerous studies on the effectiveness of completed CBI courseware, but not the contribution of particular features to the success of the whole courseware.

Although the students liked the idea of a highly interactive program, they reacted negatively to the loops and simple branching features in the preliminary courseware. It is important that more research is conducted to create interactive features that are acceptable to the first-time students of CBI courseware and provide time to apply the information. As software improves and as more students become familiar with this medium, the negative reaction to interactive features will likely diminish. 
With student evaluation results as guidelines, the final courseware was developed in a linear, studentnavigated progression. Each topic section concluded with multiple choice questions that supplied feedback for each answer. The courseware consisted of approximately 380 multicolored panels and provided for extensive interaction time, approximately, 10-14 hours.

Three groups of students who evaluated the courseware agreed or strongly agreed that text, visual images, examples, and test questions were interesting or enhanced understanding. Although many students found the video segments interesting and wanted more of them, other students reacted negatively to the content of one segment. Audio voices that repeated the text on the screen and music that stopped abruptly were seen as distracting to some students. The students who used the CBI courseware as the course curriculum, although positive, were generally more critical of the CBI courseware than the students who only evaluated the program. Research is needed to compare student learning styles and identify any special learning needs.

Overall, the positive results from the student evaluations indicated the features of the final CBI courseware modules were considered interesting and enhanced understanding of research methodology. 
REFERENCES

Arnold, D. G. (1994). Critical evaluation of computer courseware in an undergraduate nutrition and dietetics research methodology course. Unpublished master's project, San Jose State University, San Jose, CA.

Basch, C. E. (1987). Eocus group interview: An underutilized research technique for improving theory and practice in health education. Health Education Quarterly, Winter, 411-448.

Castelli, V. G. (1994). Evaluation of the effectiveness of computer based instruction (CBI) courseware for teaching research methodology to undergraduate students. Unpublished master's project, San Jose State University, San Jose, CA.

Cohen, P. A., \& Dacanay, I. S. (1992). Computer-based instruction and health professions education: A metaanalysis of outcomes. Evaluations \& The Health Professions, 15(3), 25

Crespi, I. (1965). Attitude Research. Marketing Research Technique Series: American Marketing Association, (Serial No. 7).

Dwyer, F. (1978). Strategies for improving visual learning. State College, PA: Learning Services.

Elliott, P. G., Ingersoll, G. M., \& Smith, C. B. (1984). Trends and attitudes in the use of educational media and materials. Educational Technology, 20 (2), 19-24.

Fern, E. F. (1982). The use of focus groups for idea generation: The effects of group size, acquaintanceship, and moderator on response quantity and quality. Journal of Marketing Research, 19, 1-13.

Gray, S. H. (1987). The effect of sequence control on computer assisted learning. Journal of Computer Based Instruction, $\underline{14}(2), 54-56$.

Hannifin, M. J., \& Hooper, S. (1989). An integrated framework for CBI screen design and layout. Computers in Human Behavior, $\underline{5}$, 155-165. 
Hannifin, M. J., \& Peck, K. L. (1988). The design, development, and evaluation of instructional software. New York: Macmillan.

Hejmadi, M. (1993). Development of two computer based instructional modules to teach research methodology in nutrition. Unpublished master's project, San Jose State University, San Jose, CA.

Higginbotham-Wheat, N. I. (1991). CBI: System or medium? Proceeding of Selected Research Presentations at the Annual Convention of the Association for Educational Communications and Technology. (ERIC Document Reproduction Service No. ED 334 985).

Jonassen, D. H. (1988). Designing structured hypertext and structuring access to hypertext. Educational Technology, $\underline{28}(11), 13-16$.

Kulik, J. A., \& Kulik, C. C. (1987). Review of recent research literature on computer-based instruction. Contemporary Educational Psychology, 12, 222-230.

Levin J., \& Lesgold, A. (1978). On pictures in prose. Educational Communications and Technology Journal, 26(3), 233-243.

MCDermott, D. R. (1987). Assessing future directions for designing an academic program through focus groups interviews. Journal of Professional Services Marketing, $\underline{2}(4), 113-118$.

Merrill, M. D. (1987). The new component design theory: Instructional design for courseware authoring. Instructional Science, 16, 19-34.

Mevarech, Z. R., Silber, O., \& Fine, D. (1991). Learning with computers in small groups: Cognitive and affective outcomes. Journal of Educational Computing Research, $\underline{7}(2), 233-243$.

Milheim, W. D., \& Lavix, C. ( 1992, May/June). Screen design for computer-based training and interactive video: Practical suggestions and overall guidelines. Performance and Instruction, pp. 13-21.

Morgan, D. L. (1988). Focus groups as qualitative research. Newbury Park: Sage Publications. 
Morrison, G. R. (1989). Reconsidering the research on CBI screen design. Proceedings of Selected Research Papers at the Annual Meeting of the Association for Educational Communications and Technology. (ERIC Document Reproduction Service no. ED 308 829).

O' Day, E. F., Kulhavy, R. W., Anderson, W., \& Malczynski, R. J. (1971). Programmed instruction: techniques and trends. New York: Appleton-Century-Crofts.

Pavio, A. (1986). Mental representations: A dual coding approach. New York: Oxford University Press.

Peterson, P. L. (1988). Making instruction meaningful: Lessons from research on cognition and instruction. Educational Psychologist, 23, 365-374.

Rambally, G. K., \& Rambally, R. S. (1987). Human factors in CAI design. Computer Education, 11(2), 149-153.

Rieber, I. P. (1989). A review of animation research in computer-based instruction. Proceedings of Selected Research Papers at the Annual Meeting of the Association for Educational Communications and Technology. (ERIC Document Reproduction Service no. ED 308 832).

Reigeluth, C. M., \& Stein, F. S. (1983). The elaboration theory of instruction. In C. M. Reigeluth (Ed.), Instructional Design Theories and Models. Hillsdale, NJ: Erlbaum.

Rivas, Y. (1993). Evaluation of the effectiveness of computer based instruction courseware materials in an undergraduate nutrition and dietetics research methodology course. Unpublished master's project, san Jose State University, San Jose, CA.

Ross, S. M., \& Morrison, G. R. (1989). Reducing the density of text presentations using alternative control strategies and media. Proceedings of Selected Research Papers at the Annual Meeting of the Association for Educational Communications and Technology. (ERIC Document Reproduction Service no. ED 308 829).

Ross, S. M. (1990). Uses and effects of learner control of context and instructional support in computer-basedinstruction. Proceedings of Selected Paper Presentations 
at the Convention of the Association for Educational Communications and Technology. (ERIC Document

Reproduction Service no. ED 323 945).

Seiler, L. H. and Hough, R. L. (1970). Empirical comparisons of the Thurstone and Likert techniques. In G. F. Summers (Ed.), Attitude Measurements (pp. 159-173). Chicago: Rand McNally \& Company.

Shiang, C. P., \& MCDaniel, E. (1991). Examining the effects of questioning on thinking processes with a computerbased exercise. Journal of Educational Computing Research, $\underline{7}(2)$, 203-217.

Shlecter, T. M. (1992). Students' attitudes toward small group CBI: A question of aptitude. Proceedings of Selected Research and Development Presentations at the Convention of the Association for Educational Communications and Technology and Sponsored by the Research and Theory Division. (ERIC Document Reproduction Service no. ED 348 022). 
APPENDICES 


\section{Appendix A}

Questionnaire, Evaluation of Preliminary courseware

Please mark the following scales with an $x$ to rate the courseware. If you need more space, please use the back of the questionnaire or attach a separate sheet.

1. This course has increased my knowledge and understanding of research methodology (experimental research / epidemiological research). If strongly disagree or wish to comment, please explain.

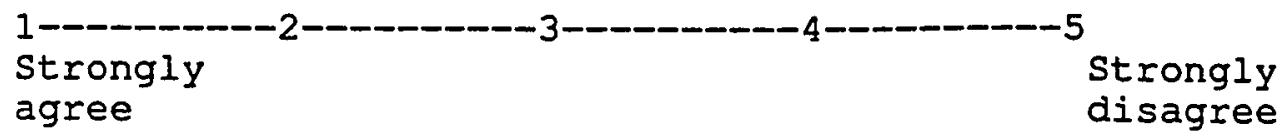

Comments :

2. The material was presented in a logical manner. If strongly disagree or wish to comment, please explain.

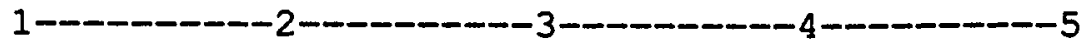

Strongly Strongly

agree disagree

Comments :

3. The content of this section was appropriate to my level of understanding. If strongly disagree or wish to comment, please explain.

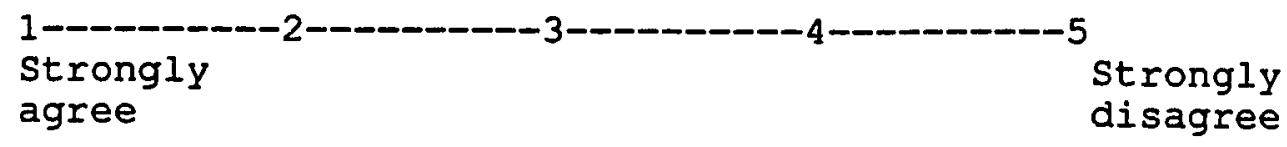

Comments : 
Appendix A (continued)

4. The examples provided in this section enhanced my understanding of the theory. If strongly disagree or wish to comment, please explain.

$\begin{array}{ll}\text { l-angly } & \text { Strongly } \\ \text { Strongree } & \text { disagree }\end{array}$

Comments:

5. The visual images were appropriate for the information provided. If strongly disagree or wish to comment, please explain.

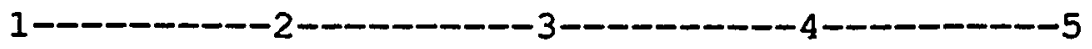

Strongly

agree Strongly disagree

Comments :

6. New terms were clearly explained. If strongly disagree or wish to comment, please explain.

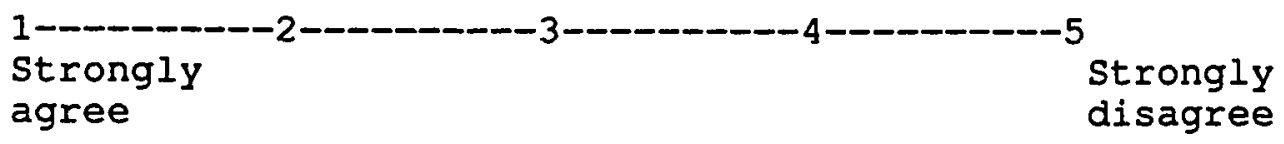

Comments:

7. I would like to see more of section. Circle your answer or answers.

$\begin{array}{lll}\text { Text } & \text { Audio } & \text { Images } \\ \text { Examples } & \text { Test Questions } & \text { Video } \\ \text { Others (specify) } & \end{array}$


Appendix A (continued)

8. I would like to see less of section. Circle your answer or answers.

$\begin{array}{lll}\text { Text } & \text { Audio } & \text { Images } \\ \text { Examples } & \text { Test Questions } & \text { Video } \\ \text { Others (specify) } & \end{array}$

9. The articles provided in the critical thinking section were simple to understand. If not, please give examples of what you did not understand.

$\begin{array}{ll}\text { Strongly } & \text { Strongly } \\ \text { agree } & \text { disagree }\end{array}$

Comments :

10. The questions in the critical thinking section were helpful in evaluating the research design of studies. If not, please suggest ways we can improve them.

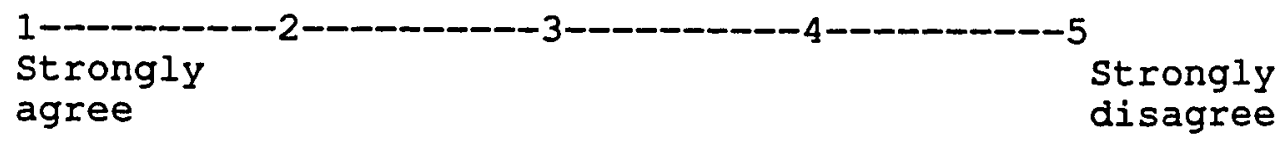

Comments : 


\author{
Appendix B \\ Questionnaire, Stage III, Group One
}

Please mark the following scales with an $\mathrm{X}$ to rate the courseware. You do not have to mark a specific number but can mark anywhere on the scale that you feel is appropriate

1. The material was presented in a logical manner that was easy to follow. If strongly disagree or wish to comment, please explain.

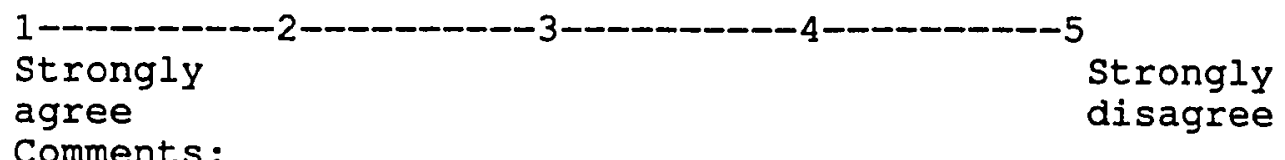

2. The content of this section was appropriate to my level of understanding. If strongly disagree or wish to comment, please explain.

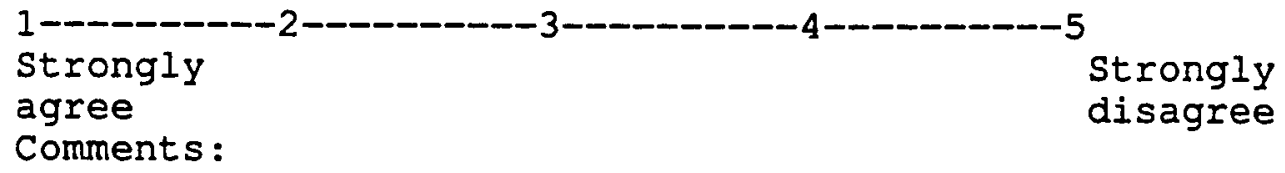

3. The examples provided in this section enhanced my understanding of the theory. If strongly disagree or wish to comment, please explain.

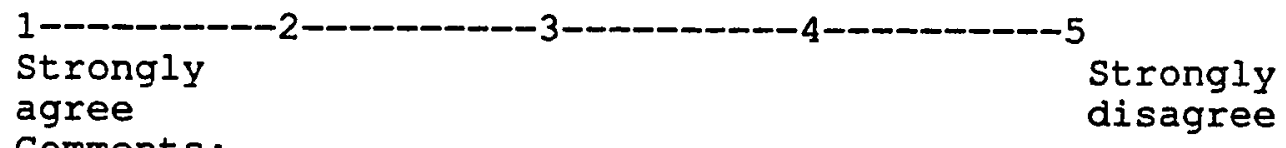

4. The audio/video option enhanced my learning in this section. If strongly disagree or wish to comment, please explain.

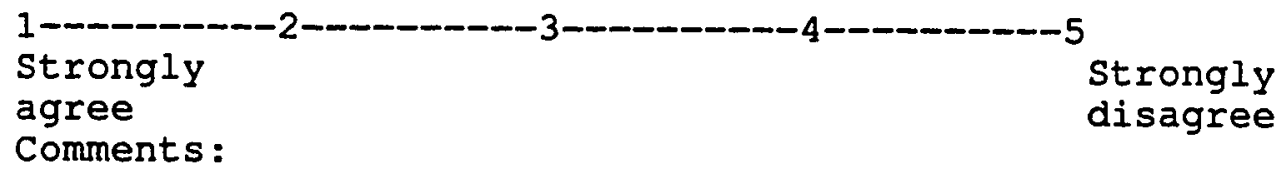


Appendix B (continued)

5. The visual images enhanced my understanding of the information provided. If strongly disagree or wish to comment, please explain.

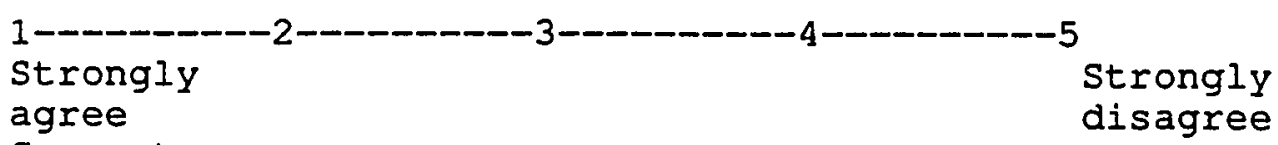

6. The visual images made the information in this section more interesting. If strongly disagree or wish to comment, please explain.

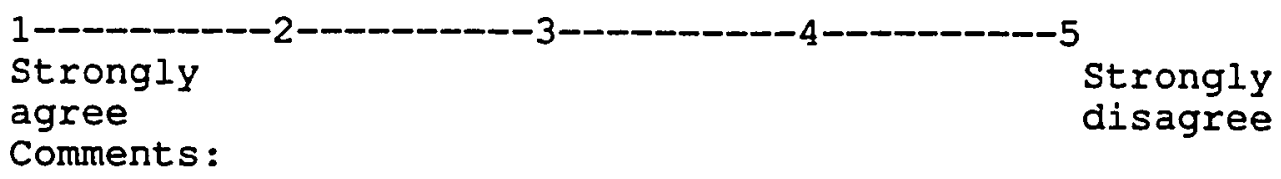

7. The test questions provided at the end helped me to adequately test myself on this section. If strongly disagree or wish to comment, please explain.

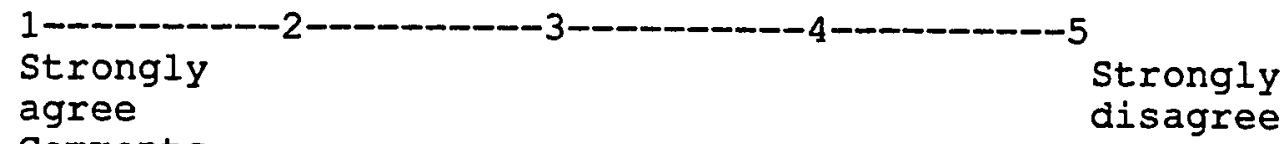

8. New terms were clearly explained. If strongly disagree or wish to comment, please explain.

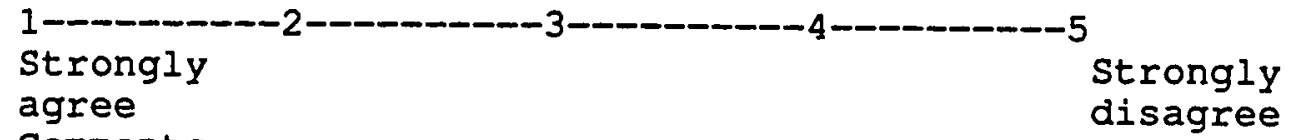

9. The text, images and video flowed in a logical order/sequence. If strongly disagree or wish to comment, please explain.

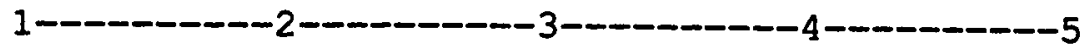

$\begin{array}{ll}\text { Strongly } & \text { Strongly } \\ \text { agree } & \text { disagree }\end{array}$

Comments : 
Appendix B (continued)

10. To make this section ideal, I would change Please give at least one example.

11. I would like to see more of section. Circle your answer or answers.

$\begin{array}{lll}\text { Text } & \text { Audio } & \text { Images } \\ \text { Examples } & \text { Test Questions } & \text { Video } \\ \text { Others (specify) } & \end{array}$

13. I would like to see less of section. Circle your answer or answers.

$\begin{array}{lll}\text { Text } & \text { Audio } & \text { Images } \\ \text { Examples } & \text { Test Questions } & \text { Video }\end{array}$

in this

Others (specify)

13. Rank the importance of the components in this section from most (\#1) to least important (\#7).

$\begin{array}{ll}\square & \text { Text } \\ & \text { Still Images } \\ & \text { Test Questions } \\ & \text { Video } \\ & \text { Examples } \\ & \text { Graphics }\end{array}$


Appendix C

Questionnaire - Group Two

NUFS 195

SPRING 1994

EVALUATION

Name (Optional)

Circle the number that most closely reflects your opinion, in the following areas, based on a scale from 1-5. Please give additional comments below each question especially if you strongly agree or strongly disagree.

$\begin{array}{lllll}1 & 2 & 3 & 4 & 5 \\ \text { Strongly } & \text { Agree } & \begin{array}{l}\text { Neither } \\ \text { agree nor } \\ \text { disagree }\end{array} & \text { Disagree } & \begin{array}{l}\text { Strongly } \\ \text { disagree }\end{array}\end{array}$

1. Overall, the Computer Based Interactive (CBI) program was an effective method for understanding the material for this course.

$\begin{array}{lllll}1 & 2 & 3 & 4 & 5\end{array}$

Comments :

2. The text was presented in a logical manner that was easy to follow.

$\begin{array}{lllll}1 & 2 & 3 & 4 & 5\end{array}$

Comments :

3. The examples provided enhanced my understanding of the theory presented.

$\begin{array}{lllll}1 & 2 & 3 & 4 & 5\end{array}$

Comments :

4. The audio (voice) enhanced my understanding of the material.

$\begin{array}{lllll}1 & 2 & 3 & 4 & 5\end{array}$

Comments: 
Appendix C (continued)

5. The video segments enhanced my understanding of the material.

$\begin{array}{lllll}1 & 2 & 3 & 4 & 5\end{array}$

Comments :

6. The visual images (photos, icons, pictures) enhanced my understanding of the material.

$\begin{array}{lllll}1 & 2 & 3 & 4 & 5\end{array}$

Comments :

7. The test questions enhanced my understanding of the material

$\begin{array}{lllll}1 & 2 & 3 & 4 & 5\end{array}$

Comments :

8. The text, audio, video and images flowed in a logical sequence.

$\begin{array}{lllll}1 & 2 & 3 & 4 & 5\end{array}$

Comments :

9. The physical setting enhanced my understanding (e.g. office, lighting, seating).

$\begin{array}{lllll}1 & 2 & 3 & 4 & 5\end{array}$

Comments : 
Appendix C (continued)

10. Viewing the modules with a partner enhanced my understanding.

$\begin{array}{lllll}1 & 2 & 3 & 4 & 5\end{array}$

Comments :

11. I would like to have more

all that apply.)

Text

Audio

Test questions

Other
Images

Examples

Video

- Circle

12. I would like to have less - Circle all that apply.)

Text

Audio

Test questions

Other
Images

Examples

Video

13. Rank the importance of the following components from most important (\#1) to least important (\#9)

\section{Text}

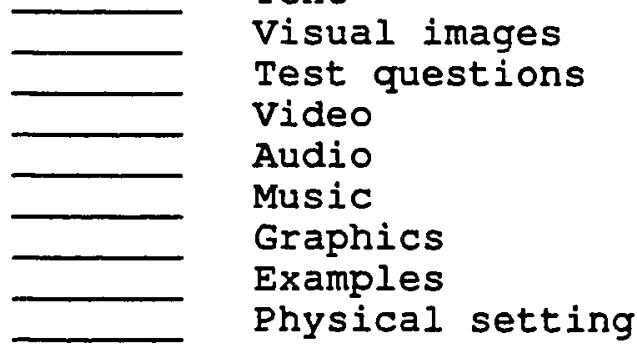

14. Additional comments 
Appendix D

Questionnaire - SDSU Students

Please mark the following scales with an $\mathrm{X}$ to rate the

courseware. You do not have to mark a specific number but can mark anywhere on the scale that you feel is appropriate

Module Topic is

Evaluator Name

1. The material was presented in a logical manner that was easy to follow. Please explain.

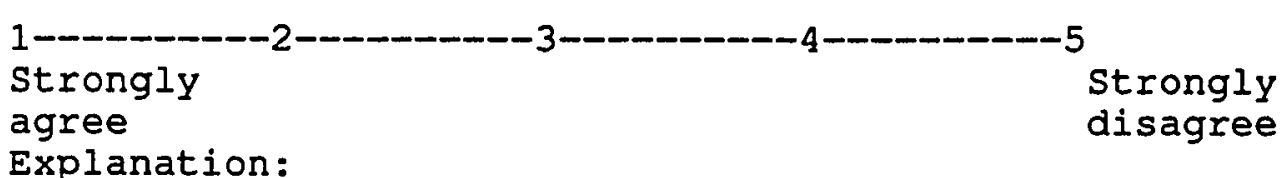

Explanation:

2. The content of this section was appropriate to my level of understanding. Please explain

$\begin{array}{ll}\text { Strongly } & \text { Strongly } \\ \text { agree } & \text { disagree } \\ \text { Explanation: } & \end{array}$

3. The examples provided in this section enhanced my understanding of the theory. Please explain

$\begin{array}{ll}\text { Strongly } & \text { Strongly } \\ \text { agree } & \text { disagree } \\ \text { Explanation: } & \end{array}$

4. The audio/video portion enhanced my learning in this section. Please explain.

$\begin{array}{ll}\text { Strongly } & \text { Strongly } \\ \text { agree } & \text { disagree } \\ \text { Explanation: } & \end{array}$


Appendix D (continued)

5. The visual images enhanced my understanding of the information provided. Please explain.

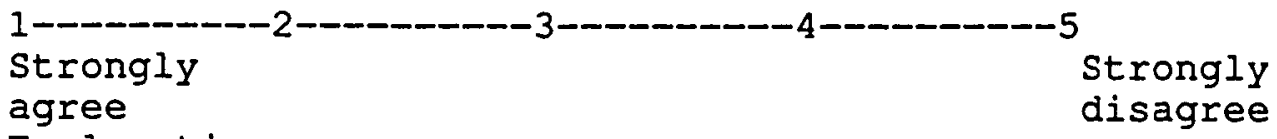

6. The visual images made the information in this section more interesting. Please explain.

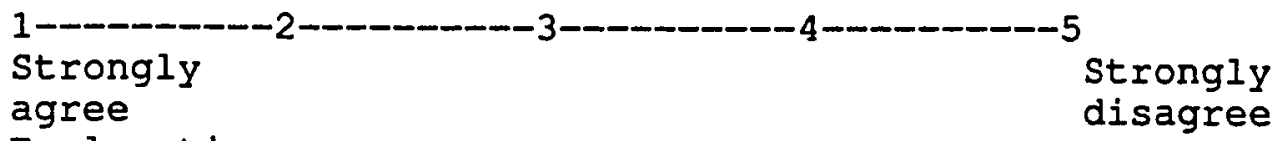

7. The test questions provided at the end helped me to adequately test myself on this section. Please explain.

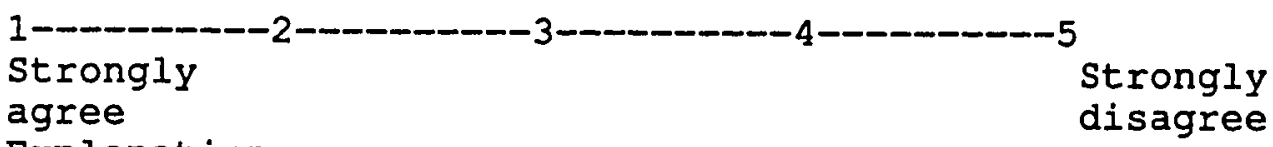

Explanation:

8. New terms were clearly explained. Please explain.

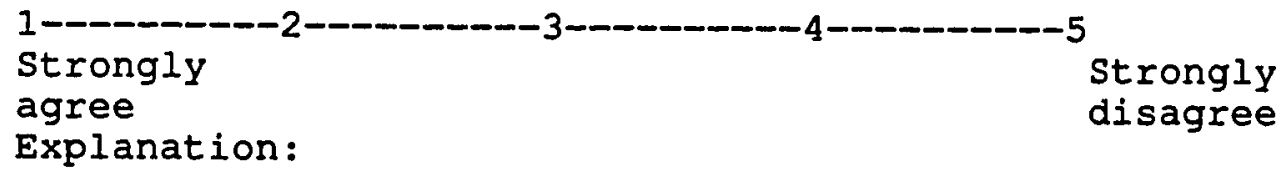

9. The text, images and video flowed in a logical order/sequence. Please explain.

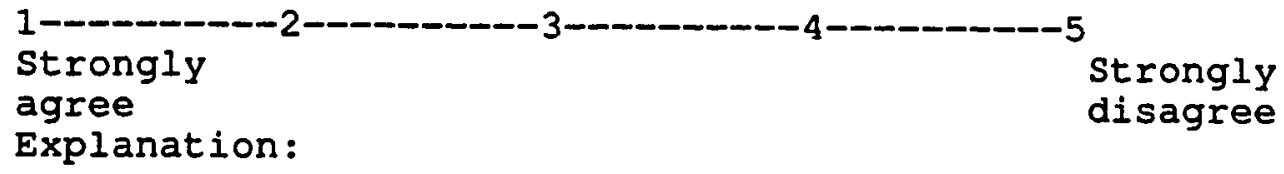


Appendix D (continued)

10. To make this section ideal, I would change Please give at least one example.

11. I would like to see more of section. Circle your answer or answers.

$\begin{array}{lll}\text { Text } & \text { Audio } & \text { Images } \\ \text { Examples } & \text { Test Questions } & \text { Video }\end{array}$
in this Others (specify)

13. I would like to see less of section. Circle you answer or answers.

$\begin{array}{lll}\text { Text } & \text { Audio } & \text { Images } \\ \text { Examples } & \text { Test Questions } & \text { Video } \\ \text { Others (specify) } & \end{array}$

13. Rank the importance of the components in this section from most (\#1) to least important (\#7).

\begin{tabular}{ll}
$\square$ & Text \\
\hline & Still Images \\
& Test Questions \\
& Video \\
& Examples \\
& Graphics
\end{tabular}


Appendix E

Topic Files with Names

\section{RESEARCH METEODOLOGY TOPICS WITH FRES}

Please observe that these topics have fles with somewhat arcane symbols. This is due to a "glitch" in the authoring software which requires very unique file letters.

Note: Files with an after them are linked to the mle immediately above them but can also be called up separately.

\section{MODULE 1}

Topies

Introduction to Research Design \& Definition of Eypothesis

True Experimental Research

Quasi-Experimental Research

Correlational Research

Descriptive Research

Epidemiological Research

Survey Research
Fllenames

Startres

Endres

Eypothes"

Birdie (contains review questions)

Unotrue

Duotrue

Quesm1tr" (coatains review questions)

Quaerp

M1ququas` (contains review questions)

Lm2corre

Lm3rdcor

Corrqm 1" (contains review questions)

Descrip

Queadeac (contsing review questions)

Epidem

Epiquem I" (contains review questions)

Surbegin

Surend

Surquem 1* (contains review questions) 
Appendix E (continued)

Page Two-n Research Methodology Topics \& Flles

MODULE 1 Continued

Topics

Bistorical Research

Case Study Research

Methodological Research

Program Related Research

Needs Assessment

Evaluation

MODULE 2

Topics

True Experimental Resentch Design

Quasi-Experimental Research Design
Files

M1histo

Histm lqu* (contains review questions)

Lmm2case

Casem 1qu" (contains review questions)

Milmmeth

Methmlqu" (contains review questions)

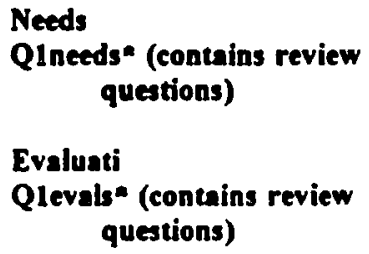
questions)

Files

Lmexdes

Lm2ndes

Trueques" (contains review questions)

Lmqunsex

Qussique* (contains review questions) 
Appendix E (continued)

Page Three ...Research Methodology Topics \& Files

MODULE 2 Continued

Topics

Research Ethics

Research Errors

Critical Evaluation Questions for Two Research Articles

Topics

Epidemiological Research

Descriptive Epidemiology

Analytical Epidemiology

\section{MODULE 3}

Files

Lmreseth

Ethicque" (contains review questions)

Lmerores

Lomparter

Errorque* (contains review questions)

Criteval

Files

Lmm2epi

Lmdepi(1

Descepiq* (contains review questions)

Lmanaep

Analydes" (contains review questions) 
Appendix F

Module 1 Program Details and External Files

Application Module: STARTRES Author:

Application Module Information

Create: Thu Feb 11 14:18:431993

Update: Fri Jun 17 15:28:54 1994

Description:

Procedures: 14 Instructions: 19

Questions: 0 Objectives: 0

Panele: 16 Variables: 0

welcome

icons

IKKPUR

purpcause

seeorg

modorg

comnon

resinmeth

resclass

basicorapp

basic

applied

resdescr

resdef

Then Arguments

Show welcome

Show icons

Show listen

Show icone

show vickivid

Show icons

ShOW LOORPURP

Show purpose

Show SEEORG

Show modorg

ShOW COMONTRAITS

Show resinmeth

Show researchclass

Show BORA

ShOW BASIC

Show applied

Show resdescr

Show researchdefin

Exit 0

QUESTION Name Evaluation

Try Points paned 
Appendix F (continued)

Application Module: STARTRES Author:

OBJECTIVE Name

PQ QR QPOS OPTB OPOB

PANEL Name

researchdefin

BASIC

researchclass

applied

resdescr

resinmeth

welcome

purpose

modorg

icons

listen

LOOKPURP

vickivid

SEEORG

COMMONTRAITS

BORA
Fm, Res Objs

$16,512 \times 480 \quad 5$

$16,512 \times 4807$

$16,512 \times 4806$

$16,512 \times 4809$

$16,512 \times 4807$

$16,512 \times 4806$

$16,512 \times 4809$

$16,512 \times 4809$

$16,512 \times 4806$

$16,512 \times 48010$

$16,512 \times 4806$

$16,512 \times 4805$

$9,512 \times 4802$

$16,512 \times 4805$

$16,512 \times 4805$

$16,512 \times 48011$ 
Appendix F (continued)

External files referenced by C: IAUTH20 IAPP ISTARTRES.AAY

Font:

(NOT FOUND)

C: IV220lvid fontleans.109

c: IV220lvidlfontlsans.112

C: lv220lvidlfont leans.114

c: lV220lvidlfontlsans.118

c: IV220lvid Ifont lsans.124

c: lV220lvidlfonelultra.109

C: IV220lvid fontlultra.112

c: IV220lvidlfontlultra.114

C: IV220lvidlfontlultra.118

C: IV220lvidlfontlultra.124

C: IV220lvidlfont lultrab.109

C: IV220lvidlfontlultrab.112

c: IV220lvidlfontlultrab. 114

c: IV220lvidlfontlultrab.118

c: IV220lvidlfontlultrab.124

Images

D: \RESMETH IMAGES $\backslash 38$ wims . C16 BORA

D: IRESMETH \IMAGES \AUDIO.C16

icons

D: \RESMETH IMAGES \BASESCR I . CI 6

researchclass

resdescr

resinmeth

welcome

D: \RESMETH IIMAGES \BASESCR2 . C16

researchdefin

BASIC

applied

D: IRESMETH IMAGES I bOYsteam. C16 COMAONTRAITS

D: \RESMETH IMAGES \Camera.C16

icons

D: \RESHETH IMAGES \FRAMNINE . CMY vickivid

D: \RESMETH IMAGES IGRAPES.C16

purpose

D: \RESMETH IMAGES \HYPODRUG. $C 16$

purpose

D: PRESKETH IMAGES \manmode 1.016 BORA

D: IRESMETH IMAGES \onebott 1.C16 applied

D: \RESHETH IMAGES \PARROTS . C16

SEEORG

D: \RESMETH IMAGES \PINBRG.C16

purpose

modorg 
Appendix F (continued)

icons

1iaten

BORA

D: \RESMETH IMAGES IREADGAT.C16 LOOKPURP

D: \RESMETH IMAGES\aleepmen.CI6 listen

D: IRESMETH IIMAGESItastee.C16 applied

D: IRESHETH IIMAGES Itechbott . C16 BASIC

AVSS

D: IRESMETH IAUDIOIICONDIR.AVS ICons

D: \RESHETH \AUDIOIRNOCKNO. AVS listen

D: IRESMETH \AUDIO IIRPURP . AVS LOOKPURP

D: \RESMETH \AUDIOYMODULAR. AVS modorg

D: \RESMETH \AUDIOIPURPURP . AVS purpose

D: PRESMETH \AUDIOITRKIIMG. AVS researchclass resdescr

D: IRESHETH IAUDIOITRKIMED. AVS BASIC resinneth COMONTRAITS

D: \RESMETH \AUDIOITRKISHRT. AVS applied SEEORG BORA

D: \RESMETH \AUDIO\WELINTRO. AVS welcome

D: IRESMETHIVIDEOIRESVICKI.AVS vickivid

Executes 
Appendix F (continued)

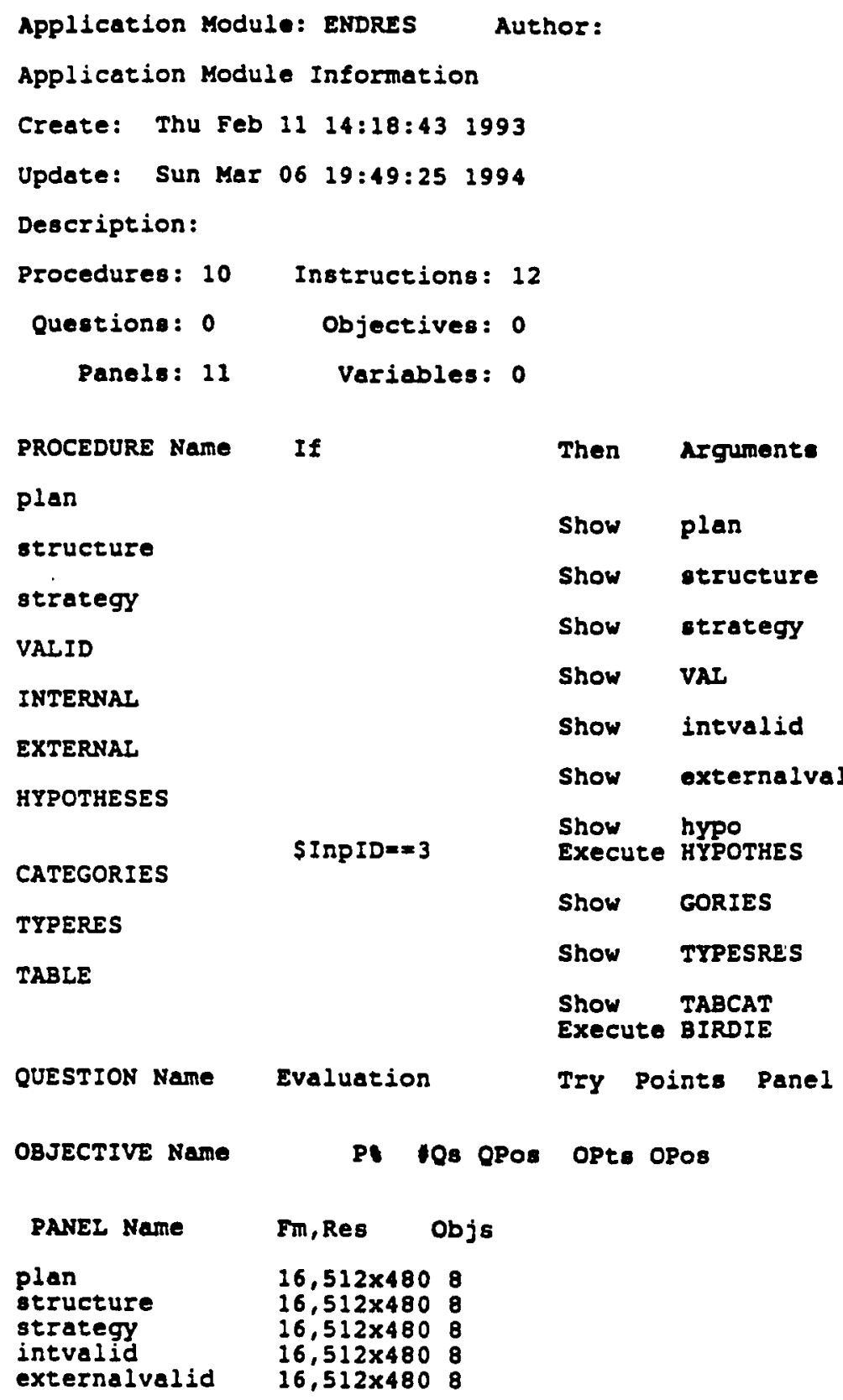


Appendix E (continued)

\begin{tabular}{|c|c|}
\hline PANEL Name & Fin, Res \\
\hline $\begin{array}{l}\text { TABCAT } \\
\text { GORIES } \\
\text { TYPESRES } \\
\text { VAI } \\
\text { hYPO }\end{array}$ & $\begin{array}{ll}16,512 \times 480 & 10 \\
16,512 \times 480 & 9 \\
16,512 \times 480 & 7 \\
16,512 \times 480 & 5 \\
16,512 \times 480 & 5\end{array}$ \\
\hline
\end{tabular}


Appendix E (continued)

External files referenced by C: IAUTH20 \APP IENDRES . MH

Fonts

(NOT FOUND)

C:IV220lvidlfont lsans. 109

c: IV220 Vvidlfont lsans. 112

c:lv220lvidlfont lsans.114

c: IV220lvidlfont lsans. 118

c: IV220lvid font lsans.124

C: lv220lvidlfontlultra.109

c: IV220lvidlfontlultra.112

c:lv220lvidlfontlultra.114

c: IV220lvidlfontlultra.118

c:lv220lvid fonelultra.124

c:IV220lvidlfontlultrab.109

c: IV220lvidlfontlultrab.112

c: IV220lvidlfontlultrab.114

c: IV220lvidlfontlultrab.118

c: lv220lvidlfontluitrab.124

Images

D: IRESMETH IMAGES $\backslash 2$ boy 8 dog. $C 16$ externalvalid

$D: \backslash R E S M E T H \backslash I M A G E S \backslash 3$ boys.C16 externalvalid

$D: \backslash R E S M E T H \backslash I M A G E S \backslash B A S E S C R I$. C16 VAr

D: IRESMETH IMAGES \BASESCR2.C16 plan

Btructure

strategy category

D: \RESMETH IMAGES \blueplan.C16 plan

D: (RESMETH IMAGES IFOURPETR. C 16 GORIES

D: IRESMETHIIMAGES IGAIBREAR. C16 GORIES

D: \RESMETH।IMAGES GGARLICLY.C16 GORIES

D: \RESMETH IMAGES INCBABY.CI6 GORIES

D: IRESMETH IMAGES \MULtip11.C16 intvalid

D: IRESMETH IMAGES \plnbkg:C16

intvalid

externalvalid

TABCAT

TYPESRES

hypo

D: \RESMETH IMAGES \SPiderwe.C16

structure

D: \RESMETH IMAGES \strategY.C16 
Appendix F (continued)

-trategy

D: IRESMETH IMAGES \eurgery. C16

intvalid

AvsS

D: IRESMETH \AUDIOICATGOR.AVS GORIES

D: IRESMETH \AUDIO\GGORIES . AVS

TYPESRES

D: \RESHETH TABCAT

D: IRESHETH IAUDIOITRRILNG . AVS intvalid

D: \RESMETH \AUDIOITRKIMED.AVS otructure externalvalid

VAL

D: IRESMETH IAUDIOITRR ISHRT . AVS plan strategy

Executes

C: IAUTH20 \APP\BIRDIE . AAM

C: \AUTH20 \APP\HYPOTHES . AAM 
Appendix E (continued)

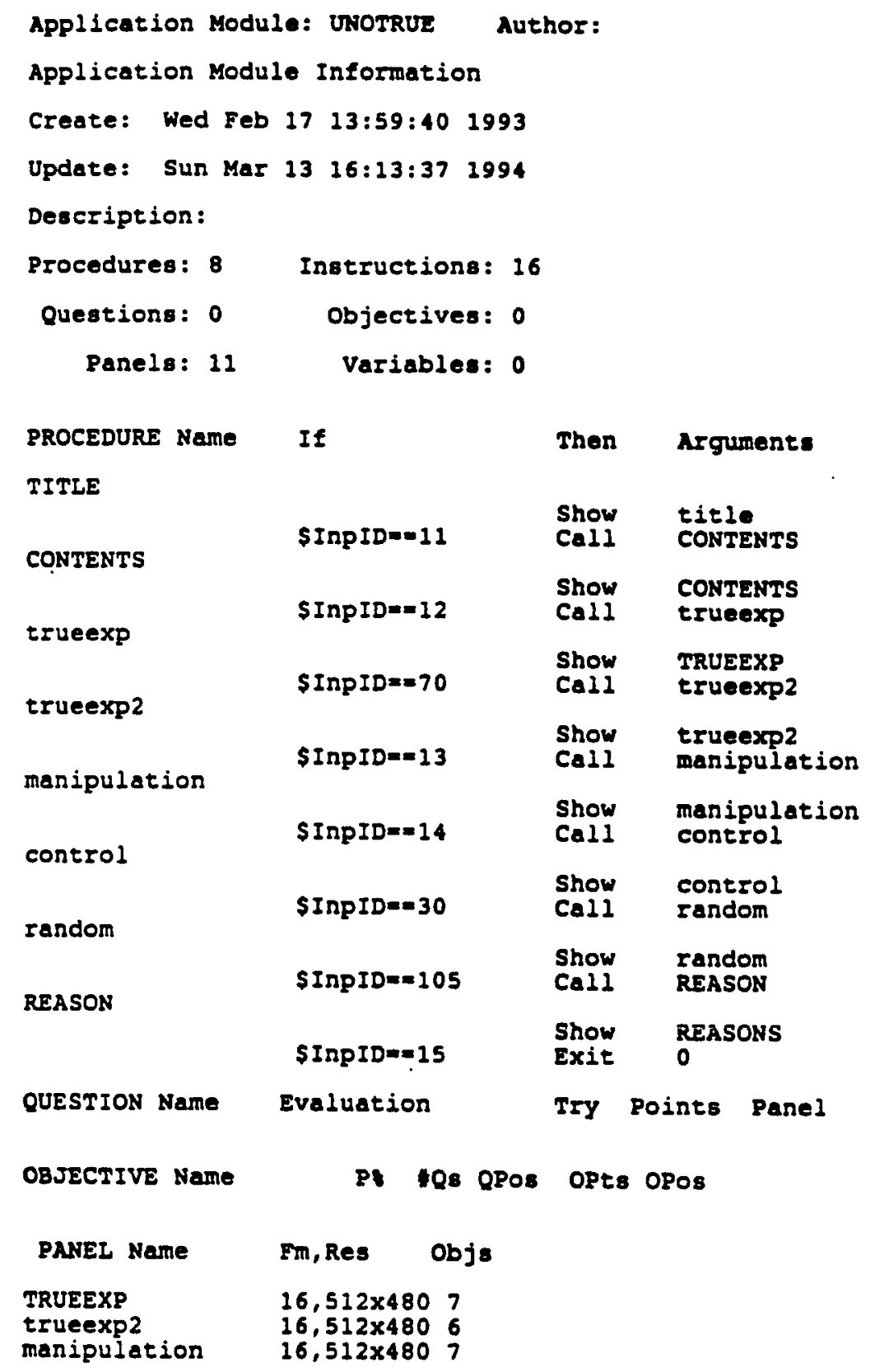


Appendix F (continued)

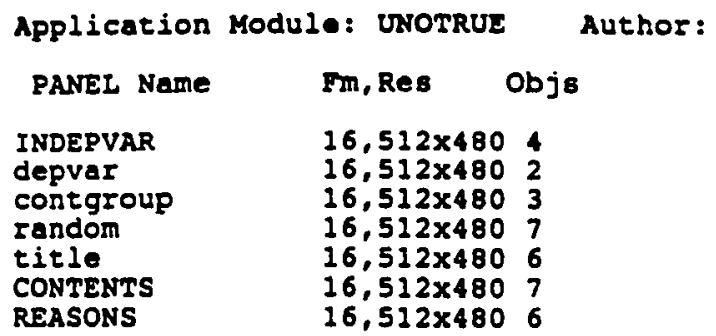


Appendix F (continued)

External files referenced by C: IAUTH20 \APP IUNOTRUE.AMH

Fonts

(NOT EOUND)

c: IV220lvidlfontlsans. 109

c: IV220lvidlfont leans.112

c: IV220lvidlfont laans. 114

C: IV220lvidlfont laans.118

C: IV220lvidlfont leans.124

C: lv220lvidlfontlultra.109

c:lv220lvid fontlultra. 112

c: IV220lvidlfontlultra. 114

c:lv220lvidlfontlultra.118

C: IV220lvidlfantlultra.124

C: IV220lvidlfont lultrab.109

C: IV220lvid font lultrab.112

c: IV220lvidlfontlultrab. 114

c:lv220lvidlfontlultrab.118

c:lv220lvidlfontlultrab.124

Images

D: \RESMETH IIMAGES \BASESCR1 .C16

TRUEEXP

title

CONTENTS

D: IRESMETH IMAGES \BASESCR2 . CI6

trueexp2

D: IRESMETH IMAGES \bnecks.C16 TRUEEXP

title

CONTENTS

D: \RESMETH IIMAGES \BROTHS . C16

contgroup

D: \RESMETH IILAGES \CONBtYaW. C16

control

D: IRESMETHIIMAGES \pastanip.C16 manipulation

D: \RESIETH IMAGES \PINBRG.C16 INDEPVAR REASONS

D: \RESMETHIIMAGES Iatrawran.C16 random

AvsS

D: \RESLETH \AUDIO \SAXFUL . AVS CONTENTS

D: \RESIYETH \AUDIOITERCGE . AVS TRUEEXP

D: IRESMETH \AUDIO।term] . AVS title

D: IRESMETH \AUDIO TTERMCR . AVS trueexp2 
Appendix E (continued)

D: IRESMETHIAUDIOITERREAS .AVS REASONS

D: \RESMETH \AUDIO\tI2 end.AVS contiol

D: IRESMETH \AUDIOItI2med.AVS

manipulation

D: IRESIETH IAUDIOItT2 BtTt. AVS

random

Executes 
Appendix F (continued)

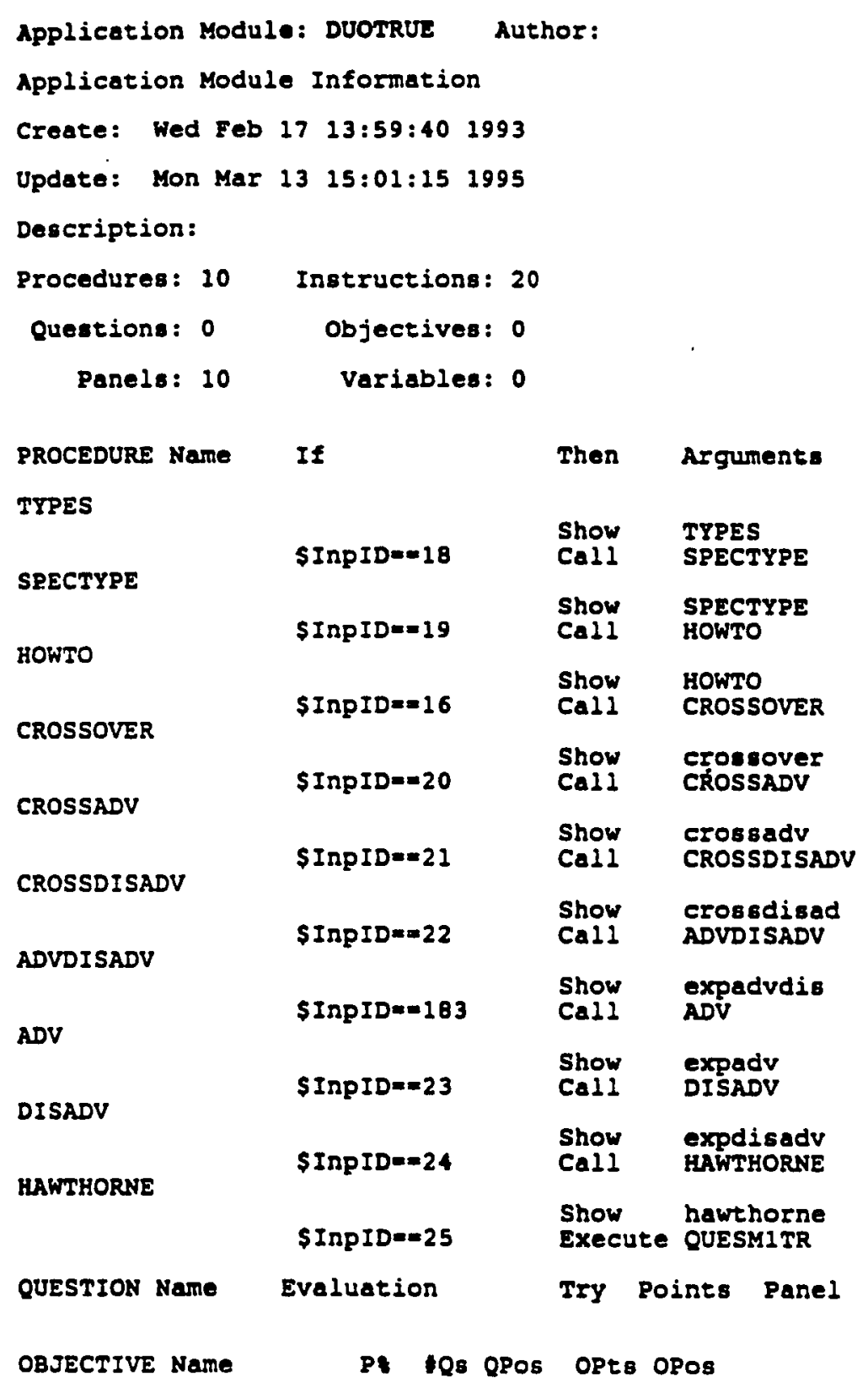


Appendix $E$ (continued)

\begin{tabular}{|c|c|}
\hline PANEL Name & $\mathrm{Fm}, \mathrm{Re}$ \\
\hline $\begin{array}{l}\text { expadvdis } \\
\text { expadv } \\
\text { expdisadv } \\
\text { hawthorne } \\
\text { crossover } \\
\text { crossadv } \\
\text { crossdisad } \\
\text { HOWTO } \\
\text { TYPES } \\
\text { SPECTYPE }\end{array}$ & $\begin{array}{l}16,512 \times 48 \\
16,512 \times 48 \\
16,512 \times 48 \\
16,512 \times 48 \\
16,512 \times 48 \\
16,512 \times 48 \\
16,512 \times 48 \\
16,512 \times 48 \\
16,512 \times 48 \\
16,512 \times 48\end{array}$ \\
\hline
\end{tabular}


Appendix F (continued)

External files referenced by C: IAUTH20 IAPPIDUOTRUE.MAM

Fonts

(NOT FOUND)

C: IV220lvidlfontlsans. 109

c:lv220lvidlfontleans. 112

C:IV220lvidlfont leane.114

C: IV220lvidlfont laans.118

c: lv220lvidlfont lsans. 124

c: lv220lvidlfontlultra.109

c:lv220lvidlfontlultra.112

c: lv220lvidlfontlultra.114

c: IV220lvidlfontlultra.118

c:lv220lvidlfontluitra. 124

C: lv220lvidlfontlultrab.109

C: IV220 Vvidlfontlultrab.112

c:lv220lvidlfontlultrab. 114

c: lv220lvidlfontlultrab.118

c:lv220lvidlfont lultrab.124

Images

D: (RESMETH IMAGES \BASESCR2 . C16

expadvdis

D: \RESMETH IMAGES \CIOEBX. CI 6

Crossover

D: \RESMETH IMAGES \hapbaby.C16

crossdisad

D: IRESMETH IMAGES \hawthorn.C16

hawthorne

D: \RESMETH IMAGES IMOMANPOP .C16 TYPES

D: \RESMETH IMAGES \pharmist . C16

expadv

D: \RESMETH IMAGES \pizzafed.C16

expdisadv

D: IRESMETH IMAGES \PLNBRG.C16

expdisadv

crossover

crossadv

HOWTO

TYPES

SPECTYPE

D: \RESMETH\IMAGES \rathead.C16 TTPES

AVSS

D: IRESMETH TAUDIO IDRUMUP . AVS expadvdi.

SPECTYPE

D: IRESMETH \AUDIO\PIANOUP . AVS expadv

D: \RESMETH\AUDIO\SAXFUL . AVS 
Appendix F (continued)

expdisadv

D: IRESMETH TAUDIOITERDISXO.AVS crosedisad

$D$ : \RESMETH \AUDIO\terxov.AVS croesadv

D: \RESMETH \AUDIOITR2END. AVS TYPES

D: IRESMETH \AUDIO TTR2MED. AVS

Crossover

D: \RESKETH \AUDIOITR2STRT , AVS hawthorne

D: IRESMETH \AUDIOITRK62 . AVS HOWTO

\section{Executes}


Appendix F (continued)

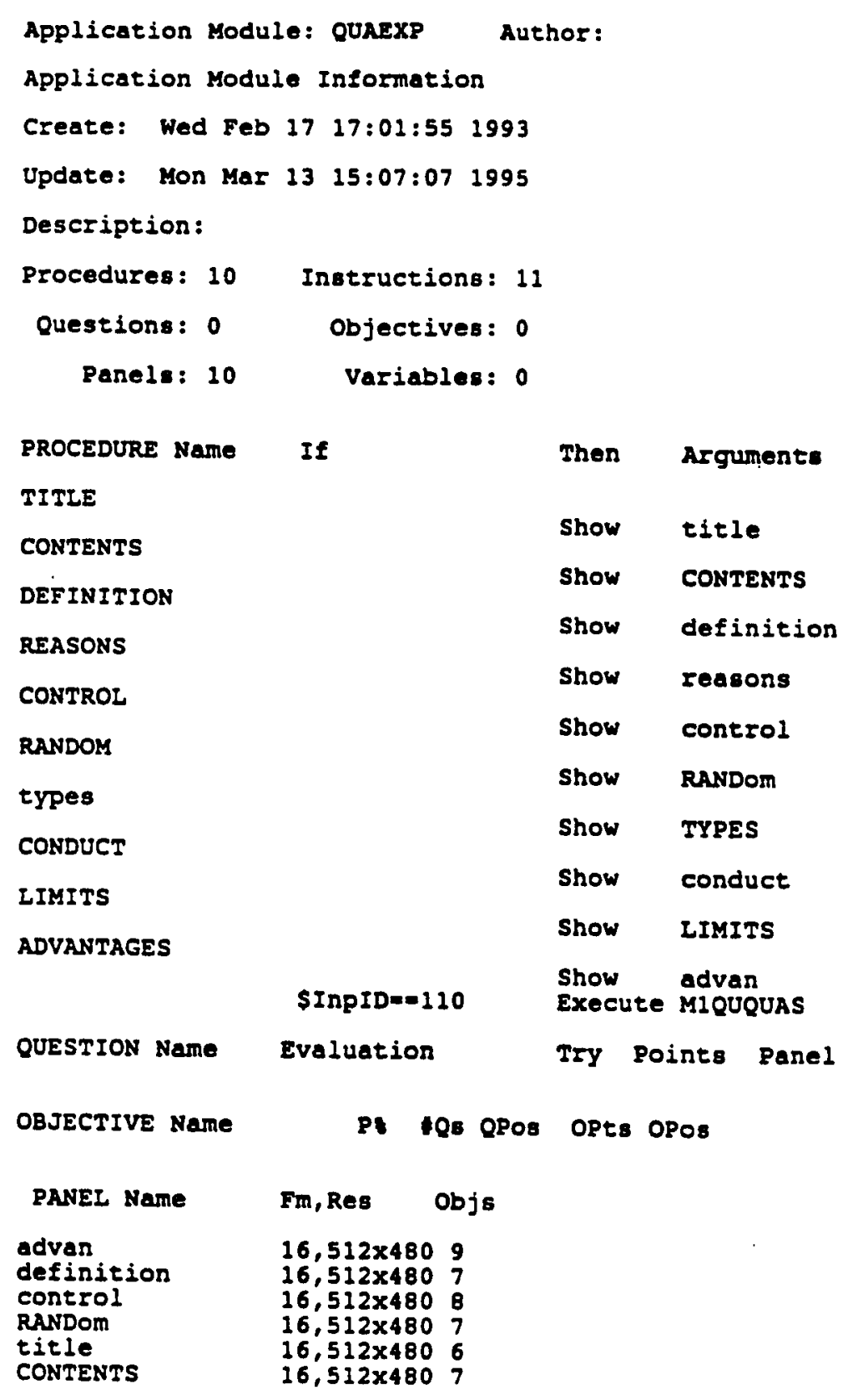


Appendix F (continued)

$\begin{array}{ll}\text { Application Yodule: QUNEXP Author: } \\ \text { PANEL Name } & \text { Im, Res Obje } \\ \text { TYPES } & 16,512 \times 4805 \\ \text { CORduct } & 16,512 \times 4807 \\ \text { LIMITS } & 16,512 \times 4806\end{array}$


Appendix F (continued)

External files referenced by C: IAUTH2OUAPPIQUAEXP.ANH

Fonts

(NOT FOUND)

c: lv220lvid font lsans. 109

c: lv220lvidlfont leane.112

C: lv220lvidlfont leans.114

c: IV220lvidlfont lsans.118

c: IV220lvidlfont leans. 124

C: IV220lvidlfont lulera.109

C: lv220lvidlfontlultra.112

C: IV220lvidlfontlultra. 114

c:lv220lvidlfontlultra.118

c: lv220lvidlfont lultra.124

C: IV220lvidlfont lultrab.109

C: IV220lvidlfont lultrab.112

c: IV220lvidlfontlultrab.114

c: IV220lvidlfont lultrab.118

C: IV220lvidlfont lultrab. 124

Images

D: \RESMETH IMAGES Iadvant. C16 advan

D: IRESMETH IMAGES \BASESCR I.C16 definition

title

CONTENTS

D: \RESMETH IMAGES \bOYPUP.C16

reasons

D: \RESMETH IMAGES \disadvan . C16

advan

D: \RESMETH IMAGES I family.C16

RANDOI

D: \RESMETH IMAGES \grp8tud.C16

reasons

D: \RESMETH IMAGES Imedical.C16

control

D: IRESMETH IMAGES PLNBRG.CI6

advan

control

RANDOI

reasons

TYPES

conduct

IIMITS

D: \RESMETHIIMAGES \quas icon.C16

advan

definition

control

title

CONTENTS

conduct

IIMITS 
Appendix F (continued)

AVSS

D: \RESMETH \AUDIO 12 tok. AVS

advan

reasons

conduct

D: \RESMETH IAUDIO \mlquaB . AVS

title

D: IRESMETHIAUDIOIquasfac.AVS

LIMITS

D: IRESMETH \AUDIO\quacontT. AVS

control

D: IRESMETH \AUDIO Iquacont\& . AVS

CONTENTS

D: \RESMETH \AUDIO \quadef . AVS

definition

D: \RESMETH \AUDIO Iquaranda. AVS

RANDOM

Executes

anaman 
Appendix F (continued)

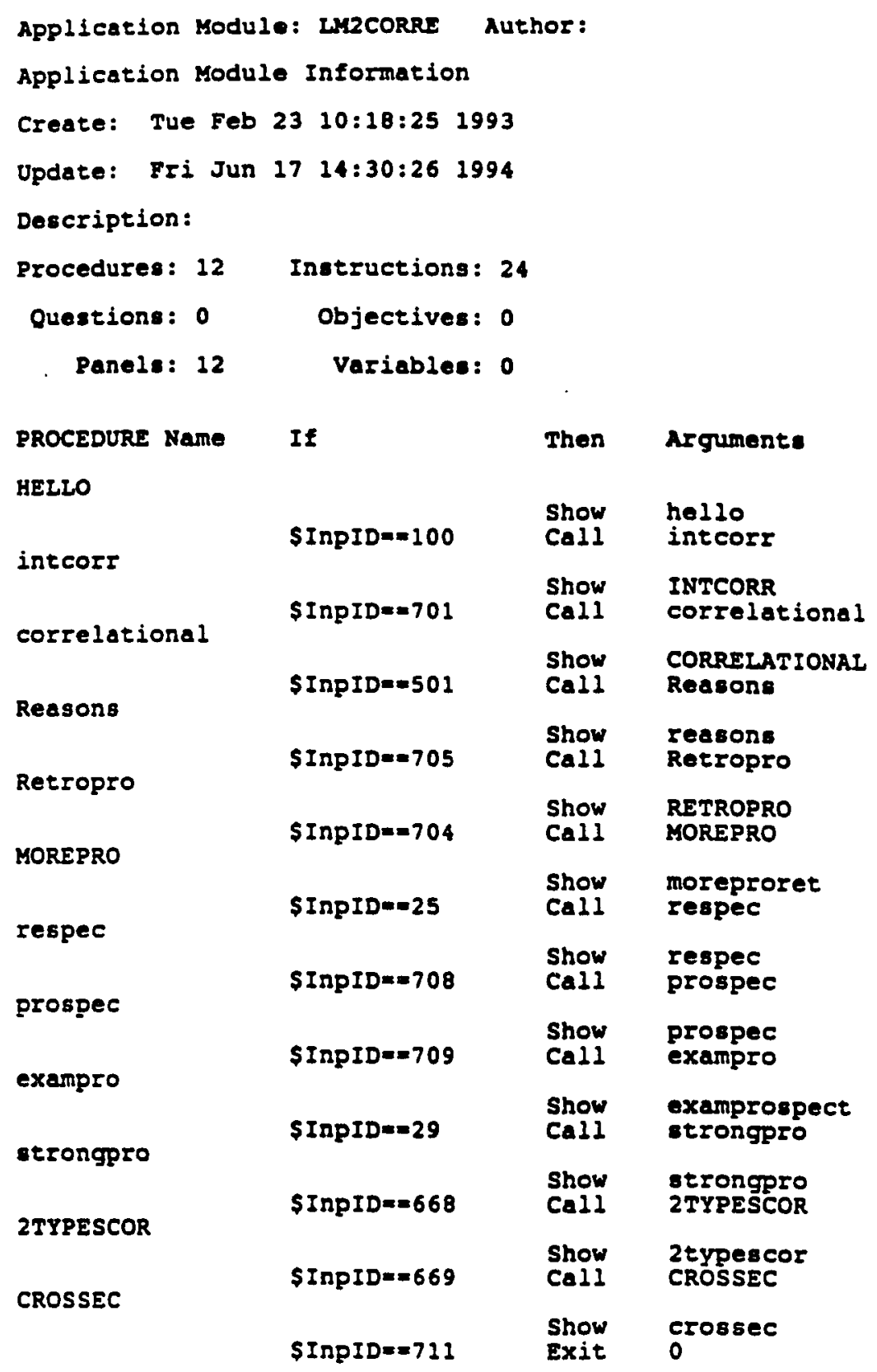


Appendix F (continued)

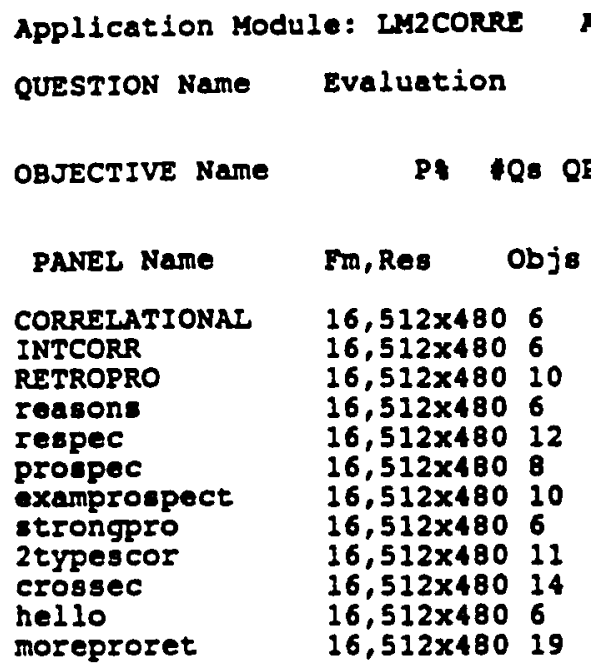


Appendix F (continued)

External files referenced by C: IAUTH2OUAPP LM2CORRE.AMH

Font:

(NOT FOUND)

c: IV220Ividlfont Isans. 109

C: lv220lvidlfont loans. 112

c: IV220lvidlfontlsans.114

c:lv220lvidlfont lsans.118

C: IV220lvidlfont leans 124

c:lv220lvidlfontlultra.109

c: IV220lvidlfont lultra.112

C: lv220lvidlfont lultra.114

c:lv220lvidlfontlultra.118

C: IV220lvidlfontlultra.124

C: IV220lvidlfontlultrab.109

c:lv220lvidlfont lultrab. 112

C: IV220lvidlfontlultrab.114

c: IV220lvidlfontlultrab. 118

c: IV220lvidlfont lultrab.124

Images

D: (RESMETH IMAGES $\backslash 2$ retro.C16 RETROPRO

respec

D: \RESMETH IMAGES \BASESCR . C16 CORRELATIONAI

INTCORR

hello

D: \RESMETH IMAGES \bPPYO.C16

examprospect

D: IRESMETH IMAGES \CORIMag. C16

hello

D: \RESMETH IMAGES \Cros s sec. 016 2 typescor crossec

D: \RESMETH IMAGES \dOta . C16 respec

D: \RESIATTHIIMAGES \long.C16 2typescor

D: \RESMETH IMAGES \momedaug . C16 prospec

D: \RESMETH IMAGES \OLDMOM.C16 respec

D: \RESKETH IMAGES IPLNBRG.C16

RETROPRO

zeasone

respec

strongpro

2 typescor

crossec

moreproret

D: \RESMETH IMAGES \8alty fds . C16

examprospect 
Appendix F (continued)

D: \RESMETH IMAGES RETROPRO

AvsS

D: \RESMETH \AUDIO 2 TYPCL. AVS 2 typescor

D : \RESMETH \AUDIO 2 TYPRP . AVS RETROPRO

D: IRESMETH \AUDIO।COTIYes . AVS hello

$D: \backslash R E S M E T H \backslash A U D I O \backslash D R U M U P$. AVS prospec examprospect

D: IRESIETH AUUDIO YPIANOFUL . AVS INTCORR

D: IRESMETH \AUDIOISAXFUL. AVS respec

D: \RESMETH \AUDIO ITR2MED . AVS moreproret

D: IRESMETH \AUDIO TRK62.AVS reasons crossec

D: \RESMETH \AUDIOIWATERPRF , AVS CORRELATIONAL

Executes

ax a n a 
Appendix F (continued)

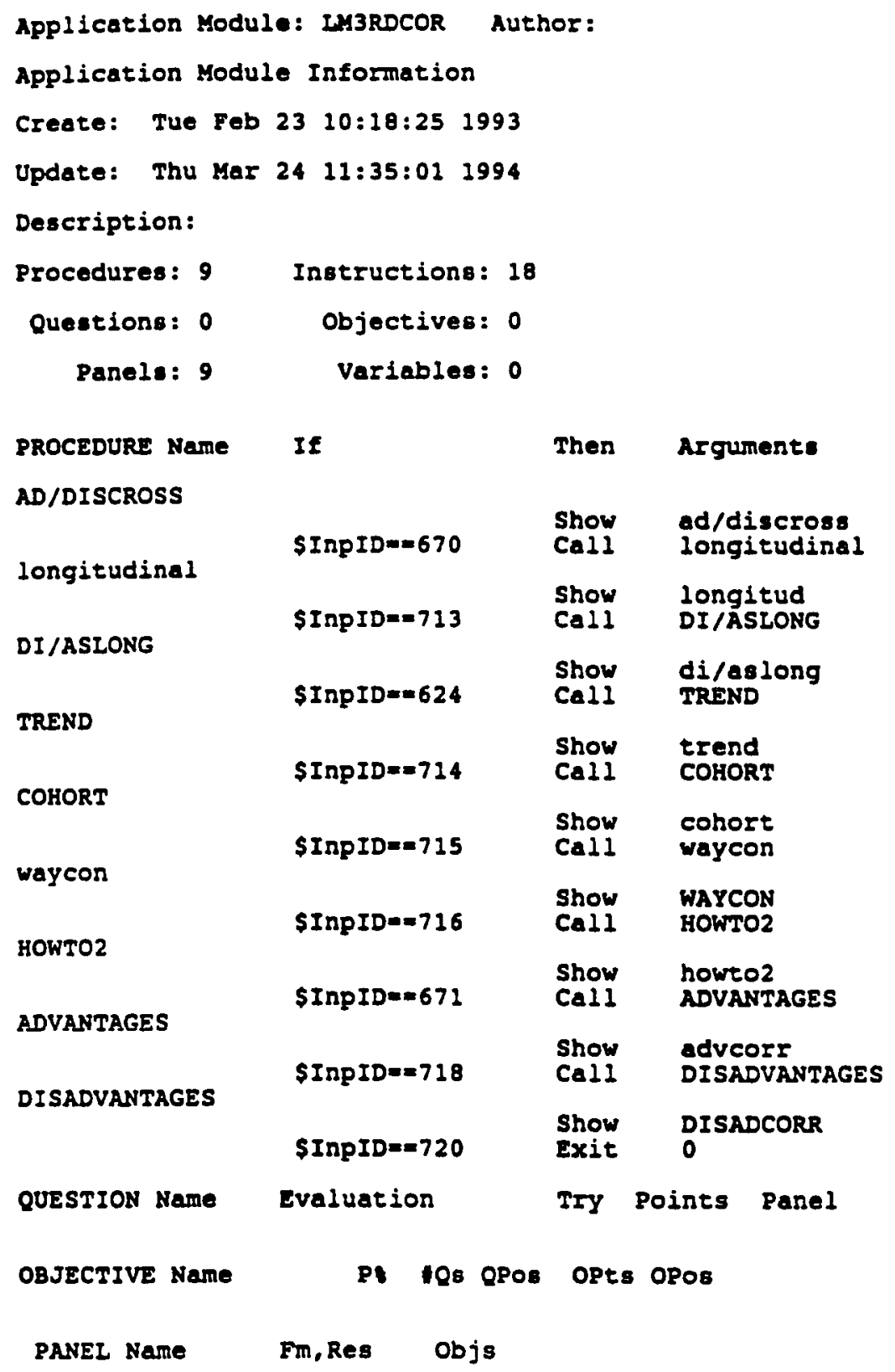


Appendix F (continued)

Application Module: LY3RDCOR Author:

PANEL Name Im,Res Objs

longitud

dilaslong

trend

cohort

WAYCON

howto2

$16,512 \times 480 \quad 10$

$16,512 \times 4808$

$16,512 \times 48016$

$16,512 \times 48010$

$16,512 \times 48010$

advcorr $\quad 16,512 \times 4806$

DISADCORR $\quad 16,512 \times 4806$ 
Appendix F (continued)

External files referonced by C: IAUTH20 (APPIEPIDEM.NM

Fonts

(NOT FOUND)

C: IV220lvidlfont lears. 109

c: IV220lvidl fontleans. 112

c: IV220 Ividlfont leans.114

c: IV220lvid Ifont lsans. 118

c: lv220lvidlfont leans. 124

c:lv220lvidlfontlultra.109

c: Iv220lvidifontlultra.112

C: IV220lvidlfontlulera.114

c: IV220lvidlfontlultra. 118

c: Iv220lvidlfontlultra.124

C:IV220 Vvidl font lultrab. 109

C: IV220lvidlfontlultrab.112

C: lv220lvidlfontlultrab.114

C: IV220lvidlfontlultrab. 118

c:IV220lvidlfontlultrab. 124

Images

D: \RESMETH IMAGES Iadvant.C16 ADVANT

D: IRESMETH IMAGES $\backslash$ BASESCR1.C16

TITLE

CONTENTS

DEFINITION

D: IRESHETH IMLGES।disadvan . C16

ADVANT

D: \RESMETH IMAGES \hapmodon . C16

REASONS

D: \RESMETH IMAGES \manfish. C16 EPIDEMIOLOGICAI

D: \RESMETH\IMAGES \mans COP. C16 analyeical

D: \RESMETH IMAGES \megascop. C16 EPIDEMIOLOGICAI

D: \RESMETH IMAGES \PLNBKG.C16 EPIDEMIOLOGICAL

HOW TO

ADVANT

IASTHOUGHT

D: IRESMETH IMAGES I Aickboy - C16

TITLE

D: IRESMETH IMAGES \wonnrice . C16 epidesc

AvSS

D: IRESIETTH AUDIOLDEFEP I . AVS DEFINITION

D: IRESMETH TAUDIO\PIANOUP . AVS epidesc 
Appendix E (continued)

D: \RESMETH \AUDIO Ieaxful . AVS

ADVANT

$D:$ IRESMETH \AUDIOISNEEZEPI . AVS

TITLE

D: IRESMETH \AUDIOITR2END.AVS

LASTHOUGHT

D: \RESMETH \AUDIOITRK13MED. AVS

REASONS

D: \RESIETH \AUDIOITRK62. AVS

anolytical

D: \RESIETH \AUDIOITRRB.AVS

CONTENTS

D: IRESKETH IAUDIOItrk9.AVS

HOW TO

D: \RESIETH \AUDIO TTPEPI . AVS

EPIDEMIOIOGICAI

Executes:

ancoman 
Appendix F (continued)

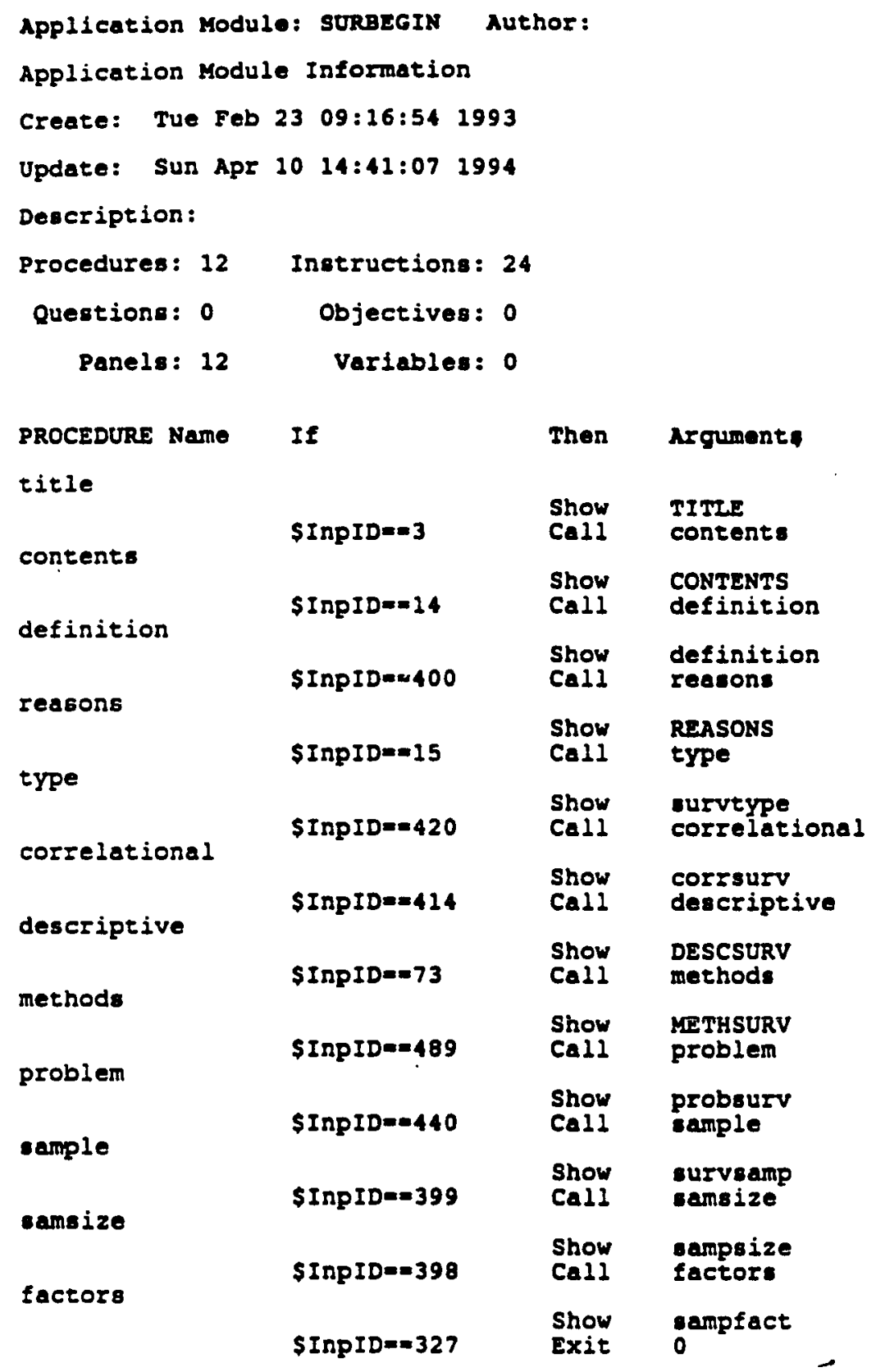


Appendix F (continued)

\begin{tabular}{|c|c|c|c|c|c|}
\hline QUESTION Name & Evaluatio & & Try & Poines & Panel \\
\hline OBJECTIVE Name & Pe & 108 QPOB & OPts & OPO8 & \\
\hline PANEL Name & Fm, Res & Objs & & & \\
\hline $\begin{array}{l}\text { definition } \\
\text { DESCSURV } \\
\text { survtype } \\
\text { corrsurV } \\
\text { METHSURV } \\
\text { probsurV } \\
\text { survsamp } \\
\text { sampsize } \\
\text { sampfact } \\
\text { TITLE } \\
\text { CONTENTS } \\
\text { REASONS }\end{array}$ & $\begin{array}{l}16,512 \times 48 \\
16,512 \times 48 \\
16,512 \times 48 \\
16,512 \times 48 \\
16,512 \times 48 \\
16,512 \times 48 \\
16,512 \times 48 \\
16,512 \times 48 \\
16,512 \times 48 \\
16,512 \times 48 \\
16,512 \times 46 \\
16,512 \times 48\end{array}$ & $\begin{array}{ll}30 & 6 \\
0 & 9 \\
0 & 10 \\
0 & 9 \\
0 & 8 \\
0 & 8 \\
0 & 7 \\
0 & 7 \\
0 & 7 \\
0 & 6 \\
0 & 6 \\
0 & 6 \\
0 & 8\end{array}$ & & & . \\
\hline
\end{tabular}


Appendix F (continued)

External fllee raferenced by C: IAUTH20 \APPISURBEGIN.MAY

Ponts

(NOT FOUND)

C: IV220ividlfont lsans .109

c: \V220|vidlfontleans.112

C: lv220lvidlfontlsans.114

c: IV220lvidlfont leans.118

c: IV220lvidlfont lsans.124

C: IV220lvidlfontlultra.109

C: IV220lvidlfontlultra.112

C: IV220lvidfontlultra.114

C: IV220lvidlfontlultra.118

C: IV220lvidlfontlultra.124

C: IV220lvidlfontlultrab.109

C: IV220lvidlfontlultrab.112

c: lv220lvidlfontlultrab.114

c: lv220lvidlfont lultrab.118

c: IV220lvidlfontlultrab.124

Images

D: \RESMETH IMAGES \4dudes .C16 survsamp

D: \RESMETH IMAGES \BASESCRI.C16

definition

TITLE

CONTENTS

D: \RESMETH IMAGES \beachewd. C16 probsurv

D: \RESMETH IMAGES \boyflag.C1 6 TITLE

D: \RESHETH IMAGES $\backslash$ fYYChX.C16

DESCSURV

survtype

D: IRESMETH IMAGES \gdsalad.C16 METHSURV

D: \RESMETH IMAGES\gelpil1.C16 survtype corrsurv

D: \RESMETH IMAGES \medonald.C16

REASONS

D: \RESMETH IMAGES \PLNBRG . CI 6

DESCSURV

ourvtype

corrsurv

sampsize

sampfact

AVSS

D: \RESMETH \AUDIO \DRUMUP . AVS DESCSURV

D: \RESKETH \AUDIOIPIANOFUL . AVS 
Appendix F (continued)

campfact

D: \RESKETH \AUDIOISURDEF. AVS

definition

D: \RESMETH \AUDIOISURQUEFM.AVS METHSURV

D: \RESMETH \AUDIOISURTYPES . AVS

survtype

D: \RESYETH \AUDIOITR2END. AVS

sampsize

D: \RESMETH TAUDIOITRK13MED. AVS

vurveamp

D: IRESMETH \AUDIOITRK6.AVS

REASONS

D: \RESMETH \AUDIOITRR62 . AVS

corrsurv

D: IRESMETH IAUDIOITRRB.AVS

probsurv

D: IRESMETH \AUDIOITRK9 . AVS CONTENTS

D: IRESMETH \AUDIOIWELSUR. AVS TITLE

Executes 
Appendix F (continued)

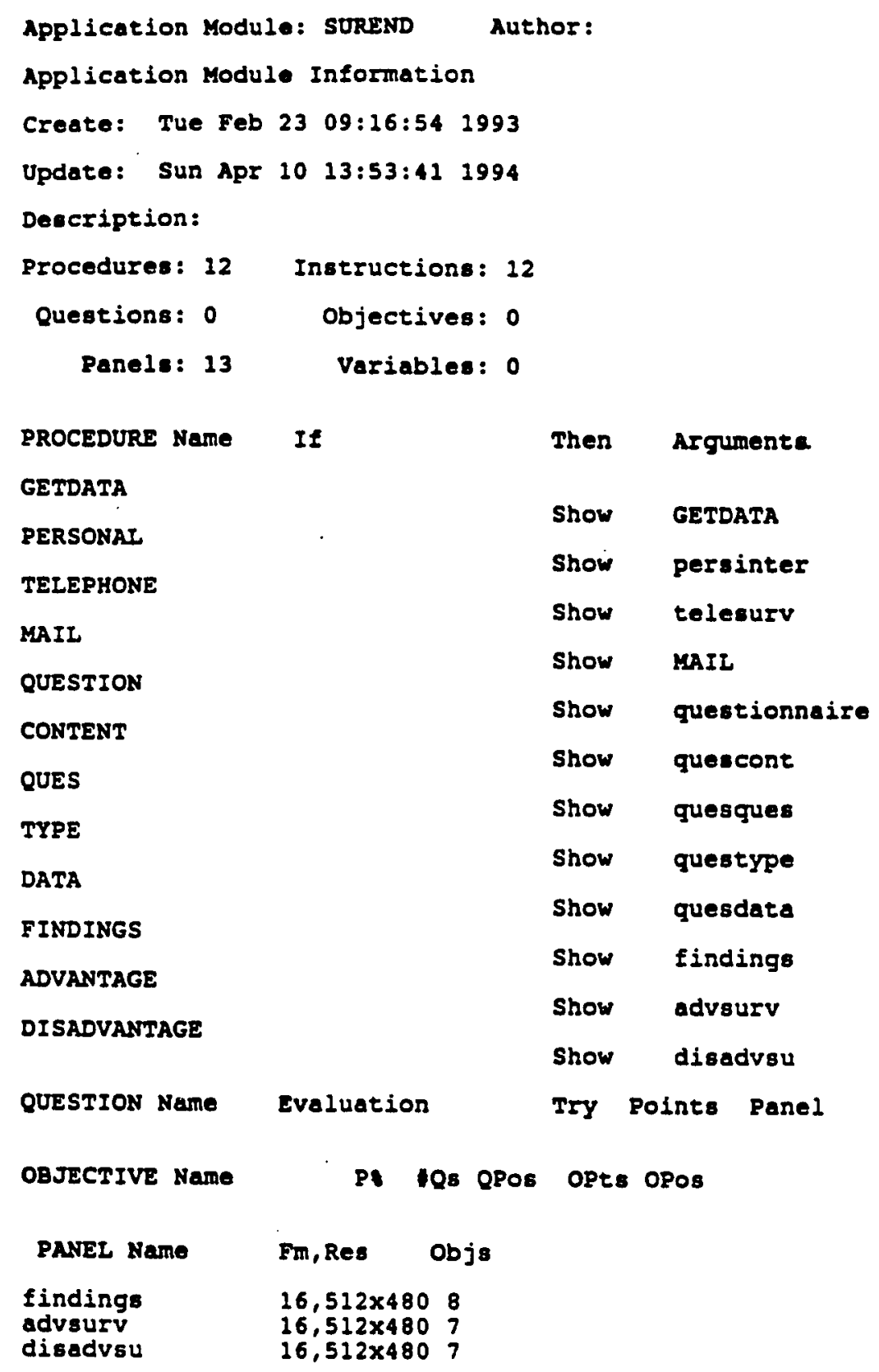


Appendix F (continued)

$\begin{array}{lll}\text { Application Module: SUREND } \\ \text { PANEL Name } & \text { Im, Res Objo } \\ \text { questionnaire } & 16,512 \times 480 & 8 \\ \text { persinter } & 16,512 \times 480 & 11 \\ \text { telearr } & 16,512 \times 480 & 10 \\ \text { quescont } & 16,512 \times 480 & 7 \\ \text { quesdata } & 16,512 \times 480 & 10 \\ \text { quesques } & 16,512 \times 480 & 7 \\ \text { questype } & 16,512 \times 480 & 7 \\ \text { MAIL } & 16,512 \times 480 & 11 \\ \text { GETDATA } & 16,512 \times 480 & 13\end{array}$


Appendix F (continued)

External filee reforenced by C: IAUTH2O \APP\SUREND. MAY

Ponts

(NOT FOUND)

C: IV220lvidlfontleans. 109

c:lv220lvidlfont lsans.112

C: lv220lvidlfontloans.114

C: IV220lvidlfontlsans.118

c: IV220lvid font lsans. 124

C: IV220lvidlfonelultra.109

c:lv220lvidlfontlultra.112

c: IV220lvidlfonelultra.114

C: IV220lvidlfontlultra.118

C: IV220lvidlfontlultra.124

C: IV220lvidlfontlultrab.109

C: IV220lvidlfontlultrab.112

C: IV220lvidlfonelultrab.114

c: IV220lvidlfont lultrab. 118

c: IV220lvidlfontlultrab.124

Images

D: IRESMETH IMAGES Iadvant . C16

adveurv

D: \RESMETH \IMAGES \BASESCR2 . C16

advaisad

D: \RESMETH IIHAGES \beachrun.C16 Eindings

D: \RESKETH IMAGES $\backslash$ BIGBUCR.C16

disadveu

D: \RESMETH IMAGES CLASSRM. C16

questionnaire

D: IRESMETH।IMAGES \CIOWdmed.C16

advsurv

D: \RESMETH IMAGES \dinerman . C16

quescont

D: IRESMETH IMAGES \disadvan.C16

disadveu

D: \RESMETH IMAGES \garlic.Cl 6

quesdata

D: \RESMETHIIKAGESIgdtalk.C16

GETDATA

D: \RESMETH IMAGES \LETTERS . C16

MAIL

GETDATA

D: \RESMETH IMAGES \phontalk.C16

telesurv

GETDATA

D: \RESHETH IMAGES \PLNBRG.CI 6

persinter

quesdata

quesques

questype

MAIL 
Appendix F (continued)

GETDATA

D: \RESMETH IMAGES \POSTMAN . C16

MAIL

D: IRESMETH IMAGES\GUBhi.C16

quesdata

D: \RESMETH IMAGES \talking.C16 persinter

AVSS

AVS

D: \RESMETH TAUDIOIPIANOUP . AVS

quesques

D: \RESMETH \AUDIO SURCEE . AVS

findings

$D:$ IRESMETH \AUDIOISUROATA. AVS quesdata

D: IRESMETH \AUDIOISURVEY 3 . AVS

questionnaire

D: IRESYETH \AUDIOISURVEYTY.AVS GETDATA

D: \RESMETH \AUDIO \TR2END. AVS

questype

D: IRESMETH TAUDIOITR2STRT . AVS adveurv

D: \RESMETH \AUDIO TTRK1 3SHT. AVS quescont

D: \RESMETH \AUDIOSTRK3 . AVS telesurv

D: IRESMETH \AUDIO\TRK6 . AVS persinter

D: IRESMETH\AUDIOITRK62. AVS disadvsu

D: \RESMETH \AUDIOITRR8 . AVS MAII

Executes

Exaranas 
Appendix F (continued)

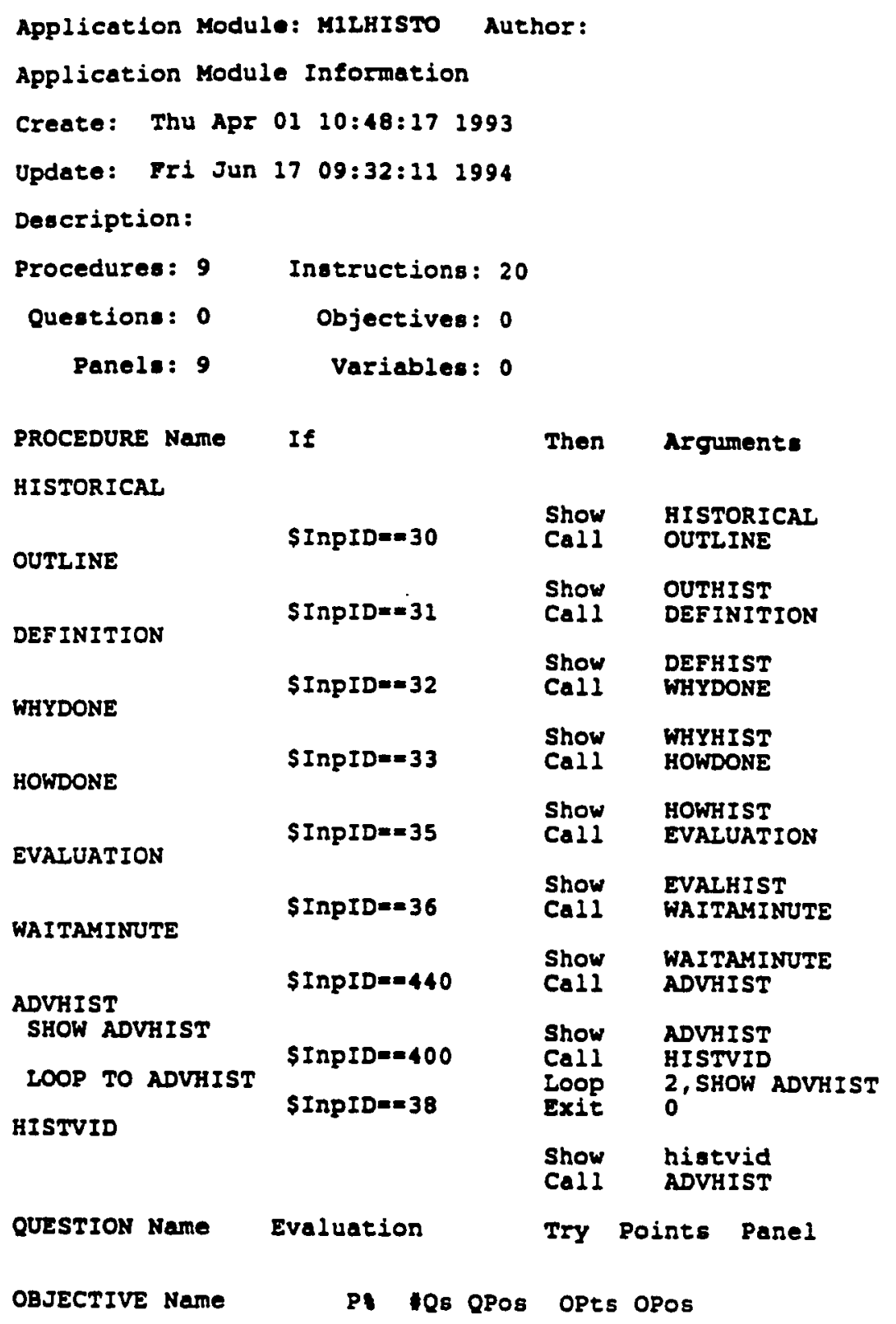


Appendix E (continued)

Application Module: MILHISTO Author:

PANEL Name Fm, Res Objs

HISTORICAL $\quad 16,512 \times 4808$

OUTHIST $\quad 16,512 \times 4806$

DEFHIST $\quad 16,512 \times 48011$

WHYHIST $16,512 \times 4809$

HOWHIST $\quad 16,512 \times 48013$

EVALHIST $\quad 16,512 \times 48013$

ADVHIST $\quad 16,512 \times 48010$

histvid $\quad 9,512 \times 4802$

WAITAMINUTE $\quad 16,512 \times 48015$ 


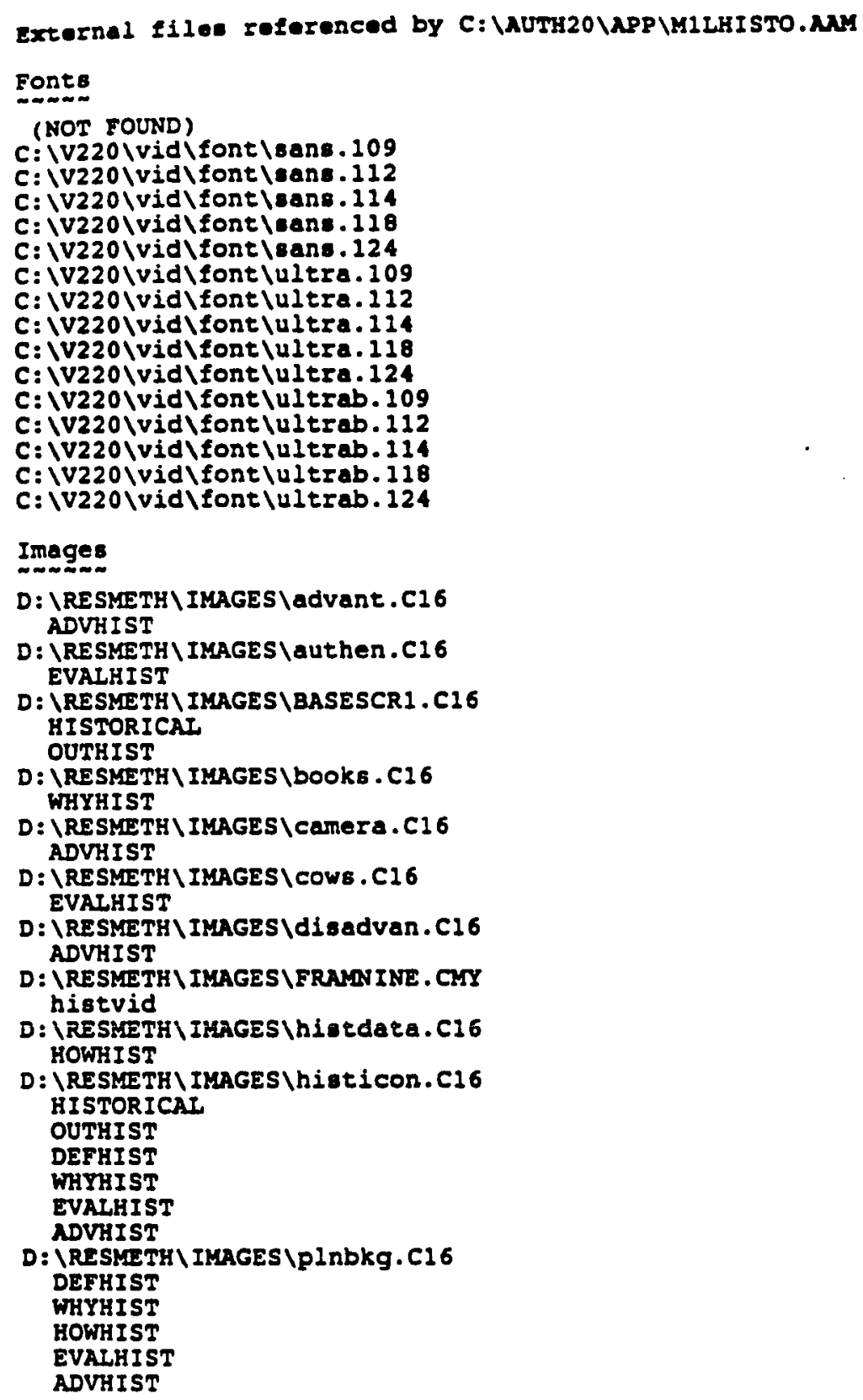

D: \RE SMETH\IMAGES \authen.C16 EVALHIST

D: \RESMETH IMAGES \BASESCR 1 .C16 HISTORICAI OUTHIST

D: IRESMETH IIMAGES \bOOk6 . C 6 WHYHIST

D: \RESMETH\IMAGES \Camera.C16 ADVHIST

D: \RESMETH IMAGES \COWB . C16 EVAIHIST

D: \RESMETH IMAGES \disadvan.C16 ADVHIST

D: IRESMETH IMAGES IFRAMNINE . CMY histvid

D: IRESMETH IMAGESIhisedara.C16 HOWHIST

D: IRESMETH IMAGES \histicon.C16 HISTORICAI

OUTHIST

DEFHIST

WHYHIST

EVALHIST ADVHIST

D: IRESMETH IMAGES \plnbkg.C16 DEFHIST WHYHIST HOWHIST EVALHIST ADVHIST 
Appendix F (continued)

WAITAMINUTE

D: \RESMETH IKAGES \EWOCar.C16

DEFHIST

AvsS

D: IRESMETH \AUDIO DRUMUP . AVS

HOWHIST

D: \RESMETHIAUDIO YHISDEF . AVS

DEFHIST

D: \RESYETH IAUDIO $H$ I SHECR . AVS

EVALHIST

D: \RESMETH \AUDIO \HISTITLE . AVS

HISTORICAL

D: IRESIETH \AUDIOIPIANOFUL . AVS

WAITAMINUTE

D: IRESWETH IAUDIOITR2END.AVS

OUTHIST

D: \RESKETH \AUDIOITRKILNG . AVS

WHYHIST

D: \RESMETHIVIDEOIHISTORY . AVS histvid

Executes

Exanam 
Appendix F (continued)

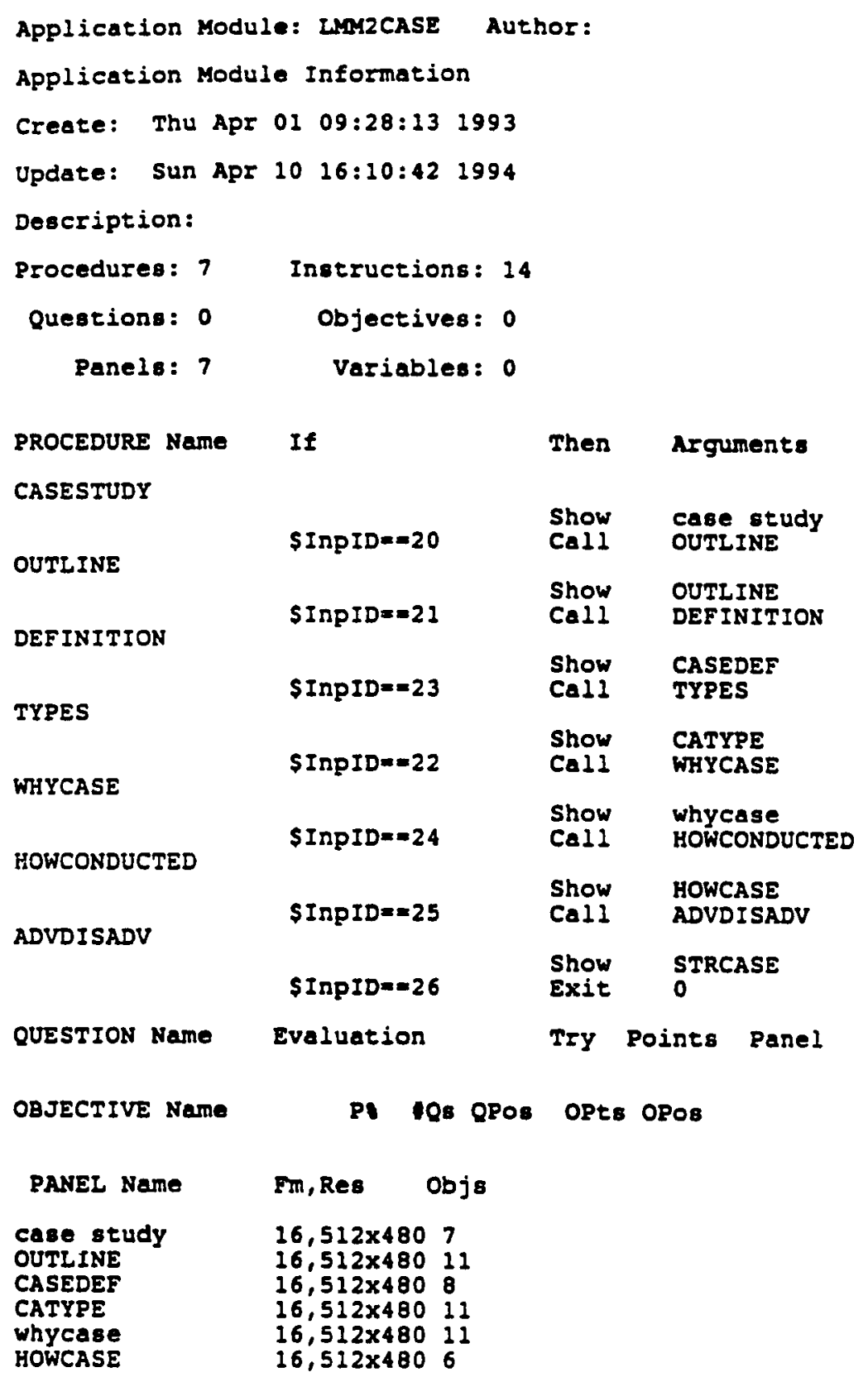


Appendix F (continued)

External filee referenced by C: IAUTH2O \APP ILAK2CASE.MM

Fonts

(NOT FOUND)

C: lv220lvidlfont leans.109

c: IV220lvidlfont laans. 112

C: IV220lvidlfontlaana.114

c: IV220lvidlfontleans.118

c: IV220lvidlfont leane. 124

c: lv220lvidlfontlultra.109

C: IV220lvidlfontlultra.112

c: IV220lvidlfontlultra.114

c: lv220lvidlfontlultra.118

C: IV220lvidlfontlultra.124

C: IV220lvidlfontlultrab.109

c: IV220lvidlfontlultrab. 112

C: IV220lvidlfontlultrab.114

c: Iv220lvidlfontlultrab.118

c:lv220lvidlfontlultrab.124

Images

D: \RESMETH IIMAGES \ADVANT. C16 STRCASE

D: IRESMETH IMAGES \BASESCR1.C16 case study OUTLINE

D: \RESMETH IIMAGES \CASE 1 . C16 case study

OUTIINE

CASEDEF

CATYPE

D: \RESMETH IMAGES\CASE2.C16 CATYPE

D: IRESMETHIIMAGESIDETAIL.C16 whycase

D: IRESMETH IMAGES \dieadvan.C16 STRCASE

D: \RESMETH IMAGES \idea.C16 whycase

D: \RESMETH IMAGES \ineight.C16 whycase

D: \RESMETH IMAGES \PINBRG.C16 CATYPE

whycase

HOWCASE

STRCASE

D: \RESMETH IMAGES \Btretch . C16 CASEDEF

Avss

D: IRESMETH \AUDIO\CASEDEF . AVS CASEdEF 
Appendix E (continued)

D: \RESKCTH VAUDIOICASETITZ . AVS case etudy

D: IRESMETH AAUDIOITR2STRT. AVS OUTLINE

D: \RESMETH \AUDIO TRRI 3MED. AVS

whycase

D: \RESMETH \AUDIO ITRK3 . AVS

STRCASE

D: IRESMETH IAUDIOLTRK8 . AVS

HOWCASE

D: \RESMETH \AUDIOITRK9 . AVS

CATYPE

\section{Executes}

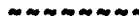


Appendix F (continued)

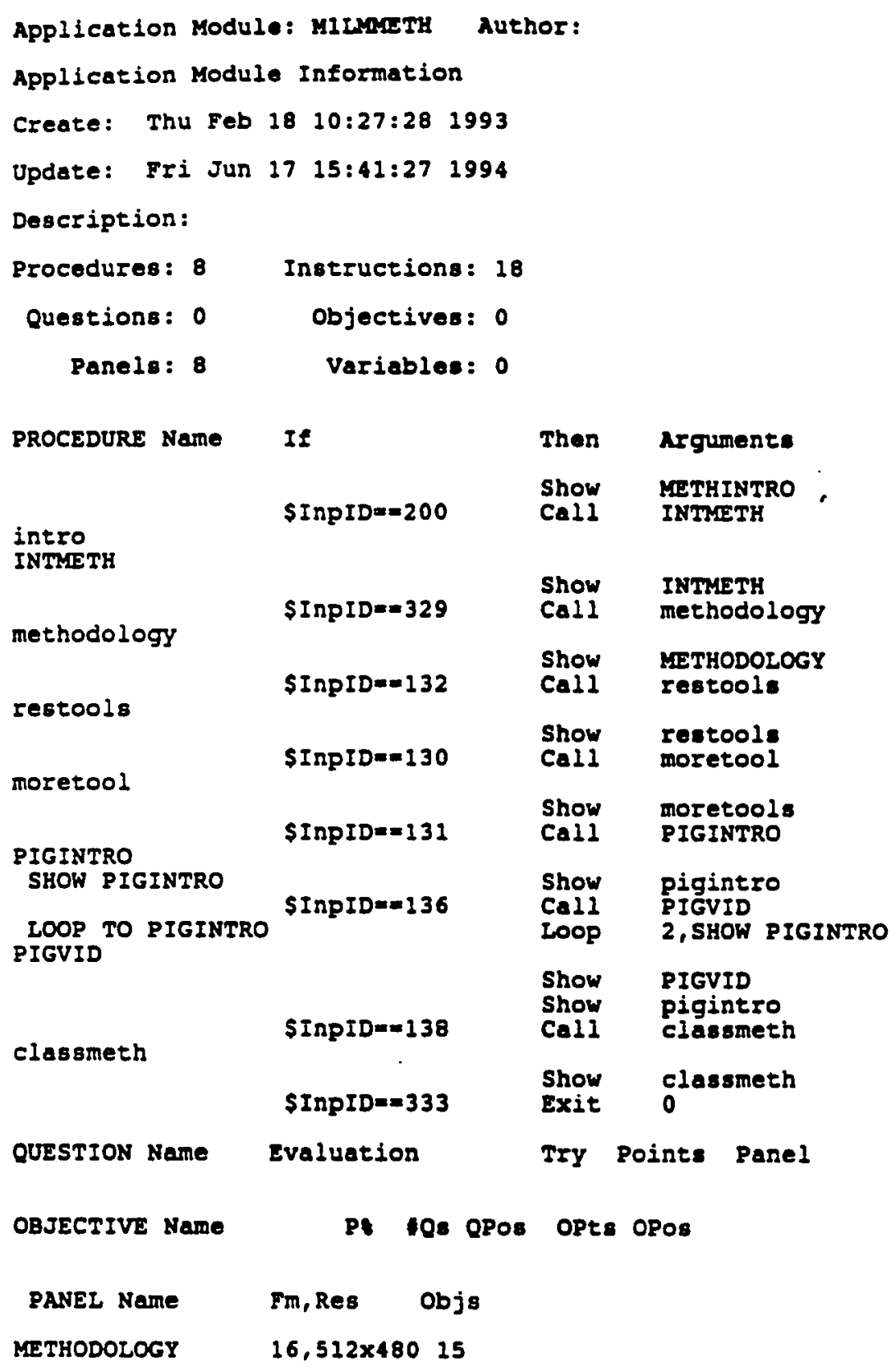


Appendix F (continued)

\section{Application Module: MILMaTh Author:}

PANEL Name Fm, Ree Objs

$\begin{array}{lrl}\text { moretools } & 16,512 \times 480 & 16 \\ \text { pigintro } & 16,512 \times 480 & 11 \\ \text { PIGVID } & 9,512 \times 480 & 2 \\ \text { Clas8meth } & 16,512 \times 480 & 16 \\ \text { INTMETH } & 16,512 \times 480 & 10 \\ \text { METHINTRO } & 16,512 \times 480 \mathrm{~B}\end{array}$


Appendix F (continued)

External files referenced by C: IAUTH20 \APP\MILMETH.AMM

Fonts

(NOT FOUND)

c:lv220 Vvidlfontlsans. 109

c: lv220lvidlfontlsans. 112

C: lv220lvidlfort leans. 114

c: IV220lvidlfont lsans.118

C: IV220lvidlfort laans. 124

C: IV220lvidlfontlultra.109

c: lv220lvidlfontlultra.112

c: IV220lvidlfontlultra.114

C: IV220lvidlfontlultra.118

c: lv220lvidlfontlulera.124

c:lv220lvidlfontlultrab. 109

C: IV220lvidlfontlultrab. 112

c: IV220lvidlfontlultrab.114

C: IV220lvidlfontlultrab. 118

$c:$ IV220lvidlfont lulerab. 124

Images

D: IRESMETH IMAGES \BASESCR1.C16 INTMETH

METHINTRO

D: \RESMETH IMAGES \Camera . C1 6

pigintro

D: RESMETH IMAGES IClampmed.C16 METHODOLOGY

D: \RESMETH IMAGES $\backslash$ COMP. $C 16$ moretools

D: \RESMETH IMAGES \COstben.C16 moretools

D : \RESMETH IMAGES \FRAMNINE. CMY PIGVID

$D: \backslash R E S M E T H \backslash$ IMAGES $\backslash$ idquest.c16 moretools

$D$ : \RESMETH IMAGES \keyboard.C16 restools

D: \RESMETH IMAGES \medical.C16 moretools

$D$ : \RESMETH IMAGES \OR'ED.C16

classmeth

classmeth

classmeth

classmeth

D: \RESMETH IMAGES \plnbkg . C16

moretools

pigintro

classmeth

D: IRESMETH IMAGES Iscapal. .616

moretools

classmeth

INTMETH 
Appendix F (continued)

\section{FETHINTRO}

AvSS

D: \RESMETH \AUDIO 1 14TRLONG. AVS moretools

D: \RESMETH TAUDIO\5TRROED . AVS

classmeth

D: \RESMETH \AUDIOIPIANOUP . AVS restools

$D:$ IRESMETH \AUDIO TRZEND. AVS METHINTRO

D: \RESKETH \AUDIOITRRILNG . AVS INTMETH

D: IRESMETH \AUDIOITRK9 . AVS METHODOLOGY

D: IRESHETH \VIDEOILAPERO.AVS PIGVID

Executes

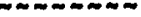


Appendix E (continued)

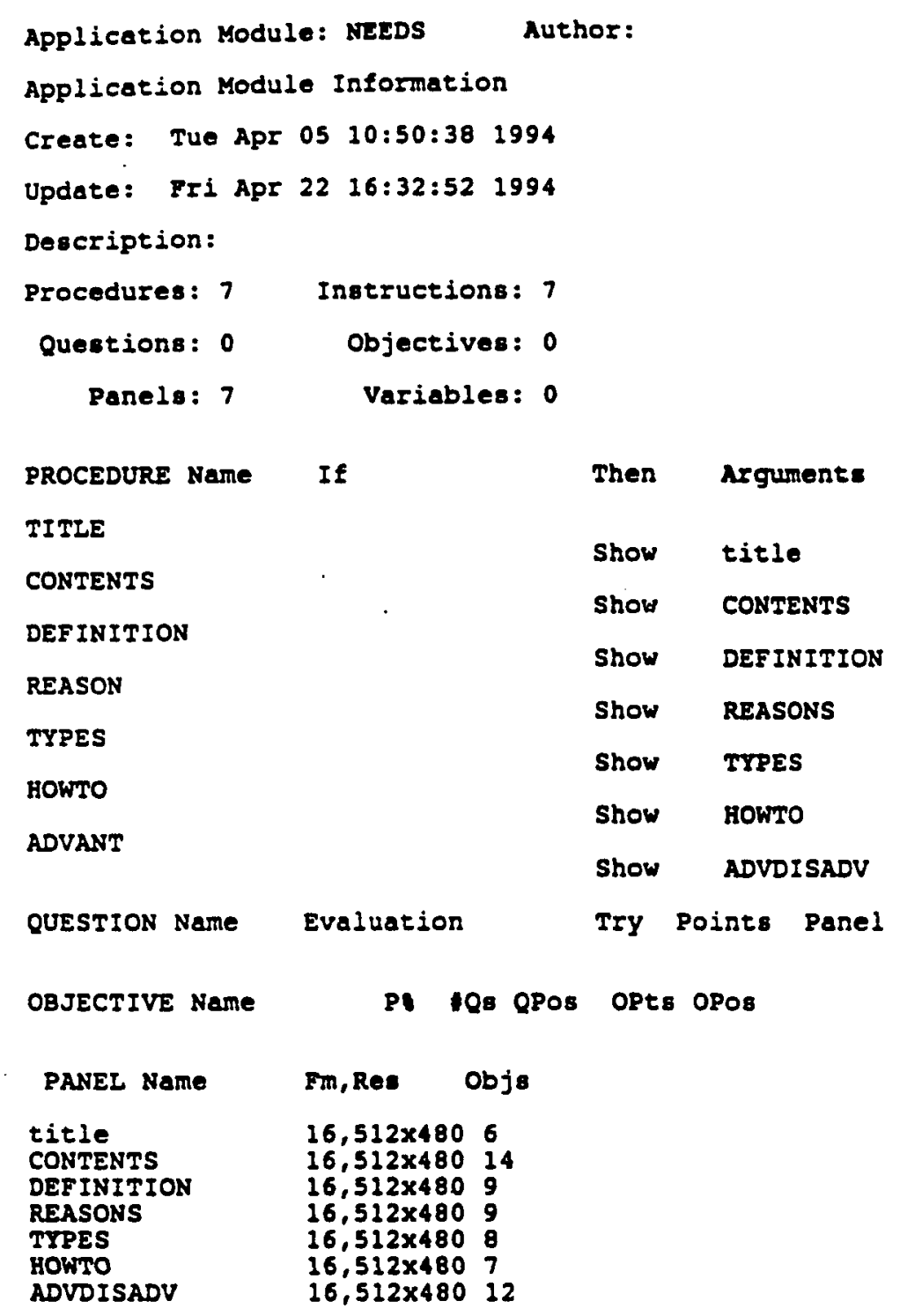


Appendix F (continued)

External files referenced by C: \AUTH20

Fonts

(NOT FOUND)

c: IV220lvidifontlans. 109

c: lV220 Vid

c: IV220lvid fontlsans.114

c:lv220lvid fontlsang.118

c: IV220lvidlfontlsans.124

c: IV220lvidlontlultra.109

C: IV220lvidlfontlultra.112

C:IV220lvidlfontlultra.114

C: lv220lvidifontlultra.118

c:lv220lvidifontlultra.124

C: IV220lvidlfont lultrab. 109

c: lv220lvidlfont lultrab. 112

c: IV220lvidfont lultrab. 114

c: IV220lvid font lultrab. 118

c:|V220।vid font lultrab.124

Images

D: \RESMETH IMAGES \ADVANT.C16 ADVDISADV

D: \RESMETH IMAGES \amish.C16 title

D: \RESMETH IMAGES \BASESCR I.C16

title

CONTENTS

D: \RESMETH IMAGES IDISADVAN . C16 ADVDISADV

D: \RESMETH\IMAGES \O1dWOM.C16 TYPES

$D:$ IRESMETH IMAGES PINBRG.C16 TYPES HOWTO ADVDISADV

D: \RESMETH IMAGES POtpie.C16 DEFINITION

D: \RESMETH IMAGES SPPlita .C16 REASONS

Avss

D: \RESMETH TAUDIOI14TRLONG. AVS DEFINITION

D: IRESMETH \AUDIOIDRUMUP. AVS ADVDISADV

D: IRESKETH TAUDIOITR2END. AVS HOWTO

D: IRESMETH \AUDIOITRK3 . AVS TYPES

D: \RESHETH \AUDIOITRR62 . AVS REASONS 
Appendix F (continued)

D: \RESMETH \AUDIOITRK7 . AVS

CONTENTS

D: \RESMETH \AUDIO TRK9 . AVS

title

Executes 
Appendix F (continued)

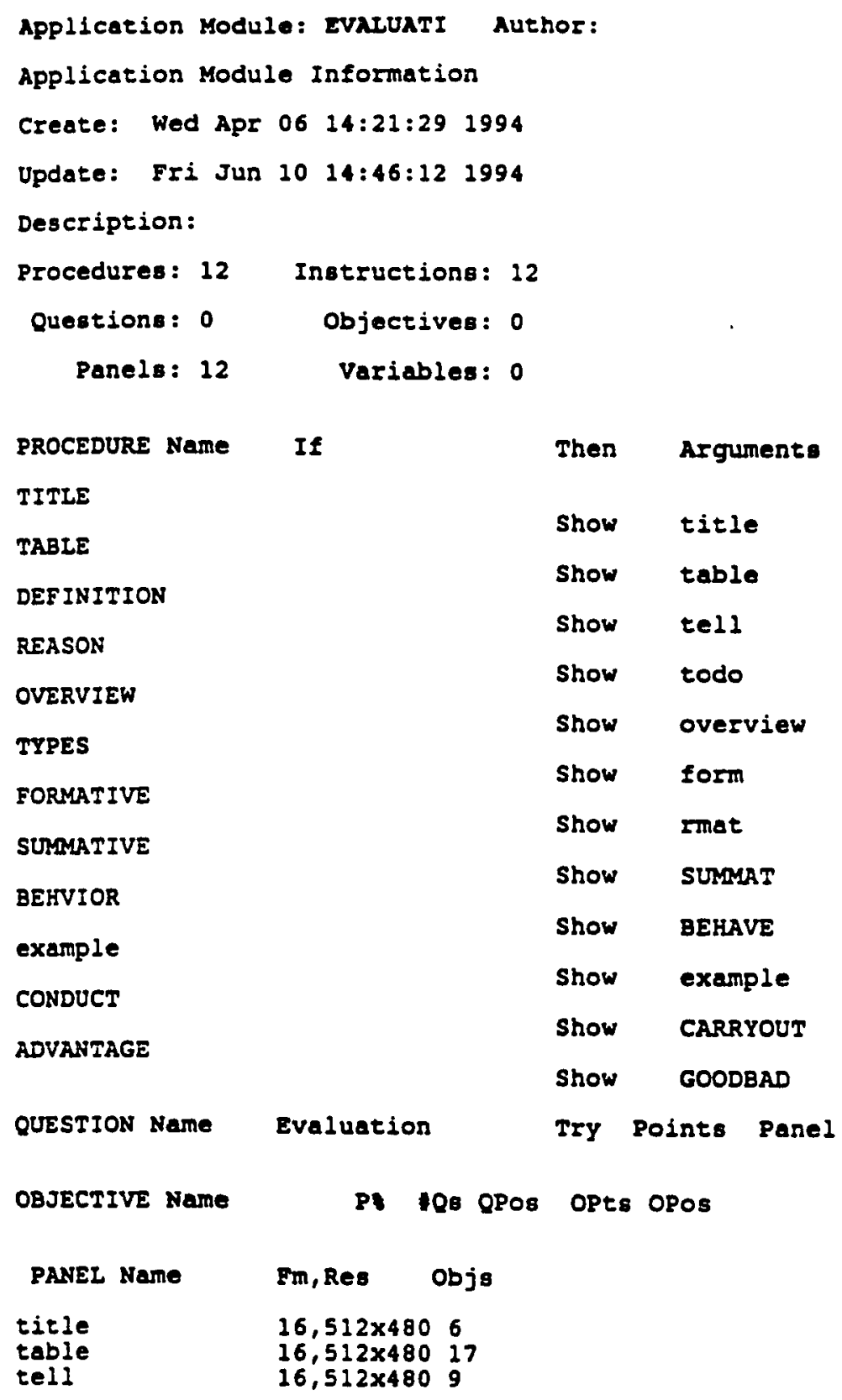


Appendix F (continued)

\section{STONE}

D: \RLSMETH IMAGES IEmoke2 .C16

exan2lim

D: \RESMETH IMAGES \tes thYPo.C16 sthree

D: \RESMETH IMAGES \toddler.C16

exanllimit

D: \RESMETH IMAGES\TIAMa . C16

SRTWO

AvsS

D: \RESMETH\AUDIO\1trk5sec.AVS

STONE

ex3linit

D: IRESMETH \AUDIO 4 trkbit . AVS

SRTWO

IIMITATIONS

exam21im

D: IRESMETH \AUDIO\trk46ec7. AVS

STRENGTHS

othree

examllimit

extlimit

Executes 
Appendix F (continued)

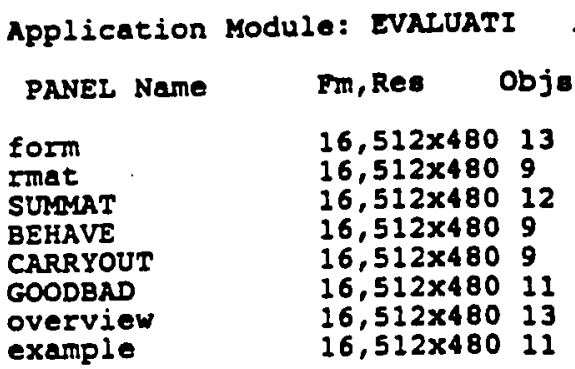


Appendix F (continued)

External filee referenced by C: \AUTH2O\APP\EVALUATI.ANH

Fonts

(NOT FOUND)

c: IV220lvidlfoneleans .109

c:lv220lvidlfontlsans. 112

C: IV220 Ivid Ifont leans. 114

c:lv220lvidlfontlans.118

C: IV220lvidlEontlans.124

c: IV220lvidlfontlultra.109

c:lv220lvidlfontlultra.112

C: Iv220lvidlfontlultra.114

c:lv220lvidlfontlultra.118

C: lv220lvid fonelultra.124

C:IV220lvidlfonelultrab. 109

C:lv220lvidlfontlulerab. 112

c: IV220lvidlfontlultrab.114

c: lv220lvidlfontlultrab. 118

c: IV220lvidlfontlultrab.124

\section{Images}

D: IRESMETH IMAGES \advant.C16 GOODBAD

D: IRESMETH IMAGES \basescr $1 . C 16$

title

table

D: \RESMETH IMAGES \dataguy.C16

form

SUNDAAT

D: \RESMETH IMAGES \disadvan . C16 GOODBAD

D: \RESMETH \IMAGES \incbaby.C16

tell

example

$D: \backslash R E S M E T H \backslash I M A G E S \backslash$ newbaby.$C 16$

tell

D: \RESMETH\IMAGES \nutsbolt.C16 Eorm

D: \RESMETH IMAGES \planchic.C16 rmat

D: \RESMETHIIMAGES \Plnbkg.C16 todo

form

SURRAT

BEHAVE

CARRYOUT

COODBAD

overview

example

D: IRESIETH IMAGES \powergal.C16

title

table

D: \RESMETH IMAGES \preggie.C16 
Appendix F (continued)

tel1

D: \RESMETH IMAGES Tteeneex.CI6 example

Avss

D: IRESMETH \AUDIO 1 4TRLONG . AVS tell

D: IRESMETH \AUDIOIITRRSSEC.AVS titlo

D: \RESMETH \AUDIO 5 TROMED. AVS todo

D: \RESMETH \AUDIO IDRUMUP . AVS

CARRYOUT

D: \RESYETH \AUDIOIPIANOFUL . AVS SURMaT

D: \RESMETH \AUDIO TRRRI 3KEDD. AVS form

D: IRESMETH \AUDIO TRRKIMED. AVS table

Executes 
Appendix G

Module II Program Details and External Files

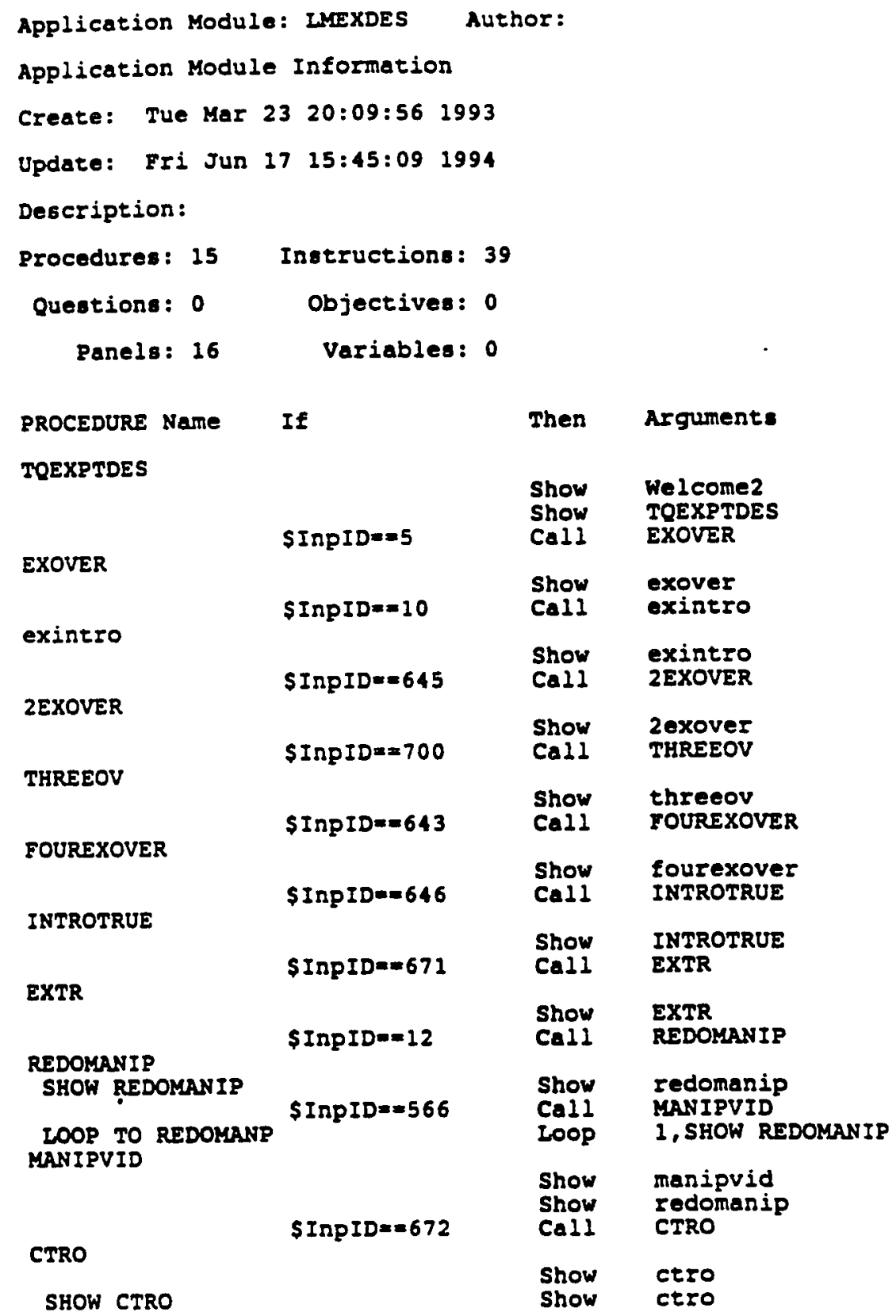


Appendix G (continued)

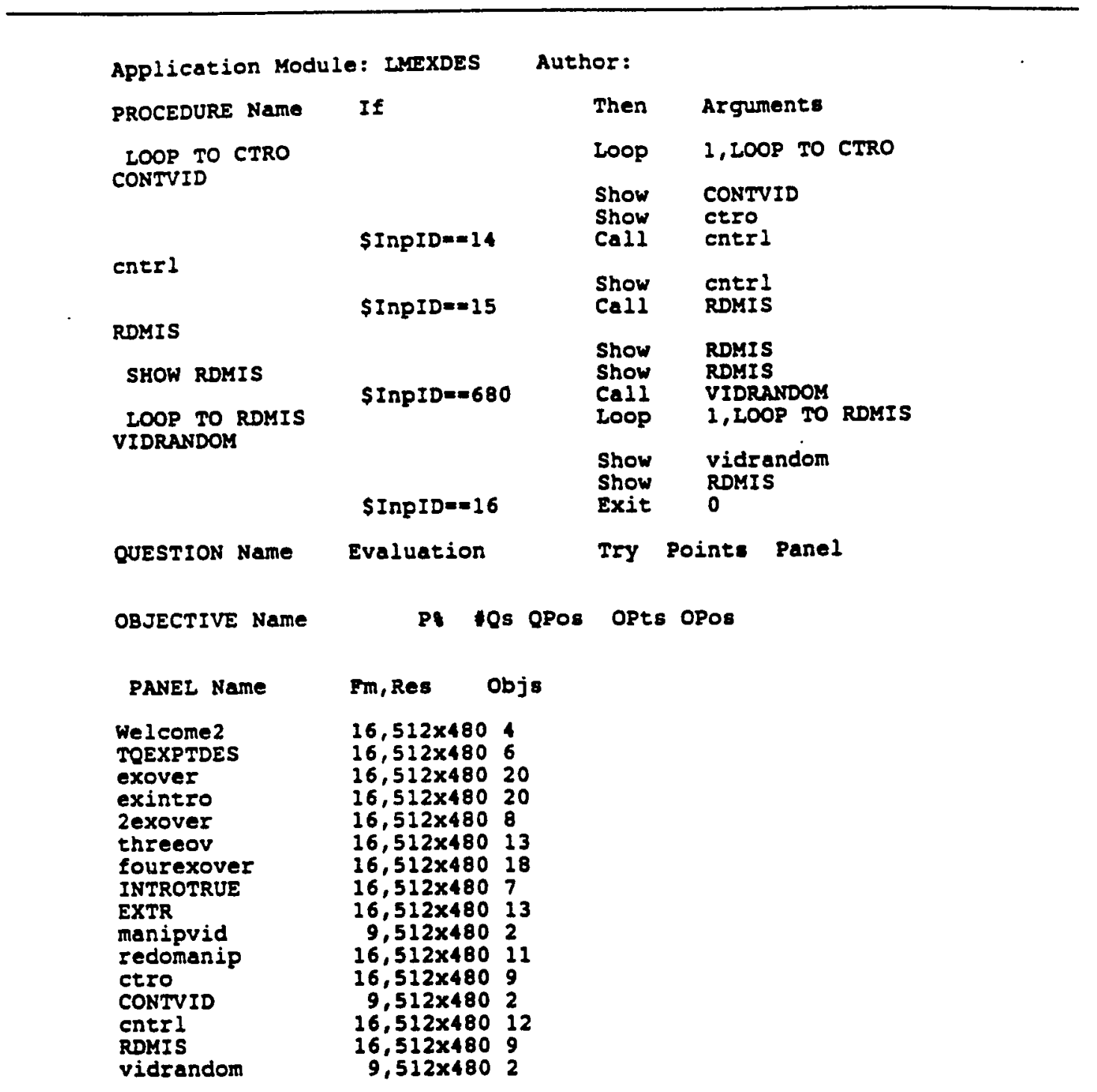


Appendix G (continued)

External files referonced by C: IAUTH2 OUAPPILMEXDES.AMY

Fonts

(NOT FOUND)

c: IV220 Vid lfont leans.109

c: IV220lvidlfont leane.112

c: lv220lvidlfont leans. 114

c: lv220lvidlfontleans. 118

c: IV220 lvidlfontleane. 124

c: lv220lvidleontlultra.109

c: lv220lvidlfontlultra.112

c: lv220lvidlfontlultra.114

c:lv220lvidlfontlultra. 118

c:lv220lvidlfontlultra. 124

c: lv220lvidlfontlultrab. 109

c: IV220lvidlfontlultrab.112

C: IV220lvidlfontlultrab.114

c: lv220lvidlfontlultrab.118

c: IV220lvidlfontlultrab. 124

Images

D: \RESMETH IMAGES \BASESCR I.C16 TOEXPTDES

D: \RESMETH IMAGES \CAmera.C16

redomanip

ctro

RDMIS

D: (RESMETH\IMAGES \dice200.C16 RDMIS

D: \RESMETH\IMAGES Iexperim.C16 threeov

fourexover

D: \RESMETH I IMAGES \FRAMN INE . CMY manipvid

CONTVID

vidrandom

D: \RESMETH IMAGES \ImCONEI \.C16

EXTR

ctro

entrl

D: IRESMETHIIMAGES \manip. C16

2exover

EXTR

redomanip

D: IRESWETH IMAGES Jmod 12 . C16

Welcome2

D: \RESMETH IMAGES \plnbkg.C16

exover

exintro

2exover

threeov

fourexover

INTROTRUE 
Appendix G (continued)

\section{EXTR}

redomanip

ctro

cntrl

RDMIS

D: \RESMETH IMAGES \quAB $i . C 16$

threeov

D: IRESMETH IMAGES Irandom2 . C16

EXTR

RDMIS

$D:$ RESMETH IMAGES SSHRIMP . C16

cnerl

D: \RESMETH IMAGES \ETUE .C16

threeov

INTROTRUE

EXIR

Ctro

cntrl

AVSS

D: \RESMETH \AUDIO\4trkbit.AVS

2exover

fourexover

D: \RESMETH \AUDIOIMINUTEM2 . AVS

TQEXPTDES

$D:$ RESMETH \AUDIOIMOD2WELL . AVS

Wel come2

$D: \backslash R E S M E T H \backslash A U D I O \backslash t 5 k 4$ sec 7 . AVS

exintro

threeov

EXTR

cotrl

D: \RESMETH \AUDIOLTRUEEXM2 . AVS INTROTRUE

D: \RESMETH\AUDIO \WHISTLE . AVS exover

D: \RESMETHIVIDEO CCONTROL . AVS

CONTVID

D: \RESMETHIVIDEO \MANIPU.AVS

manipvid

D: IRESMETHIVIDEOIRANDOM.AVS

vidrandom

Executes

axemana 
Appendix G (continued)

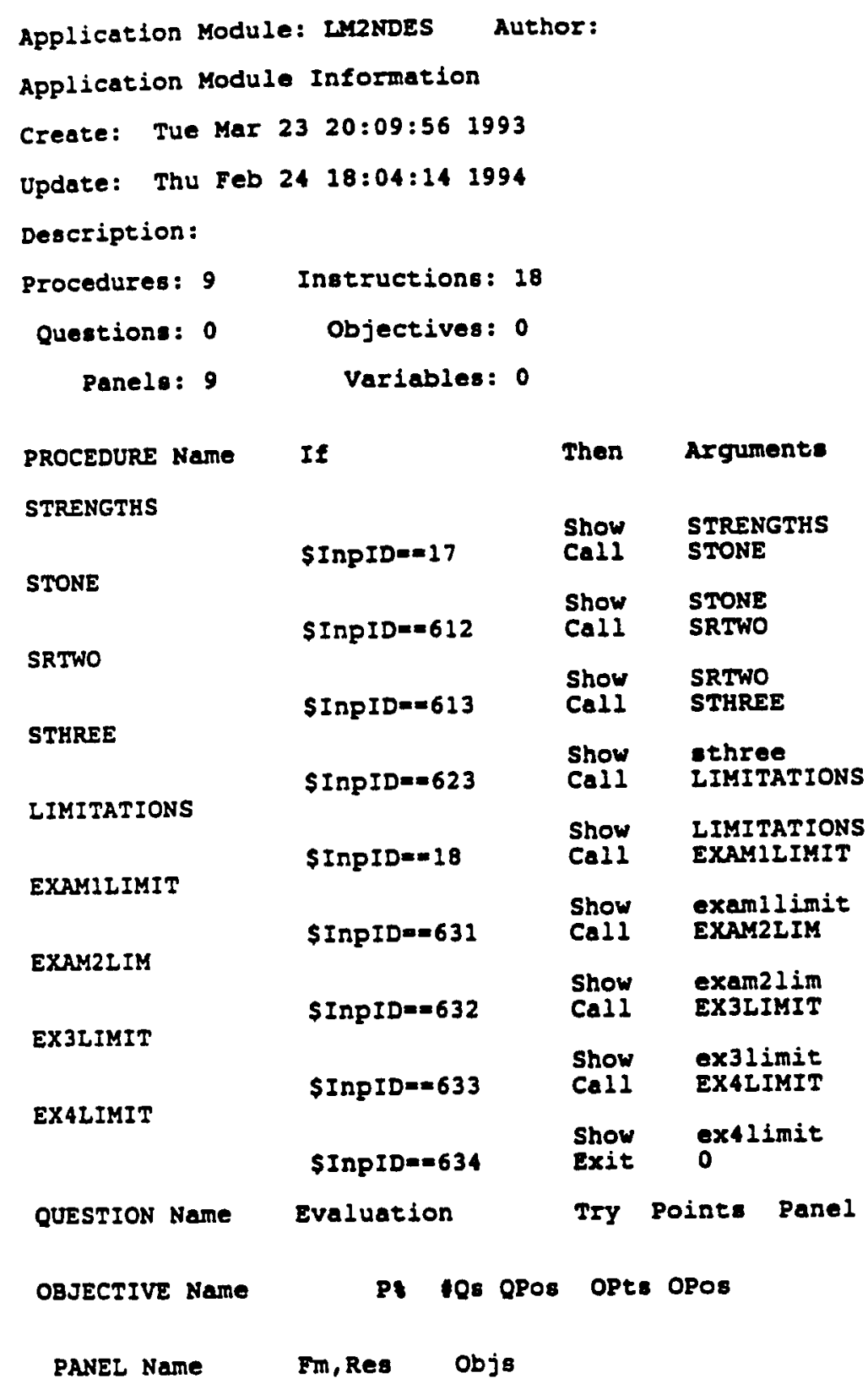


Appendix G (continued)

\begin{tabular}{|c|c|}
\hline PANEL Name & Fm, Res \\
\hline $\begin{array}{l}\text { STONE } \\
\text { SRTWO } \\
\text { sthIEe } \\
\text { LIMITATIONS } \\
\text { examllimit } \\
\text { exam2lim } \\
\text { ex3limit } \\
\text { ex4limit }\end{array}$ & $\begin{array}{ll}16,512 \times 480 & 21 \\
16,512 \times 480 & 10 \\
16,512 \times 480 & 9 \\
16,512 \times 480 & 6 \\
16,512 \times 480 & 19 \\
16,512 \times 480 & 18 \\
16,512 \times 480 & 16 \\
16,512 \times 480 & 20\end{array}$ \\
\hline
\end{tabular}


Appendix G (continued)

External files referenced by C: \AUTH20 \APPILM2NDES.ANH

Fonts

(NOT FOUND)

C: (V220lvidlfont lsans . 109

C: lv220lvidlfont lsans.112

$c: \mid v 220$ lvid font 18 ans . 114

$c: \mid V 220$ lvidlfont lsans.118

c: lv220lvidlfontlans. 124

c: lV220lvidlfontlultra.109

c: lv220lvidlfontlultra.112

c:lv220lvidlfont lultra.114

c:lv220lvidlfontlultra.118

c: IV220lvidlfontlultra. 124

c: IV220lvidlfontlultrab. 109

c: IV220lvidlfontlultrab. 112

c: IV220lvidlfontlultrab. 114

c: lv220lvidlfontlultrab. 118

c: lv220lvidlfontlultrab. 124

\section{Images}

D: \RESMETH IMAGES Iadvant. C16

STRENGTHS

STONE

SRTWO

Bthree

D: \RESMETH IMAGES \diabetes . C16

ex3limit

D: \RESMETH IMAGES\disadvan.C16

LIMITATIONS

examllimit

exam21im

ex3limit

ex4limit

D: \RESMETH\IMAGES \fatburger.C16 SRTWO

$D:$ IRESMETH IMAGES \LMCONTRL . C16 STONE

D: \RESMETH IMAGES \manip.C16 STONE

D: \RESKETH IMAGES Imoneytop.C16 ext1imit

D: \RESMETH IMAGES IPLNBRG .C16 STRENGTHS

STONE

SRTWO

ethree

LIMITATIONS

examilimit

exam2lim

ex3limit

extlimit

D: \RESMETH IMAGES Irandom 2.016 
Appendix G (continued)

STONE

D: \RESMETH IMAGES \Amoke2 .C16

exam21im

D: \RESMETH IMAGES $\backslash$ tes thypo.C16

D: IRESMETH IMAGES Itoddler. 016

examilimit

D: \RESMETH IIMAGES \tIaMa.C16

SRTWO

AVSS

D: IRESMETH \AUDIO 1 trk5sec.AVS

STONE

ex3limit

D: IRESMETH $\backslash A U D I O \backslash 4$ trkbit.AVS

SRTWO

IIMITATIONS

exam2lim

$D: \backslash R E S M E T H \backslash A U D I O \backslash t$ K 4 sec7. AVS

STRENGTHS

sthree

examllimit

extlimit

Executes

$\sim \sim n \sim \cdots$ 
Appendix G (continued)

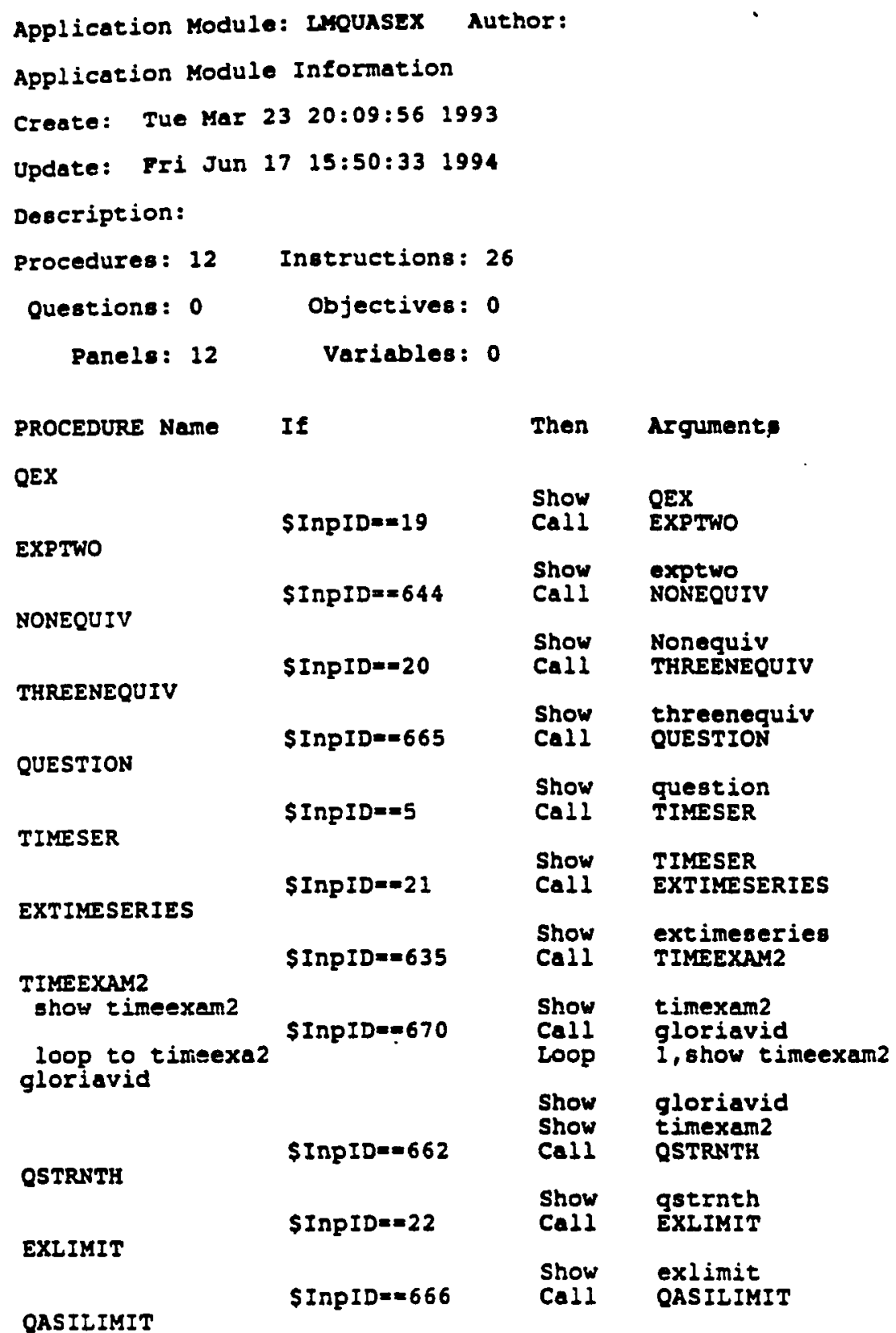


Appendix G (continued)

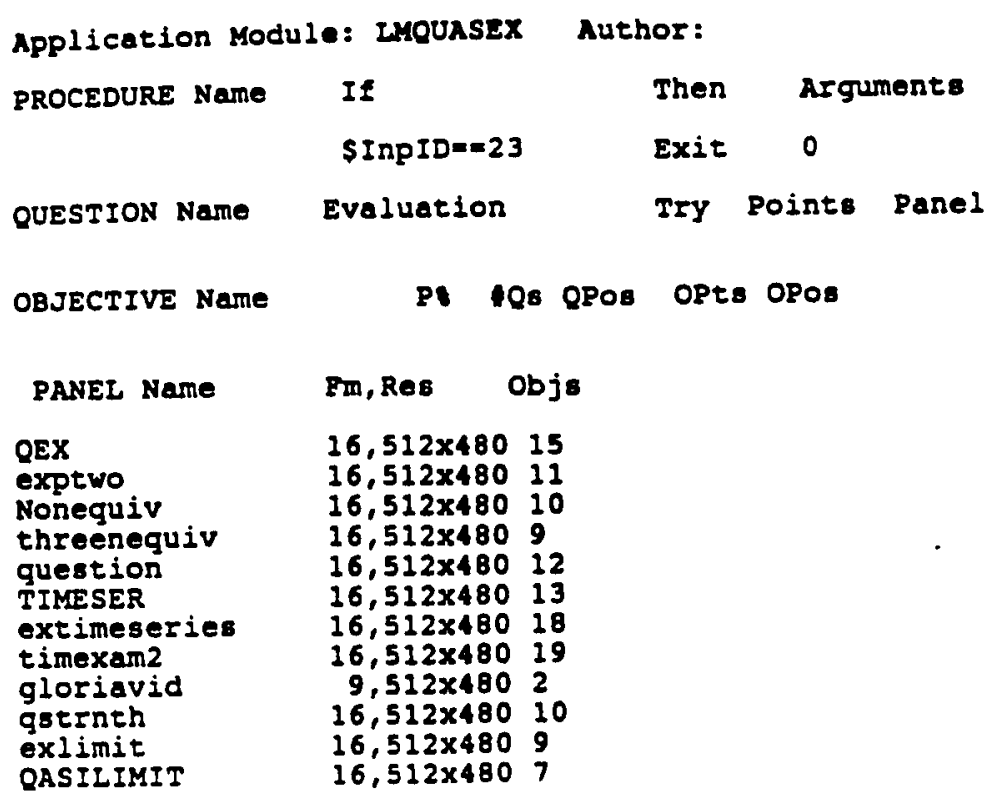


Appendix G (continued)

External files referenced by C: IAUTH20 \APP ILMQUASEX. ANY

Fonts

(NOT FOUND)

c: IV220lvidlfontlsans 109

c:lv220lvidlfontleans. 112

c: IV220lvidlfont lans.114

c:lv220lvidlfont leana.118

c:lv220lvidl font leans. 124

c: lv220lvidlfontlultra.109

c: lv220lvidlfontlultra. 112

c: IV220lvidlentlultra.114

c:lv220lvidlfontlultra.118

c: lv220lvidlfont lultra.124

c: IV220lvidlfontlultrab.109

c: lv220lvidlfontlultrab. 112

c: lv220lvidlfontlultrab.114

c: lv220lvidlfontlultrab. 118

c: IV220 Ividlfontlultrab.124

Images

D: \RESMETH IMAGES \ADVANT.C16 qotrnth

D: \RESMETH IMAGES \Camera.C16 timexam2

D: IRESHETH IMAGES\CAYPUS1.C16 gotrnth

D: |RESMETH IMAGES \DICE200.C16 question

D: \RESMETH IMAGES \disadvan.C16 exlimit QASILIMIT

D: \RESMETH IMAGES IFRAMNINE . CMY gloriavid

D: IRESMETHIIMAGES \lmcontr 1.016 QEX

D: \RESMETH IMAGES \madonna . C16 getrnth

D: IRESMETH IMAGES \Manip.C16 QEX

D: \RESMETH IMAGES \mar Chbd.C16 Nonequiv

D: |RESIETH IMAGES Inoneqi.C16 exptwo Nonequiv

D: (RESYETH IMAGES \PLNBRG.C16 QEX

exptwo threenequiv

question TIMESER extimeseries timexam2 
Appendix G (continued)

\section{getrneh}

exlimit

QASIIIMIT

$D:$ RRESMETH IMAGES \random2.Cl6

QEX

question

$D$ : IRESMETH IMAGES \SUBSAND. C16

extimeseries

D: \RESMETH IIMAGES ITIMES . C16

TIMESER

D: \RESMETH IMAGES \times 2.C16

exptwo

TIMESER

$D:$ IRESMETH IMAGES IWOCONE.C16

QASIIIMIT

AvsS

D: \RESMETH\AUDIO 12 toK. AVS

question

extimeseries

OASTIIMIT

D: IRESMETH \AUDIO $24 t r$ long. AVS

Nonequiv

TIMESER

exlimit

D: IRESMETH \AUDIO IFIELDDRN . AVS gatrnth

D: IRESMETH \AUDIO\POPQUIZ . AVS

threenequiv

$D: \backslash R E S M E T H \backslash A U D I O \backslash Q U A S I M 2$. AVS

QEX

$D:$ RRESMETH \AUDIOITRK4SEC7 . AVS

exptwo

D: IRESMETHIVIDEOIQUASI. AVS gloriavid

Executes 
Appendix G (continued)

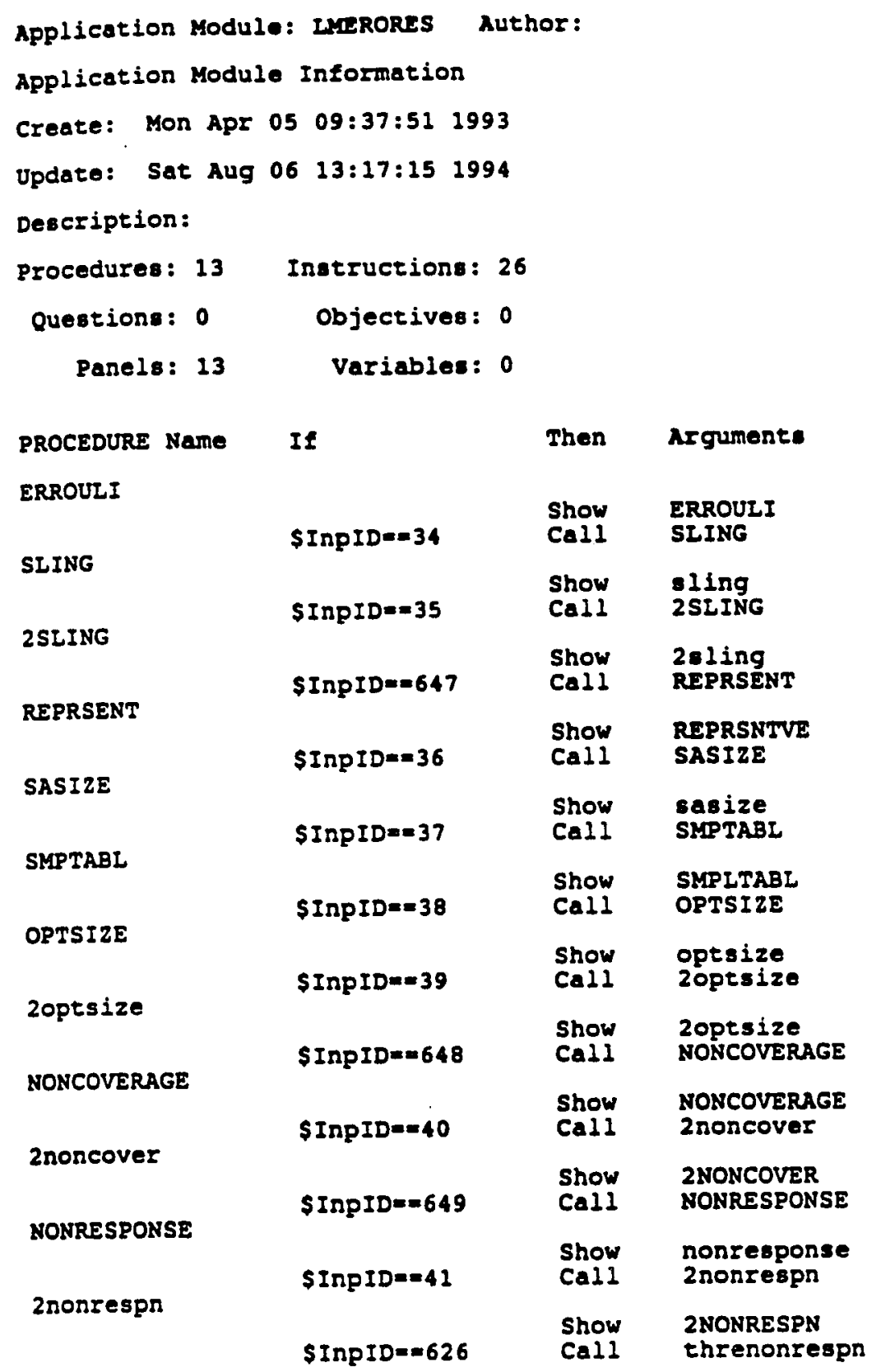


Appendix G (continued)

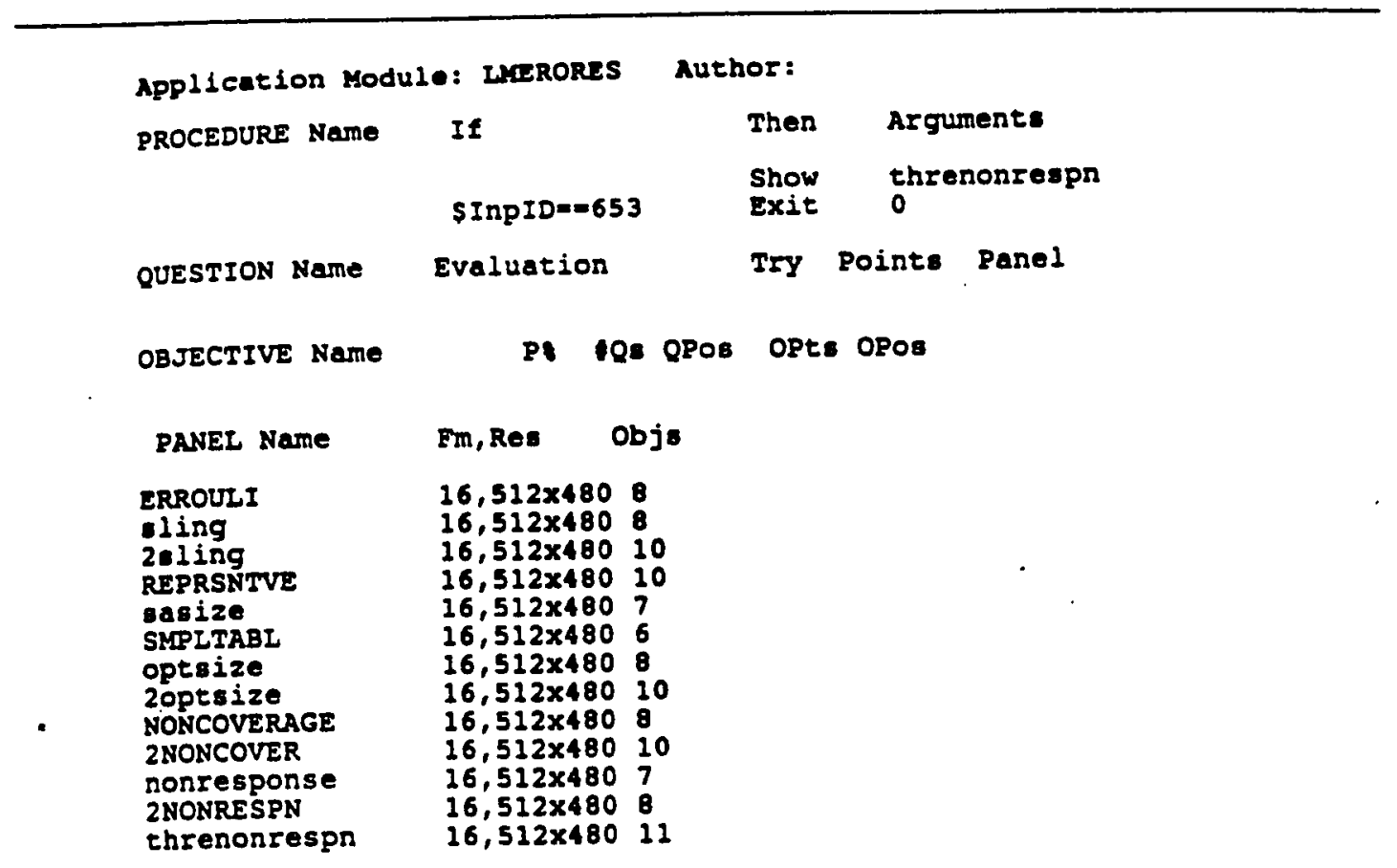


Appendix G (continued)

External files referenced by C: IAUTH2O IAPPIIM2NDES. ANA

\section{Fonts}

(NOT FOUND)

$c:|v 220 \backslash v i d|$ font leans.109

c: IV220lvidlfontloans.112

c:lv220lvidlfont leans. 114

$c$ : IV220lvidlfont leans.118

C: IV220lvidlfontlsans .124

c: lv220lvidlfontlultra.109

c:lv220lvidlfontlultra.112

c: lv220lvidlfontlultra.114

c:lv220lvidlfontlultra.118

c: lv220lvidlfontlultra. 124

c: Iv220lvidlfontlultrab.109

c: lv220lvidlfontlultrab. 112

c: lV220lvidlfontlultrab. 114

c: |v220lvidlfontlultrab. 118

c: IV220lvidlfontluI erab.124

Inages

D: IRESMETH IMAGES \advant . C16

STRENGTHS

STONE

SRTWO

sthree

D: IRESMETH IMAGES \diabetes.C16

ex31imit

D: \RESMETH IMAGES\disadvan.C16

LIMITATIONS

examllimit

exam2lim

ex3limit

ex4limit

D: \RESMETH\IMAGES \fatburger.C16 SRTWO

D: \RESMETH IIMAGES IIMCONTRL. CI6 STONE

D: \RESMETH IMAGES\manip.C16 STONE

D: \RESLETH \IMAGES \MONEYtop.C16 extlimit

D: \RESMETH IMAGES \PLNERG.C16 STRENGTHS

STONE

SRTWO

sthree

IIMITATIONS

examl limit

exam2lim

ex3limit

ex4limit

D: IRESMETH\IMAGES \random $2 . C 16$ 
Appendix G (continued)

STONE

D: \RESMETH IMAGES I Imoke2 . C16

exam2iim

D: \RESMETH \IMAGES TEs thypo.C16

sthree

D: \RESMETH IMAGES \toddler . C16

examilimit

D: \RESMETH IMAGES \ETama.C16

SRTWO

AvsS

D: \RESMETH \AUDIO 1 trk5sec. AVS

STONE

ex3limit

D: IRISMETH \AUDIOI 4 tkbit. AVS

SRTWO

LIMITATIONS

exan21im

D: \RESMETH \AUDIO $t$ tK 4 sec7 . AVS

STRENGTHS

sthree

examlinit

extlimit

Executes 
Appendix G (continued)

External files raferenced by C: IAUTH20 IAPPIIMERORES.MAM

Fonts

(NOT FOUND)

c: lv220lvidlfontlsans.109

c: Vv220lvidlfoneleans .112

c: IV220lvidlfont leans.114

c: lV220lvidlfont leans. 118

$c$ : lv220lvidlent leane . 124

c: lv220lvidlfontlultra.109

c: lv220lvidlfontlultra.112

c: IV220lvidlontlultra.114

c:lv220lvidlfontlultra.118

c: lv220lvidlfontlultra.124

c: IV220lvidlfontlultrab. 109

c: lv220lvidlfontlultrab. 112

c: lv220lvidlfont luitrab.114

c: IV220lvidlfontlultrab. 118

C: lv220lvidlfontlultrab.124

Images

D: IRESMETH IMAGES I lgsample.C16 Basize

D: IRESMETH IMAGES \NONCOVER . C16 NONCOVERAGE

2NONCOVER

D: \RESMETH IIKAGES INONRESPN . C16

nonresponse

2NONRESPN

D: \RESMETH IMAGES \OOpS . C16

ERROULI

D: \RESMETH IMAGES loptsize.C16

optsize

D: \RESMETH IMAGES \PLNBRG.C16

ERROULI

sling

28ling

REPRSNTVE

sasize

SMPLTABL

optaize

2optsize

NONCOVERAGE

2NONCOVER

nonresponse

2HONRESPK

threnonrespn

$D$ : \RESHETH IMAGES \Samperr . C16

eling

REPRSNTVE

D: \RESMETH \IMAGES \STUDUS . CI 6

281 ing

$D: \backslash R E S M E T H \backslash I M A G E S I S T U S T U D . C 16$ 
Appendix G (continued)

2oling

D: \RESMETH IMAGES t tablel.C16 SMPLTABL

D: \RESMETH IMAGES \weighin.C16 threnonrespn

AvSS

D: IRESMETH TAUDIO 14 TGOOD. AVS zoptsize

D: \RESMETH \AUDIO I14TRLONG . AVS SMPLTABI

D: IRESMETH \AUDIO 5 TRREXC. AVS threnonrespn

D: IRESMETH \AUDIO \STROEED. AVS 2NONRESPN

D: IRESMETH IAUDIO \ERCOVER . AVS NONCOVERAGE

D: IRESHETH IAUDIO YERESPON. AVS nonresponse

D: IRESMETH \AUDIOIERLARSAM. AVS sasize

D: IRESMETH \AUDIOIERREP . AVS optsize

D: IRESMETH \AUDIOIERSAM.AVS 2 oling

D: IRESMETH\AUDIO\ERSTART . AVS ERROULI

D: \RESMETH \AUDIO TTRI 4MED. AVS 2NONCOVER

$D: \backslash R E S M E T H \backslash A U D I O \backslash T R R 1 M E D$. AVS sling

D: IRESMETH \AUDIO TRRK4SEC7 . AVS REPRSNTVE

Executes

Exand an 
Appendix G (continued)

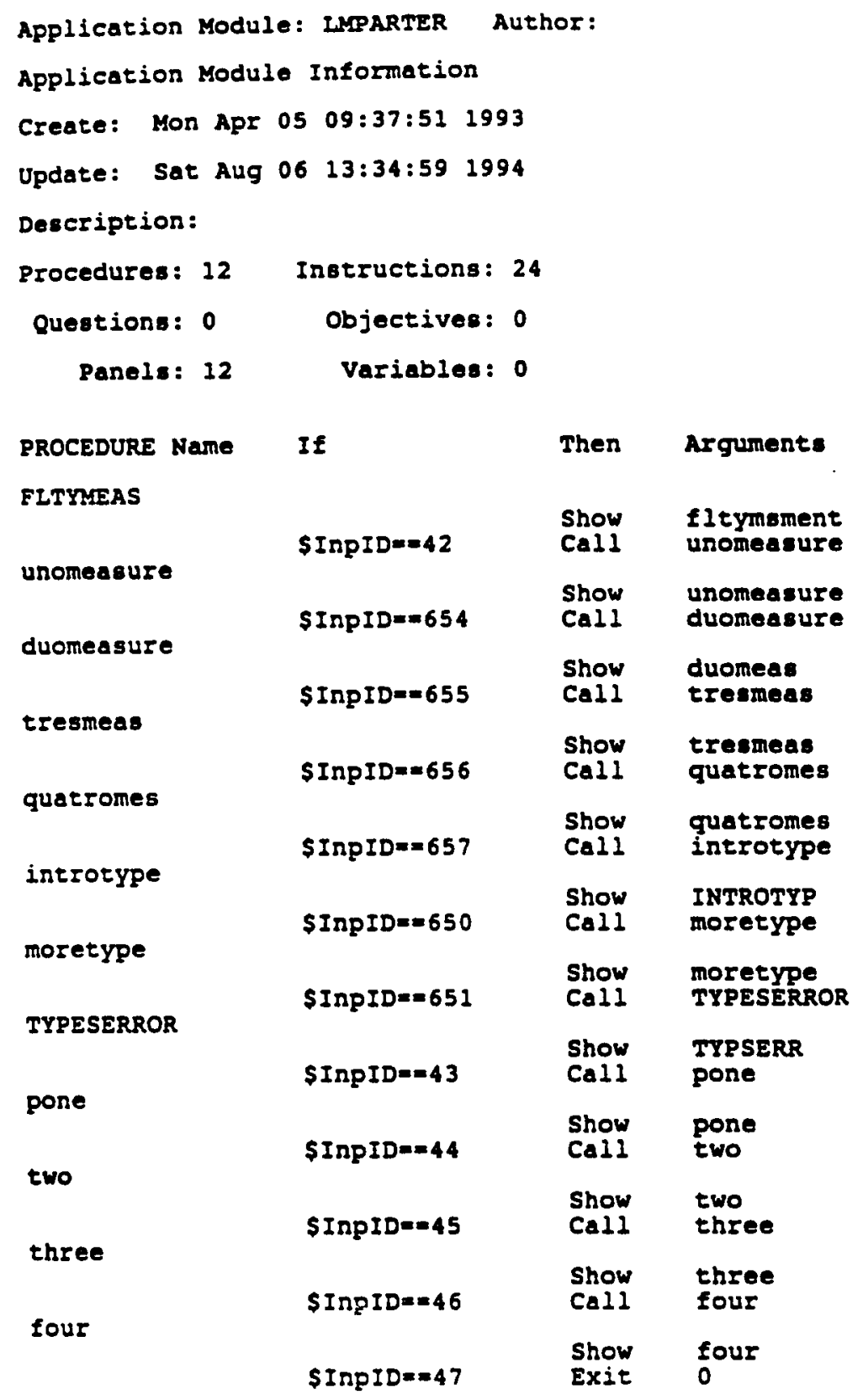


Appendix G (continued)

\begin{tabular}{|c|c|c|c|c|c|}
\hline QUESTION Name & Evaluation & & T5Y & Pointe & Panel \\
\hline OBJECTIVE Name & $\mathbf{P}$ & Q8B QPOE & OPts & 8 OPOB & \\
\hline PANEL Name & Fm, Res & Objs & & & \\
\hline $\begin{array}{l}\text { fltymsment } \\
\text { unomeasure } \\
\text { duomeas } \\
\text { tresmeas } \\
\text { quatromes } \\
\text { INTROTYP } \\
\text { moretype } \\
\text { TYPSERR } \\
\text { pone } \\
\text { two } \\
\text { three } \\
\text { four }\end{array}$ & $\begin{array}{l}16,512 \times 480 \\
16,512 \times 480 \\
16,512 \times 480 \\
16,512 \times 480 \\
16,512 \times 480 \\
16,512 \times 480 \\
16,512 \times 480 \\
16,512 \times 480 \\
16,512 \times 480 \\
16,512 \times 480 \\
16,512 \times 480 \\
16,512 \times 480\end{array}$ & $\begin{array}{l}7 \\
11 \\
14 \\
11 \\
11 \\
11 \\
9 \\
0 \\
0 \\
0 \\
0 \\
0 \\
0 \\
0 \\
0 \\
0 \\
0 \\
0 \\
0\end{array}$ & & & - \\
\hline
\end{tabular}


Appendix G (continued)

External files referenced by C: IAUTH2 OLAPPILMPARTER. AMM

\section{Fonts}

(NOT FOUND)

C: IV220lvidlfont leans. 109

c: lv220lvidlfont leane. 112

C: iv220lvidlfont leans. 114

c:lv220lvidl font leane. 118

c: IV220lvidlfont leans.124

c:lv220lvidlentlultra.109

c: lv220lvidlfontlultra.112

c: lv220lvidlfontlultra.114

c: iv220lvidlfontlultra.118

c: lv220lvidlfontlultra.124

c: lv220lvidlfontlultrab. 109

c: IV220lvidlfontlultrab. 112

c: lv220lvidlfont lultrab.114

c: IV220lvidlfontlultrab. 118

C: IV220lvidlfontlultrab.124

Images

D: IRESMETH IIMAGES $\backslash 2001$ be .C16 unomeasure

D: IRESMETH IMAGES Ibadtool.C16 duomeas

D: \RESMETH IMAGES \goodtool .C16 duomean

D: \RESMETH।IMAGES \helperga.C16 tresmeas

$D: \mid R E S M E T H \backslash I M A G E S \backslash M E A s U R 2 . C 16$ fltymsment unomeasure duomees tresmeas quatromes

D: IRESMETHIIMAGES IPLNBRG . C16 Eltymment unomeasure duomeas tresmeas quatromes INTROTYP moretype TYPSERR

pone

two

three

four

D: IRESMETH IMAGES IIObin.C16 quatromes

D: IRESMETH IMAGES Itype . C16 INTROTYP TYPSERR 
Appendix G (continued)

\author{
D: \RESMETH IMAGES TYYP2 . C16 \\ INTROTYP \\ D: \RESMETH \AUDIO IFIETYPES . AVS \\ INTROTYP \\ $D: \backslash R E S M E T H \backslash A U D I O \backslash P I A N O U P$. AVS \\ two \\ D: \RESMETH \AUDIOITRR62 . AVS \\ four \\ Executes
}


Appendix H

Module III Program Details and External Files

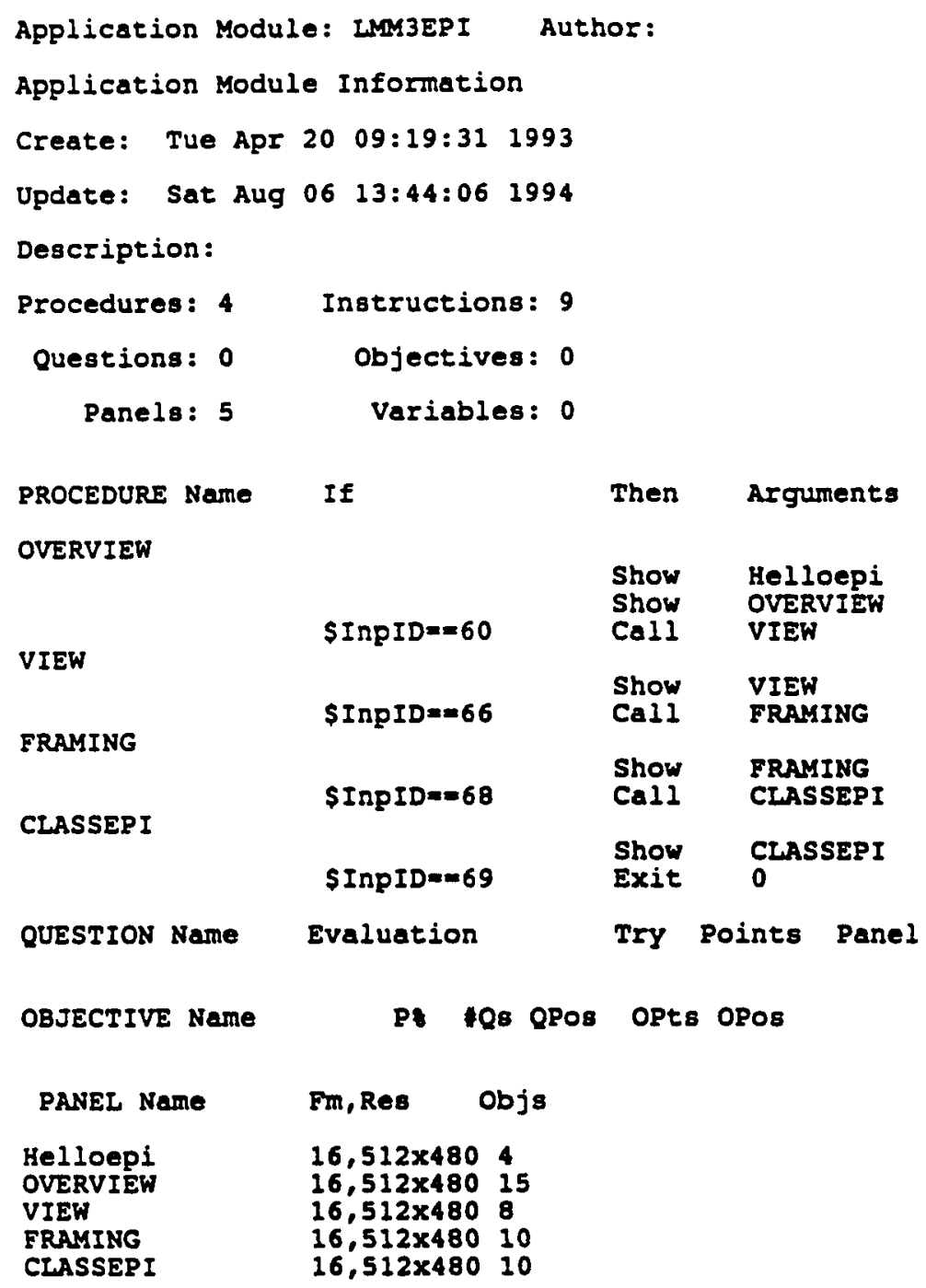


Appendix H (continued)

External files roferenced by C: \AUTH20 \APP\IMM3EPI. AAM

Fonts

(NOT FOUND)

C: IV220 Vvid lfontlsans. 109

c: lv220lvidlfont lsans.112

C: IV220lvidlfont lsang. 114

c: IV220lvidlfontlsans. 118

c: lv220lvidlfontlsans. 124

c: lv220lvidlfontlultra.109

c: IV220 Vvidlfontlultra.112

c: IV220lvidlfontlultra.114

C: IV220lvidlfontlultra.118

C: IV220lvidfontluitra.124

C: IV220lvidlfontlultrab.109

c: IV220lvidlfont lultrab.112

c: lv220lvidlfont lultrab.114

C: IV220lvidlfontlultrab. 118

c: IV220lvidlfontlultrab.124

Images

D: \RESMETH IMAGES 1 sister. $C 16$ FRAMING

D: \RESMETH IMAGES $\backslash 2$ sisters.C16 FRAMING

D: \RESMETH \IMAGES \ANEPIDEM.C16 CLASSEPI

D: \RESMETH IMAGES \COUntIY.C16 OVERVIEW

D: \RESMETH IMAGES DESEPID.C16 CLASSEP I

D: \RESMETH IMAGES \DOCHEART.C16 VIEW

D: \RESMETH IMAGES $\backslash$ inwhom.C16 OVERVIEW

D: \RESMETH IMAGES \MOd13.C16 Helloepi

D: \RESMETH IMAGES \PINBKG.C16 OVERVIEW

VIEW

FRAMING

CLASSEPI

D: IRESMETH IMAGES \where.C16 OVERVIEW

AVSS

D: \RESMETH \AUDIO IEP3DEA . AVS CLASSEPI

$D:$ IRESMETH \AUDIO IEP3DEF . AVS OVERVIEW

D: \RESMETH \AUDIO $E P 3 I N T R O$. AVS helloepi 
Appendix $H$ (continued)

D: IRESMETH AAUDIO YPIANOUP . AVS

FRAMING

D: IRESMETH \AUDIOITRK62 . AVS

VIEW

Executes

$\sim \sim \sim \sim \sim \sim$ 
Appendix H (continued)

\begin{tabular}{|c|c|c|c|}
\hline \multirow{2}{*}{\multicolumn{4}{|c|}{$\begin{array}{l}\text { Application Module: IMDEPI(l Aut } \\
\text { Application Module Information }\end{array}$}} \\
\hline & & & \\
\hline Create: Tue Apr & $20 \quad 12: 20: 40 \quad 1993$ & & \\
\hline Update: Sat Aug & $06 \quad 13: 58: 11 \quad 1994$ & & \\
\hline \multicolumn{4}{|l|}{ Description: } \\
\hline Procedures: 15 & Instructions: 30 & & \\
\hline Questions: 0 & Objectivea: 0 & & \\
\hline Panels: 15 & Variables: 0 & & \\
\hline PROCEDURE Name & If & Then & Arguments \\
\hline \multicolumn{4}{|l|}{ DSCRIP } \\
\hline PREVINC & SInPID $=70$ & $\begin{array}{l}\text { Show } \\
\text { Call }\end{array}$ & $\begin{array}{l}\text { dscIip } \\
\text { PREVINC }\end{array}$ \\
\hline PRERATE & SInpID= $=71$ & $\begin{array}{l}\text { Show } \\
\text { call }\end{array}$ & $\begin{array}{l}\text { PREVINC } \\
\text { PRERATE }\end{array}$ \\
\hline INRATE & SInPID $==72$ & $\begin{array}{l}\text { Show } \\
\text { call }\end{array}$ & $\begin{array}{l}\text { PRERATE } \\
\text { INRATE }\end{array}$ \\
\hline aninsid & SInpID $=75$ & $\begin{array}{l}\text { Show } \\
\text { Call }\end{array}$ & $\begin{array}{l}\text { INRATE } \\
\text { aningid }\end{array}$ \\
\hline TYPEDEPI & SIתPID $=6667$ & $\begin{array}{l}\text { Show } \\
\text { Call }\end{array}$ & $\begin{array}{l}\text { aningid } \\
\text { TYPEDEPI }\end{array}$ \\
\hline ECOLOGICAL & $\$$ InpID $==76$ & $\begin{array}{l}\text { Show } \\
\text { Call }\end{array}$ & $\begin{array}{l}\text { TYPEDEPI } \\
\text { ECOLOGICAL }\end{array}$ \\
\hline DADVECO & SInPID $=77$ & $\begin{array}{l}\text { Show } \\
\text { Call }\end{array}$ & $\begin{array}{l}\text { ECOLOGICAL } \\
\text { DADVECO }\end{array}$ \\
\hline ECOEXAMP & \$InpID= $=78$ & $\begin{array}{l}\text { Show } \\
\text { Call }\end{array}$ & $\begin{array}{l}\text { DADVECO } \\
\text { ECOEXAMP }\end{array}$ \\
\hline CASEREP & SInPID $=79$ & $\begin{array}{l}\text { Show } \\
\text { call }\end{array}$ & $\begin{array}{l}\text { ECEXAMP } \\
\text { CASEREP }\end{array}$ \\
\hline ADCASE & SInpID $=80$ & $\begin{array}{l}\text { Show } \\
\text { call }\end{array}$ & $\begin{array}{l}\text { CASEREP } \\
\text { ADCASE }\end{array}$ \\
\hline EXAMCASE & \$InPID $==81$ & $\begin{array}{l}\text { Show } \\
\text { Call }\end{array}$ & $\begin{array}{l}\text { ADCASE } \\
\text { EXAMCASE }\end{array}$ \\
\hline & \$InPID $=882$ & $\begin{array}{l}\text { Show } \\
\text { Call }\end{array}$ & $\begin{array}{l}\text { EXAMCASE } \\
\text { CROSSSEC }\end{array}$ \\
\hline
\end{tabular}


Appendix H (continued)

\begin{tabular}{|c|c|c|c|c|c|}
\hline \multicolumn{6}{|c|}{ Application Module: LMDEPI(l Author: } \\
\hline PROCEDURE Name & \multicolumn{2}{|c|}{ If } & Then & \multicolumn{2}{|c|}{ Arguments } \\
\hline ADCROSS & \multicolumn{2}{|l|}{ SInpID $=84$} & $\begin{array}{l}\text { Show } \\
\text { call }\end{array}$ & \multicolumn{2}{|c|}{$\begin{array}{l}\text { CROSSSEC } \\
\text { ADCROSS }\end{array}$} \\
\hline EXAMCROSS & \multicolumn{2}{|l|}{$\$ \operatorname{InpID}=8=85$} & $\begin{array}{l}\text { Show } \\
\text { Call }\end{array}$ & \multicolumn{2}{|c|}{$\begin{array}{l}\text { ADCROSS } \\
\text { EXAMCROSS }\end{array}$} \\
\hline & \multicolumn{2}{|l|}{ SInPID $=86$} & $\begin{array}{l}\text { Show } \\
\text { Exit }\end{array}$ & \multicolumn{2}{|c|}{$\begin{array}{l}\text { ExCROSS } \\
0\end{array}$} \\
\hline QUESTION Name & \multicolumn{2}{|l|}{ Evaluation } & Try & Points & Panel \\
\hline OBJECTIVE Name & P8 $\quad Q_{8}$ & QPOS & OPts & OPOS & \\
\hline PANEL Name & Fm, Res & & & & \\
\hline $\begin{array}{l}\text { dSCrIP } \\
\text { PREVINC } \\
\text { PRERATE } \\
\text { INRATE } \\
\text { ANIISID } \\
\text { TYPEDEPI } \\
\text { ECOLOGICAL } \\
\text { DADVECO } \\
\text { ECEXAMP } \\
\text { CASEREP } \\
\text { ADCASE } \\
\text { EXAMCASE } \\
\text { CROSSSEC } \\
\text { ADCROSS } \\
\text { EXCROSS }\end{array}$ & $\begin{array}{ll}16,512 \times 480 & 9 \\
16,512 \times 480 & 1 \\
16,512 \times 480 & 1 \\
16,512 \times 480 & 1 \\
16,512 \times 480 & 1 \\
16,512 \times 480 & 1 \\
16,512 \times 480 & 1 \\
16,512 \times 480 & 9 \\
16,512 \times 480 & 1 \\
16,512 \times 480 & 1 \\
16,512 \times 480 & 1 \\
16,512 \times 480 & 9 \\
16,512 \times 480 & 8 \\
16,512 \times 480 & 9 \\
16,512 \times 480 & 9\end{array}$ & $\begin{array}{l}9 \\
11 \\
12 \\
11 \\
10 \\
12 \\
15 \\
5 \\
10 \\
1 \\
10 \\
3 \\
3\end{array}$ & & $\cdot$ & \\
\hline
\end{tabular}


Appendix H (continued)

External fileg referenced by C: \AUTH20 \APP\IMDEPI(1.AAM

Fonts

(NOT FOUND)

C: IV220lvidlfont lsans.109

c: IV220 IVid font lsans. 112

C: IV220lvid font lsans. 114

C: \V220 Vid font lsans. 118

C: IV220lvidlfont lsans. 124

C: IV220lvidlfontlultra.109

c: IV220lvidlfontlultra.112

C: IV220lvidlfontlultra.114

C: IV220lvidlfontlultra.118

c:lv220lvidlfontlultra.124

c: IV220lvid fontlultrab. 109

c: IV220lvid fontlultrab.112

C: IV220lvidlfontlultrab. 114

C: IV220lvidlfontlultrab. 118

c: IV220lvidlfontlultrab.124

Images

D: \RESMETH IMAGES \ADVANT . C16

DADVECO

ADCASE

ADCROSS

D: \RESMETH\IMAGES \biobaby.C16

EXAMCASE

D: \RESMETH IIMAGES \Calendar . C16

ECOLOGICAL

D: \RESMETH IMAGES \CAMPUS3 . C16

EXCROSS

D: IRESMETH IMAGES ICAse $1 . C 16$

TYPEDEPI

CASEREP

$D:$ IRESMETH IMAGES \Case2.C16

CASEREP

D: \RESMETH IMAGES \COUNEYY.C16

ECOLOGICAL

D: \RESMETH IMAGES \CROSSSEC.C16

TYPEDEPI

CROSSSEC

D: \RESMETH IIMAGES \DESEPID.C16

decrip

PREVINC

PRERATE

INRATE

aninsid

D: \RESMETH IMAGES\disadvan. C16

DADVECO

ADCASE

ADCROSS

D: \RESMETH IIMAGES \ECOLOGY .C16 TYPEDEPI 
Appendix H (continued)

STONE

D: \RESMETH IMAGES \Amoke2 . C16

exam2 2 im

D: \RESMETH \IMAGES \tes thYpo.C16

Bthree

D: IRESMETH IMAGES $\backslash$ toddler. C1 6

examilimit

D: \RESMETH \IMAGES Itrama .C16

SRTWO

AVSS

D: \RESMETH \AUDIO\1trk58EC.AVS STONE

ex3limit

D: IRESMETH IAUDIO\Atrkbit. AVS

SRTWO

LIMITATIONS

exam2lim

D: \RESMETH \AUDIO \trk4 Bec7 . AVS

STRENGTHS

sthree

examilimit

extlimit

Executes 
Appendix H (continued)

ECOLOGICAL

D: \RESMETH IMAGES $\backslash$ econstat . C16

ECOLOGICAI

D: \RESMETH IMAGES\icincid.C16

PREVINC

INRATE

aninsid

D: \RESMETH IMAGES \icprev.CI6

PREVINC

D: \RESMETH IMAGES \insid.C16

aninsid

$D: \backslash R E S M E T H \backslash I M A G E S$ \Observe. C1 6 dscrip

D: \RESMETH IMAGES \over 65.016 ECEXAMP

D: \RESMETH IMAGES \PLNBRG.C16

dscrip

PREVINC

PRERATE

INRATE

aninsid

TYPEDEPI

ECOLOGICAL

DADVECO

ECEXAMP

CASEREP

ADCASE

EXAMCASE

CROSSSEC

ADCROSS

EXCROSS

D: \RESMETH IMAGES \preval.C16 PRERATE

AVSS

D: \RESMETH \AUDIOII 4TGOOD.AVS INRATE

ADCROSS

D: \RESMETH \AUDIO\DEPCASE . AVS EXAMCASE

D: \RESMETH \AUDIOIDEPCROSS . AVS EXCROSS

D: IRESMETH \AUDIO\DEPECO. AVS ECEXAMP

D: \RESMETH \AUDIO DEPINCL . AVS TTPEDEPI

D: IRESMETH \AUDIOIDEPINTRO. AVS decrip

D: \RESMETH \AUDIOIDRUMUP . AVS CROSSSEC

D: IRESMETH IAUDIOIPIANOFUL.AVS CASEREP

D: \RESMETH \AUDIOIR IANOUP . AVS DADVECO 
Appendix H (continued)

D: \RESMETH\AUDIO\SAXFUL. AVS

ADCASE

D: \RESMETH \AUDIO\TRR3 . AVS

PREVINC

D: \RESMETH \AUDIO\TRR6 . AVS

aninsid

D: \RESMETH \AUDIO\TRR62 . AVS

ECOLOGICAI

D: IRESMETH \AUDIOITRRO . AVS

PRERATE

Executes

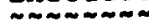


Appendix H (continued)

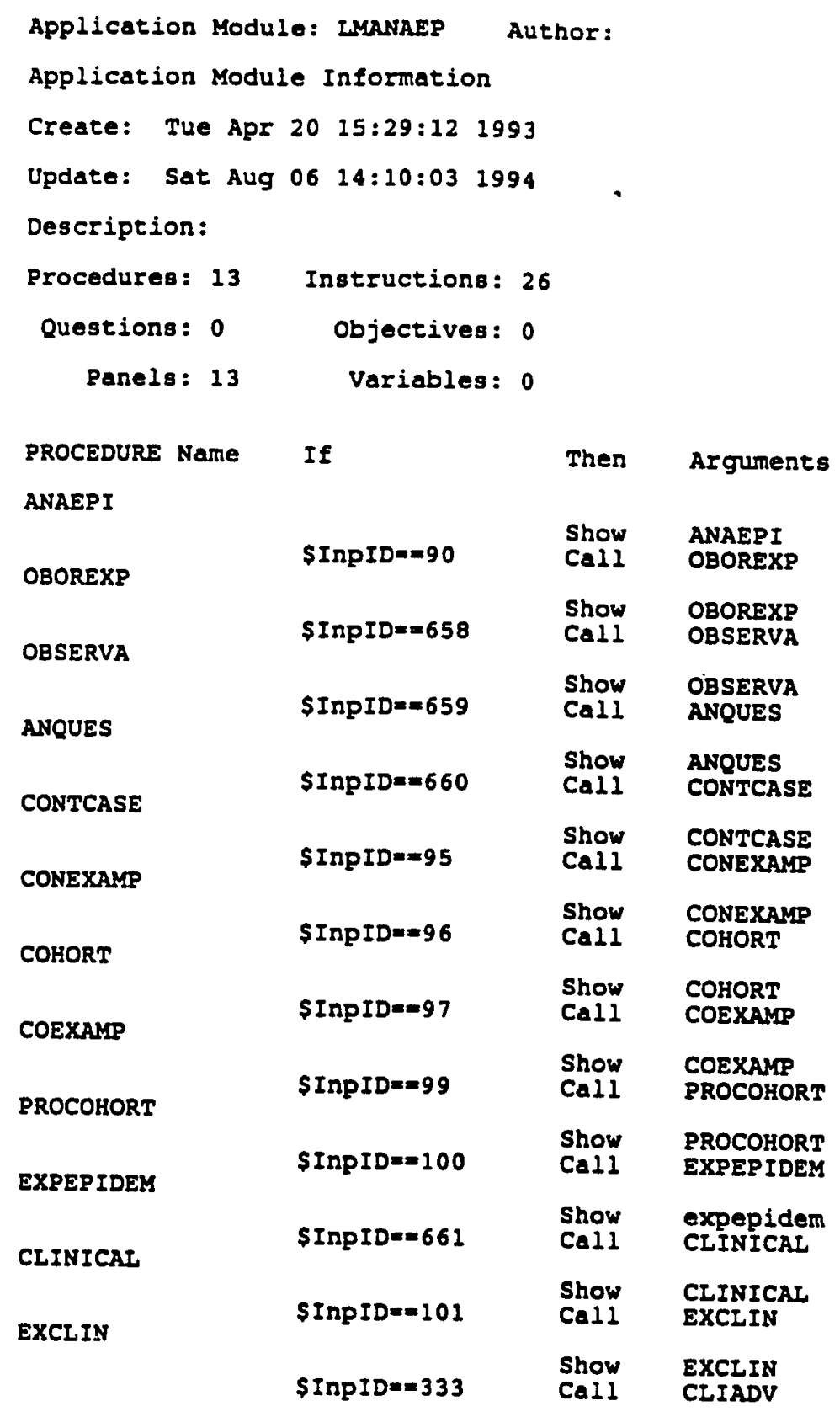


Appendix H (continued)

\begin{tabular}{|c|c|c|c|c|c|}
\hline \multicolumn{2}{|c|}{ Application Module: LMANAEP } & \multicolumn{4}{|c|}{ Author: } \\
\hline \multirow[t]{2}{*}{ PROCEDURE Name } & If & & Then & \multicolumn{2}{|c|}{ Arguments } \\
\hline & \multicolumn{2}{|l|}{ SInpID $=334$} & $\begin{array}{l}\text { Show } \\
\text { Exit }\end{array}$ & \multicolumn{2}{|c|}{$\begin{array}{l}\text { CLIADV } \\
0\end{array}$} \\
\hline QUESTION Name & \multicolumn{2}{|l|}{ Evaluation } & Try & Points & Panel \\
\hline OBJECTIVE Name & Pq & QPOB & OPEs & S OPOB & \\
\hline PANEI Name & Fm, Res & & & & \\
\hline $\begin{array}{l}\text { ANAEPI } \\
\text { OBOREXP } \\
\text { OBSERVA } \\
\text { ANQUES } \\
\text { CONTCASE } \\
\text { CONEXAMP' } \\
\text { COHORT } \\
\text { COEXAMP } \\
\text { PROCOHORT } \\
\text { EXPEPIdEM } \\
\text { CLINICAL } \\
\text { EXCIIN } \\
\text { CLIADV }\end{array}$ & $\begin{array}{l}16,512 \times 480 \\
16,512 \times 480 \\
16,512 \times 480 \\
16,512 \times 480 \\
16,512 \times 480 \\
16,512 \times 480 \\
16,512 \times 480 \\
16,512 \times 480 \\
16,512 \times 480 \\
16,512 \times 480 \\
16,512 \times 480 \\
16,512 \times 480 \\
16,512 \times 480\end{array}$ & $\begin{array}{l}0 \\
0 \\
2 \\
3 \\
1 \\
2 \\
2 \\
1\end{array}$ & & & \\
\hline
\end{tabular}


Appendix H (continued)

External files referenced by C: \AUTH20 \APP ILMANAEP. AAM

Fonts

(NOT FOUND)

C: IV220lvidlfont lsans. 109

c: lv220lvidlfont lsans.112

c: IV220lvid font lsans.114

C: |V220|vidlfont lsans.118

C: lv220lvidlfontlsans. 124

C: lv220lvidlfontlultra.109

c: IV220lvidlfont lultra. 112

C: lv220lvidlfont lultra.114

c:lv220lvidlfontlultra.118

c:lv220lvidlfontlultra.124

c: IV220lvidlfontlultrab.109

c: IV220lvidlfontlultrab. 112

c: lv220lvidlfonelultrab. 114

C: IV220lvidlfont lultrab. 118

c: IV220lvidlfontlultrab.124

\section{Images}

D: IRESMETH\IMAGES $\backslash 2 \mathrm{drugs} \mathrm{.C16}$ CLINICAL

$D: \backslash$ RESMETH IMAGES $\backslash 2$ tablets . C16 EXCLIN

D: \RESMETH\IMAGES \advant.C16 CLIADV

D: \RESMETH IMAGES \analepi.C16 ANAEP I OBSERVA

D: \RESMETH\IMAGES \anepidem. C16 ANAEPI

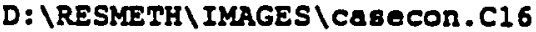
OBSERVA CONTCASE

D: \RESME TH।IMAGES \disadvan.C16 CLIADV

D: IRESMETH IMAGES \HIFAT.C16 CONEXAMP

D: \RESMETH\IMAGES\Imeohort.C16 OBSERVA COHORT

D: \RESMETH IMAGES IMEXPEI . C16 OBOREXP

D: \RESMETH IMAGES \Imobser . C1 6 OBOREXP

OBSERVA

CONTCASE COHORT

D: \RESMETH IMAGES \pastpres .C16 PROCOHORT

D: \RESMETH IMAGES \plnbkg.C16 ANAEPI 
Appendix H (continued)

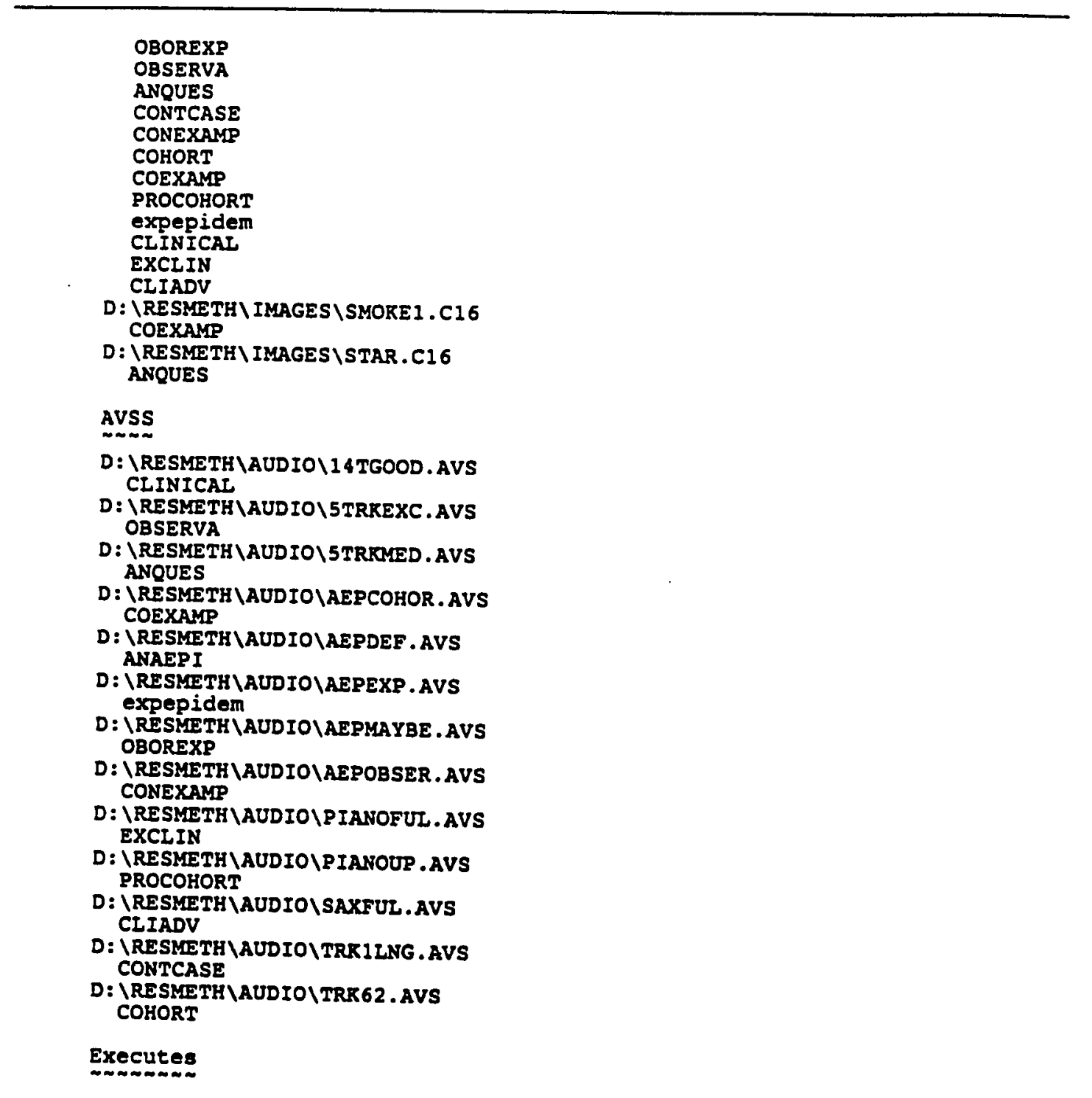


Appendix I

V. Castelli - Master's Project

July 11,1995

I give Laura McEwen permission to include my Master's project "Evaluation of the Effectiveness of Computer Based Instructional (CBI) Courseware for Teaching Research Methodology to Undergraduate Students" as an appendix to her Master's thesis.

Veituis. Casth:

Victoria G. Castelli 
Appendix I (continued)

EVALUATION OF THE EFFECTIVENESS OF COMPUTER BASED INSTRUCTIONAL (CBI) COURSEWARE FOR TEACHING RESEARCH METHODOLOGY TO UNDERGRADUATE STUDENTS

\begin{abstract}
A Research Project
Presented to

The Faculty of the Department of Nutrition and Food Science San Jose State University
\end{abstract}

In Partial Fulfillment

of the Requirements for the Degree

Master of Science

By

Victoria G. Castelli

April 10, 1995

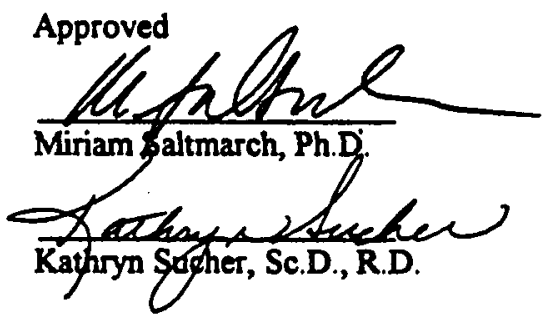


Appendix I (continued)

EVALUATION OF THE EFFECTIVENESS OF COMPUTER BASED INSTRUCTIONAL (CBI) COURSEWARE FOR TEACHING RESEARCH METHODOLOGY

TO UNDERGRADUATE STUDENTS

\section{Victoria G. Castelli}

April 10, 1995

Running Head: CBI EVALUATION 
Appendix I (continued)

\section{Preface}

The joumal article titled "Evaluation of the Effectiveness of Computer Based Instructional Courseware (CBI) to Teach Research Methodology to Undergraduate Students" comprises Appendix D of this document. It was written according to the information for authors of the Joumal of Educational Multimedia and Hypermedia. 
Appendix I (continued)

Table of Contents

Acknowledgments


Appendix I (continued)

Tables

Table I Ranked Subject Selection by GPA ...................................................51

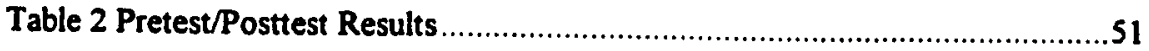

Table 3 Pretest Score Results by GPA .........................................................52

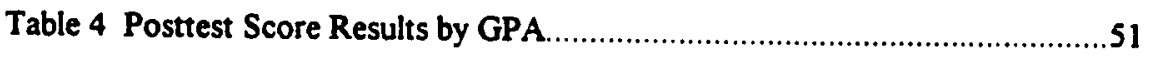


Appendix I (continued)

\author{
Acknowledgments
}

I would like to thank several people who helped make the completion of this project possible. I thank Dr. Miriam Saltmarch for her advice, enthusiasm and guidance. Her commitment and dedication to this project made its completion possible. I thank $\mathrm{Dr}$. Kathryn Sucher for her advice on this project and for her support throughout my experience in the nutrition department. I am grateful to Stephen Aquino for his help with the statistical analysis and for his patient explanations.

I thank my mother Grace Castelli for her unconditional love, her eternal optimism, and her quiet strength. She was my first nutrition teacher.

Finally, I thank Dr. Joni Finney for her friendship, encouragement and absolute confidence in me. Her efforts on my behalf have been extraordinary. 
Appendix I (continued)

Evaluation of the Effectiveness of Computer Based Instructional (CBI) Courseware for Teaching Research Methodology to Undergraduate Students

Abstract

The potential effectiveness of computer-based instruction (CBI) as a pedagogical tool has been suggested by numerous studies. Its benefits include logical well-sequenced instruction, a self-paced individualized approach, and the ability to provide immediate feedback to the student. This versatile technology is ideal for teaching the complicated concepts of research methodology. CBI courseware was developed at San Jose State University (SJSU) to teach an undergraduate, semester-long course in research methodology. The purpose of this study was to evaluate the effectiveness of that courseware. Subjects were undergraduate students in a one credit course for nutrition and food science majors at SJSU enrolled during the spring 1994 semester. Students were assigned to a treatment or control group based on ranked random selection according to grade point average. The control group $(n=14)$ received the course material through the traditional lecture and discussion format with the usual classroom teacher. The treatment group ( $n=17$ ) received the same material via the $C B I$ courseware. Analysis of pretest and posttest scores indicated a statistically significant positive difference in achievement in the treatment group over the control group at the $p=0,02$ confidence level. 
Appendix I (continued)

Introduction

Nutrition research appropriately applied has profound and far-reaching implications. It may improve patient outcomes in the hospital setting, enhance the quality of life of those managing a long term condition such as diabetes or hypertension, enrich the health of the general public and promote interest and support for the conthued study in the field of nutrition. The volume of nutrition information currently available is astounding.

Research supports and directs the clinical practice of nutrition (Monsen \& Cheney, 1988). It is the backbone of the dietetics profession. The public is eager for nutrition information, but is for the most part unprepared to apply it to making healthy food choices for their own diets. Increasingly, registered dietitians (R.D.) are asked to interpret nutrition research and to define its implications for the health of their clients. As a result, the American Dietetic Association (ADA) has placed stronger emphasis on the study of research methodology and the development of critical thinking skills in the curriculum for dietetic students, and stresses these issues among its professional competencies for R.D.'s.

Concerned that their students be prepared to successfully write the examination for registered dietitians and that they be competent to interpret the complexities of nutrition research in their professional practices, the faculty of the Department of Nutrition and Food Science at San Jose State University (SJSU) began to develop a one credit, undergraduate course in research methodology. Computer-based instruction (CBI) was chosen as the instructional medium for the course because of the potential it had shown in teaching other subjects. Many of CBI's features make it ideal for teaching the complex concepts and definitions of research methodology. Those features include a logical, well- 
Appendix I (continued)

sequenced program of instruction, the ability for repetition and review and a format that allows students to proceed through the material at their own pace.

In 1991, the (USDA) awarded a grant to the Department of Nutrition and Food Science at San Jose State University (SJSU) to develop Computer-Based Instructional (CBI) courseware materials for the purpose of teaching NUFS 195 Research Methodology a one credit undergraduate course. The program utilizes Intel's Digital Video Interactive (DVI) technology which enables the programmer to incorporate still images, text, graphics, sound and moving video in a compressed format. If determined to be effective in aiding students in meeting the course's goals and objectives, the courseware package will be transferred to compact disc and distributed to other interested dietetic programs around the country for a nominal charge.

The purpose of this study was to determine the effectiveness of CBI courseware to the teaching of an undergraduate course in research methodology as compared to the traditional lecture and discussion format.

\section{Review of Related Literature}

\section{Computer-based instraction (CBI) is a technological method for delivering} instructional material to students. $\mathrm{CBI}$ is defined as the interaction of computer systems and individuals to help individuals leam new material or improve their knowledge of previously studied material (Azarmsa, 1991). With CBI, a student need never miss instruction due to an absence since the instructional material is retained in the computer's data base and can be delivered at any time. The computer delivers instruction free of instructor bias, and does not wander off the topic thus eliminating the mediocre human contribution to teaching (Wade \& Thiele, 1973). CBI offers variety, flexibility, immediate 
Appendix I (continued)

feedback, eternal patience and accurate record keeping. When used to its fullest capacity, CBI can actively engage students because of its individualized approach to leaming.

$\mathrm{CBI}$ can be employed in several ways: the electronic blackboard, drill and practice, simulation, instructional dialogue, and record keeping (Arons, 1984). Its simplest format is as an electronic textbook or blackboard through which lecture notes are converted to computer screen, and the computer writes and erases the lessons like the instructor would do on the blackboard. Drill and practice programs enable students to practice the skills they have learned in the classroom such as math problems and new vocabulary words. The three dimensional graphics and moving video available through the computer can be used to simulate physical phenomenon such as molecular structure and dissections.

A more complex use of $\mathrm{CBI}$ is as an instructional dialogue which utilizes a function know as branching in which the computer engages the leamer in a conversation by asking questions. A correct response allows the student to progress to the next level of difficulty or complexity. An incorrect response sends the learner back to a previous section of the text for review or into a remedial sequence and then more questions. There are many applications for this feature. For example, it could be used to present symptoms and signs to medical students requiring them to give an accurate diagnosis (Arons, 1984).

CBI can be used to administer and grade exams, accurately record grades and produce a printout of results for the instructor. Finally, CBI can be used as a complete self-study course incorporating all the other features into a comprehensive program of study.

After an exhaustive analysis of the literature regarding the use of $\mathrm{CBI}$ in the classroom, Kulik and Kulik (1987) concluded that students generally: leamed more in classes when they received help from the computer; learned with less instructional time; liked their classes more; and developed more positive attitudes towards computers. CBI appears to be as effective or more effective than traditional lecture methods for teaching 
Appendix I (continued)

various subjects as evidenced by higher posttest scores among CBI students (Boysen and Francis, 1982; Drake, 1988; Vogler, O'Quinn and Paterson, 1991).

Researchers attribute higher posttest scores to several of CBI's features. The branching ability of $\mathrm{CBI}$ enables students to progress through the material at their own pace, or weave their own path through the lessons (Cohen, 1983; Emerson, 1988; Ries \& Granell, 1985; Schroeder \& Kent, 1982; Wade \& Thiele, 1973). Schroeder and Kent (1982) reported that CBI students in a renal diet therapy class not only learned more with the $\mathrm{CBI}$ than those in the lecture group, but the students feit they were more efficient in their learning because they could skip over material they already knew and concentrate on mastering new information. In a study using CBI to teach the principles of a vegetarian diet to nutrition students, Ries and Granell (1985) reported that students found CBI to be an efficient way to learn the material since it saved time and improved their grades.

CBI allows students to periodically test their knowledge through self-test questions and practical exercises that may not count for a grade (Boysen \& Francis, 1982). This feature allows students who respond incorrectly to a question or problem to go back to a previous portion of the lesson for additional work while student who answer correctly can advance to the next section. CBI thus spares students the embarrassment of answering a teacher's question incorrectly in front of the class by allowing them to make mistakes privately (Rockman, 1993).

The graphics, color, moving video and audio features available through the computer can illustrate functions and phenomena more realistically than the one dimensional illustrations on a blackboard or in a textbook (Arons, 1984; Boysen \& Francis, 1982).

The consultation with a programmer required for the development of $\mathrm{CBI}$ courseware generally leads to a logical, well-sequenced and highly structured program of study with clear and explicit objectives (Kulik and Kulik, 1987). The process of converting lecture material to computer software demands that the instructor rethink the 


\section{Appendix I (continued)}

fundamentals of the course (WICHE, 1994). This point is strengthened by the fact that when two instructors are used, one for the $\mathrm{CBI}$ group and a different one for the lecture group, the CBI group scores higher than when the same teacher is used for both groups (Clark, 1985). The CBI instructor had to go through the planing process with the programmer to develop the CBI courseware and therefore was forced to reorganize her course material so that it could be presented in the logical fashion required by the computer which inevitably leads to a more logical presentation of material overall and higher posttest scores.

CBI seems to confer benefits over and above the effective delivery of instructional material. Drake (1988) found that students not only leamed more nutrition information with $\mathrm{CBI}$, but they also retained more of that knowledge up to five months after taking the course. Vogler, O'Quinn and Paterson (1991) found that students in a sociology course not only scored higher on posttests, but their "critical thinking skills developed from rigid to flexible" and they were more comfortable asking the instructor questions. In a biomechanics course, Boysen and Francis (1982) found not only higher posttest scores, but that the computer presented more practical exercises and graded them for the students freeing the teacher from grading duties.

Even in studies where CBI did not produce statistically significant results on . posttests, the computer learning experience seemed to impart some benefit to students. Students developed positive attitudes towards computers and technology in general as a result of working with CBI (Vogler, O'Quinn and Paterson, 1991). In a renal diet therapy class, Schroeder and Kent (1982) found no significant difference in posttest scores, but CBI group students expressed a more positive attitude towards CBI that the control group students expressed towards the traditional lecture method of instruction. Ries and Granell (1985) found that there was no significant difference in posttest scores using CBI to teach a course in vegetarianism, but $\mathrm{CBI}$ students had positive responses to leaming by 
computer and $\mathrm{CBI}$ spared the instructor from time spent evaluating student practice efforts.

CBI may have the potential to change students' attitudes about a subject. Using CBI to teach the difficult concept of nutrient density, Edmunds, Wyse and DeBloois (1987) found no significant difference in posttest scores, but students had positive feelings towards the material presented and the technology used to teach it. Using CBI to teach statistics produced positive but not statistically significant posttest results for Collis, Oberg and Shera (1989). However, students expressed an improved attitude toward statistics and toward CBI. Furthermore, the instructors felt positive about their own and the students experiences with the computer modules.

Several factors may have contributed to the positive outcomes found in many of the studies besides the use of the computer. Students in CBI classes may have spent more time with material than students in lecture classes. The greater time spent on a subject may have been the reason for the higher posttest scores not the CBI (Hagler \& Knowlton, 1987). CBI programs may be presenting more material than lecture teachers which would give CBI group students an advantage on posttests (Gillingham \& Guthrie, 1987). In situations where two different instructors were used, the better teacher may have been assigned to the CBI group which led to the higher posttest scores not the computer (Clark, 1985). The novelty effect of a new teaching method of any kind may have inspired students to work harder in CBI classes than students in the traditional lecture classes.

Cohen (1983) points out that as class size increases, CBI can be used to aid teachers by decreasing the amount of time they must spend in labor intensive tasks such as grading exams and record keeping. CBI will allow teachers to spend more time tutoring students with individual needs. In terms of instructor productivity, it has been asserted that technology frees instructors from routine teaching assignments and allows them to spend more time in critical thinking sessions with students (WICHE, 1994). 
Appendix I (continued)

CBI may have the potential to improve student-teacher interactions. The instructor of CBI classes had more time to answer questions than the instructor in the traditional classroom (Boysen \& Francis, 1988; Vogler, O'Quinn \& Paterson, 1991). In a recent study involving several colleges and universities, researchers found overwhelming support for CBI and other instructional technologies as teaching methods (WICHE, 199.4). Students characterized the quality of their interactions with faculty and other students as equal to or better than those that they had experienced in other classes. Faculty praised instructional technology such as computer based instruction because it put the student at the center of the learning experience and it kept conversations focused on content and not on peripheral matters (WICHE 1994).

The use of CBI and other instructional technology (IT) in colleges and universities seemed to reach a culmination point the late 1980 's with a institutions that had initiated programs getting their programs operational, but most institutions still lagging far behind. Possible reasons for the limited use of technology in higher education include: lack of reward system for faculty to develop instructional innovation; lack of programming skills or lack of access to programmers; risk aversion among faculty to trying new instructional methods; resource constraints recently imposed on higher education (Geoghegan, 1994).

CBI has been used to teach several subjects. This literature review has not produced any study using CBI to teach research methodology. The study conducted at SJSU is the first to use CBI to teach this subject.

Methods

Subject Selection

Subjects were undergraduate students, 32 females and 1 male, $(n=33)$ enrolled in NUFS 195 Research Methodology a one credit course for Nutrition and Food Science majors at San Jose State University during the spring 1994 semester. Nine seniors were 
Appendix I (continued)

granted permission by the department chairperson to simultaneously enroll in NUFS 195 and another department course that met at the same time in order to meet graduation requirements. These nine double-enrolled students. were placed in the experimental group.

All other students for the experimental group were selected using stratified random sampling and grouped according to their grade point averages. The four grade point average (GPA) groups were: those with GPA 3.5 or greater $(n=6)$, those with GPA greater than 3.0 but less than $3.5(n=12)$, those with GPA greater than 2.5 but less than $3.0(n=9)$, and those with GPA less than $2.5(n=6)$ (Table 1). The nine double enrolled students in the experimental group were placed in one of these four GPA groups also. Students selected for the experimental group who did not wish to participate were given the opportunity to stay in the lecture group. Only one student selected this option and was substituted with a student with a similar GPA from the control group.

After four introductory class sessions, the control group participated in the usual lecture and discussion for the course provided by the usual instructor while the experimental group received the remainder of the course material from the CBI teaching modules. A graduate student or faculty member was always present during the CBI sessions to answer questions or provide technical assistance.

\section{Module Development}

Intel's digital video interactive technology (DVI) was used to develop the courseware for this class. This technology allows for the integration of moving video, still images, audio, text and graphics into a compressed format. Authology was the authoring program used. CBI modules were developed directly from the lecture notes of the classroom instructor and the textbook for the course. The control group and experimental group students received the same course material.

Testing Methods 


\section{Appendix I (continued)}

The pretest was administered to all students on the first day that the class met prior to the breakout of the experimental group and before any instruction began. The posttest was administered on the last day the class met and was also given to all students. Both tests were identical and contained fifty multiple choice questions. The test was developed from the lecture notes and textbook material (Rivas, 1993). The pre/posttest was independent of the final exam and was not used to determine students' grades for the course.

The pre/posttests were reviewed for validity with the aid of a discrimination index using choice analysis. The discrimination index measured the degree of differentiation in responses between students comprising the upper and lower twenty-seventh percentiles of all test takers. A discrimination index of -0.5 to +0.5 was considered desirable. Questions with discrimination scores outside of this range were considered invalid (Rivas, 1993). Although the pre/posttest was administered with eighty questions, after choice analysis was performed, thirty questions were eliminated leaving fifty questions for statistical analysis.

An independent student t-test was performed using the Statistical Package for the Social Science (SPSS/PC, Chicago, II.) software on the overall mean pre/posttest scores of the control and experimental groups. An analysis of GPA subgroups was not conducted due to the small sample size in each subgroup.

Experimental group students provided their feedback regarding the CBI courseware through a written survey and selected interviews (Appendix C).

\section{Results}

Scores were collected from the control and treatment groups and reviewed prior to conducting any statistical tests. It was observed that in the treatment group two cases showed extreme variability in their scores; the posttest scores were much lower than the pretest scores. Recognizing the potential effect this could possibly have on the 


\section{Appendix I (continued)}

requirements of the statistical test, it was decided to eliminate these two particular cases from inclusion in the data prior to analysis using the student $t$ test. Explanation of these two aberrant scores would only be speculative. Lack of seriousness in taking the posttest since it did not contribute to the final course grade may have contributed to this result.

An independent student t-test $(n=31)$ produced a $t$ value of 2.46 at the $p=0.02$ confidence level. Mean posttest scores were higher in the experimental group than the control group across all four GPA subgroups. The most dramatic result was in the group with GPA's less than 2.5 (Table 5). Here the experimental group had mean posttest scores 12.2 points above the control group mean.

\section{Discussion}

Students in the experimental group scored higher on the posttest than students in the control group indicating that CBI had a more positive effect on the leaming of the experimental group than the lecture method had on the learning of the control group. These findings are consistent with that of previous research (Kulik \& Kulik, 1987). This trend is more pronounced perhaps because the instructor for the lecture and CBI groups was different. Previous research indicates that when two instructors are used posttest results are more divergent (Clark, 1985 and Kulik \& Kulik, 1987).

The close grouping of posttest scores among students in the experimental group indicates that the CBI courseware had a universally positive effect on the learning of all students. Additionally, the posttest scores of the students in the experimental group were higher than those in the control group within each GPA subgroup indicating that CBI was effective for students of all academic ability levels.

While it might be expected that those stidents in the top GPA group would be successful regardless of instructional method used, the results of the lowest GPA group were unexpected. CBI's positive effects on leaming are most powerfully illustrated in the lowest GPA group. These students scored within one point of those in the top GPA 
Appendix I (continued)

group. Without the $\mathrm{CBl}$ courseware, these students would have scored comparable to their counterparts in the control group. The CBI courseware enabled them to compete equally with more successful students eliminating the leaming barriers which, under traditional academic teaching methods, negatively impacts their performance resulting in lower GPA's and lower self-esteem (Rockman, 1993).

The Hawthome effect cannot be overlooked as a possible influence on the higher scores among the computer group on the posttest. The experimental group may have worked harder to produce the results that they thought the researchers were expecting to see. Similarly, the novelty of exposing students to a new learning tool may have produced sufficient enthusiasm among the computer group students to encourage them to work harder and score higher on the posttest. However, Emerson (1988) controlled for the novelty effect in teaching a biology course to undergraduates, and the CBI group students still scored significantly higher on posttests.

Close controls were in place in the $\mathrm{CBI}$ group to ensure attendance at all sessions. With the exception of one student, all CBI group students attended all CBI sessions and viewed all the modules. Class attendance in the lecture group was not as strictly enforced or monitored. The CBI group may have had more instructional time with the computer than the lecture group had with the classroom teacher. Furthermore, individual study time was not accounted for. The amount of time students spend with new material may contribute to mastery of the material and ultimately to learning (Clark, 1985). This factor may have contributed to the higher postrest scores in the CBI group.

\section{Students' Comments}

Students in the computer group provided comments regarding their experience in the form of a written survey that utilized a five point Likert-type scale (Appendix C). Additionally, six students were randomly selected and interviewed. Overall, experimental group students enjoyed the learning experience with CBI. They thought the text in the 
Appendix I (continued)

computer modules was thorough and concise. They liked the videotape segments and visuals including the pictures, graphics and icons. Several students expressed a desire for improvements of the interactivity features such as more branching, the addition of more video segments, enhancements of color and graphics, more self-test questions and greater access to the computer lab.

Comments concerning the audio aspects were less positive. For example, some students enjoyed the background music while others were distracted by it. A few students expressed a desire for time for interaction with other students or an instructor to discuss material that was covered in the computer modules.

Students' recommendations for improvement indicated their support for $\mathrm{CBI}$ and their positive feelings towards it as an instructional tool. Students wanted more video segments, more interactivity, more self-test questions. The individual interviews conducted with selected students elicited similar comments and served to reinforce and clarify the responses given on the written surveys rather than to reveal new information. No comments were solicited from the control group students.

Limitations of the Study

Clearly the CBI courseware had a positive and significant effect on posttest scores and, therefore, on the learning of the students in this study. However, due to the small sample size, the results of this study should be interpreted with caution. They do, however, support previous research in suggesting that CBI is a feasible alternative to the lecture and discussion format.

The survey given to $\mathrm{CBI}$ group students was not given to the lecture group students. This information could have been used to compare the attitudes and feelings of students towards their respective leaming situations.

Recommendations for Further Research 
Appendix I (continued)

Additional trials, perhaps with larger samples, are needed to verify the posttest trends seen in this experiment. More importantly, future research is needed to more specifically identify the characteristics of CBI that led to the trend seen in this study and previous studies with regard to the characteristics and instructional components that are responsible for these results (Keane, Norman and Vickers, 1991 and Gillingham \& Guthrie, 1987). Identifying the specific features of CBI that promote improvements in leaming would allow these features to be identified so that they could be replicated in future CBI courseware. Furthermore, it would settle the debate over the value of $\mathrm{CBI}$ as a pedagogical method.

The issue of retention should also be addressed in future trials. Students could be assessed at various intervals following the conclusion of the course to determine CBI's effect on long term retention of material.

\section{Conclusion}

The purpose of this study was to evaluate the effectiveness of $\mathrm{CBI}$ courseware in teaching research methodology to undergraduate students. Analysis of posttest scores indicate that $\mathrm{CBI}$ is an effective tool for this purpose. Furthermore, students expressed a positive attitude toward CBI. They appreciated its completeness and conciseness in covering the course material, and enjoyed its multimedia format. Following the completion of minor improvements in the program based on student's recommendations, copies of this $\mathrm{CBI}$ courseware should be made available to other dietetic programs around the country and should be utilized to teach this course for its next offering. 
Appendix I (continued)

\section{References.}

Clark, R. E. (1985). Confounding in educational computing research. Joumal of Educational Computing Research, 1 (2), 137-148.

Collis, B., Oberg, A., Shera, W. (1988). An evaluation of computer-based instruction in statistical techniques for education and social work students. Joumal of Educational Technology Systems, 117 (1), 59-71.

Drake, M. A. (1988). A comparison of two teaching methods in an introductory college nutrition course: lecture vs. personalized system instruction. Joumal of Nutrition Education, 20 (1), 11-14.

Emerson, I. (1988). A comparative evaluation of computer based and noncomputer based instructional strategies. Journal of Computers in Mathematics and Science Teaching. 10, 46-49.

Gillingham, M. G., Guthrie, J. T. (1987). Relationships between CBI and research on teaching. Contemporary Educational Psychology, 12, 189-199.

Hagler, P., Knowlton, J. (1987). Invalid implicit assumption in CBI comparison research. Journal of Computer-based Instruction, 14 (3), 84-88.

Keane, D. R., Norman, G. R., Vickers, J. (1991). The inadequacy of recent research on computer-assisted instruction. Academic Medicine. 66 (8), 444-448.

Kulik, J. A., Kulik, C. C. (1987). Review of recent research literature on computer-based instruction. Contemporary Educational Psychology. 12, 222-230.

Monsen, E. R., Cheney, C. L. (1988). Research methods in nutrition and dietetics: Design, data analysis, and presentation. Joumal of the American Dietetic Association.

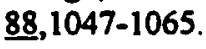

Rachal, J. (1993). Computer-assisted instruction in adult basic and secondary education: a review of the experimental literature, 1984-1992. Adult Education Quarterly, 43 (3), 165-172.

Rivas, Y. (1993). Evaluation of the effectiveness of computer based instruction courseware materials in an underoraduate nutrition and dietetics research methodology course. Unpublished Master's Project, San Jose State University, San Jose, CA. 
Appendix I (continued) Loumal

Rockman, S. (1993) Asking the right questions. The American School Board

Schroeder, L., Kent, P.(1982). Computer-based instruction in dietetics education. Journal of Computer-based Instruction, $\underline{8}$ (4), 85-90.

Steinberg, E. R. (1983). Reviewing the instructional effectiveness of computer courseware. Educational Technology,

Vogler, C., O'Quinn, K., Paterson, W. (1991). Grade and knowledge improvement as a result of computer-assisted instruction. Joumal. of Educational Technology Systems, 19 (3), 201-213. 
Appendix I (continued)

Appendix B: Student Survey

NUFS 195

Spring 1994

NAME (Optional):

Circle the number that most closely reflects your opinion, based on a scale from 1-5, on the following areas. Please give additional comments below each question especially if you strongly agree or strongly disagree.

$\begin{array}{lllll}1 & 2 & 3 & 4 & 5 \\ \text { Strongly agree } & \text { Agree } & \text { Neither agree } & \text { Disagree } & \text { Strongly } \\ & & \text { nor disagree } & & \text { disagree }\end{array}$

1. The text was presented in a logical manner that was easy to follow.

$\begin{array}{lllll}1 & 2 & 3 & 4 & 5\end{array}$

Comments:

2. The examples provided enhanced my understanding of the theory presented.

$\begin{array}{llllll}1 & 2 & 3 & 4 & 5\end{array}$

Comments:

3. The audio (voice) enhanced my learning of the material. 
Appendix I (continued)

Comments:

4. The video segments enhanced my learning of the material.

1

2

3

4

5

Comments:

5. The visual images (photos, icons, pictures) enhanced my learning of the material.

$\begin{array}{lllll}1 & 2 & 3 & 4 & 5\end{array}$

Comments:

6. The test questions enhanced my learning of the material.

$\begin{array}{lllll}1 & 2 & 3 & 4 & 5\end{array}$

Comments

7. The text, audio, video and images flowed in a logical sequence.

1

2

3

4

5

\section{Comments:}


Appendix I (continued)

8. The physical setting enhanced my learning (e.g. office, lighting, seating)

1

2

3

4

5

Comments:

9. Viewing the modules with a partner enhanced my learning.

$$
1
$$

2

3

4

5

\section{Comments:}

10. I would like to have more (Circle all that apply.)

\begin{tabular}{ll} 
Text & Images \\
Audio & Examples \\
Test questions & Video \\
Other & \\
\hline
\end{tabular}

11. I would like to have less (Circle all that apply.)

$\begin{array}{ll}\text { Text } & \text { Images } \\ \text { Audio } & \text { Examples } \\ \text { Test questions } & \text { Video } \\ \text { Other } & \end{array}$


Appendix I (continued)

12. Rank the importance of the following components from most important (\#1) to least important (\#9)

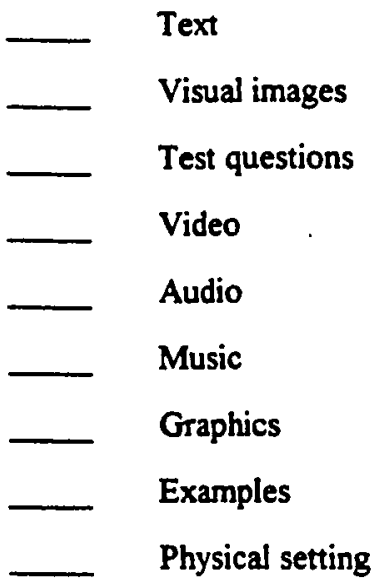

13. Overall, the Computer Based Interactive (CBI) program was an effective method for learning the material for this course.

$\begin{array}{llll}1 & 3 & 4 & \end{array}$

14. Additional comments: 
Appendix I (continued)

Appendix C: Students Comments

Responses to Students' Survey

\begin{tabular}{|c|c|c|c|c|c|c|}
\hline Survey Question & & uens & of & ad & & nses \\
\hline & 1 & 2 & 3 & 4 & 5 & Total \\
\hline $\begin{array}{l}\text { 1. Overall, the CBI program was an } \\
\text { effective method for understanding the } \\
\text { material for this course }\end{array}$ & 1 & 8 & 2 & 4 & 1 & 16 \\
\hline $\begin{array}{l}\text { 2. The text was presented in a logical } \\
\text { manner that was easy to follow }\end{array}$ & 3 & 11 & 2 & 0 & 0 & 16 \\
\hline $\begin{array}{l}\text { 3. The examples provided enhanced my } \\
\text { understanding of the theory presented. }\end{array}$ & 7 & 7 & 1 & 1 & 0 & 16 \\
\hline $\begin{array}{l}\text { 4. The audio (voice) enhanced my leaming } \\
\text { of the material. }\end{array}$ & 1 & 3 & 8 & 3 & 1 & 16 \\
\hline $\begin{array}{l}\text { 5. The video segments enhanced my } \\
\text { leaming of the material. }\end{array}$ & 5 & 4 & 5 & 1 & 1 & 16 \\
\hline $\begin{array}{l}\text { 6. The visual images (photos, icons, } \\
\text { pictures) enhanced my learning of the } \\
\text { material. }\end{array}$ & 5 & 4 & 6 & 1 & & 16 \\
\hline $\begin{array}{l}\text { 7. The test questions enhanced my learning } \\
\text { of the material.. }\end{array}$ & 4 & 5 & 6 & 1 & 0 & 16 \\
\hline $\begin{array}{l}\text { 8. The text, audio, video and images flowed } \\
\text { in a logical sequence }\end{array}$ & 3 & 11 & 2 & 0 & 0 & 16 \\
\hline $\begin{array}{l}\text { 9. The physical setting enhanced my } \\
\text { leaming (e.g. office, lighting, seating) }\end{array}$ & 1 & 1 & 3 & 2 & 9 & 16 \\
\hline $\begin{array}{l}\text { 10. Viewing the modules with a partner } \\
\text { enhanced my learning. }\end{array}$ & 3 & 4 & 6 & 2 & 1 & 16 \\
\hline
\end{tabular}

NOTE (1): A response of 1 indicted strongly agree and 5 indicated strongly disagree 


\section{Appendix I (continued)}

\section{Additional Students' Comments}

\section{Environment}

Too much noise, hard to concentrate

Not the greatest environment

Space too small, noisy, high traffic area, poor lighting

Uncomfortable, too many distractions, people coming in and out, phone calls

\section{Group interaction}

Missed out on group interaction on critique of research articles; don't feel like I know how to critique research

\section{Music}

Music should continue to next screen or section; I thought something was wrong when the music stopped

Music ended abruptly which was annoying

Soft music was nice, however, it frequently ended abruptly

\section{Audio}

Audio distracted from reading the material on the screen

Audio with video was better than just audio

Audio should match the print on the screen

The audio voice was annoying

5. Text

Very thorough, to the point, concise, there was an example for everything

I strongly agree that the computer was effective for learning this material, however it helps

if there is a discussion so we can review the material thoroughly

Subject headings and overview made it easy to follow the text

Icons were helpful in illustrating the point

\section{Video}

Video explained some concepts better than the notes

Pictures and video very helpful

\section{Would like te see more}

Video- 10 (10 students mentioned this item)

Images-4

Examples-9

Test Questions-5

Audio--2 
Appendix I (continued)

Other--ability to interact with other students/teacher--2

\section{Would like to see less}

Test Questions--3

Audio--6

Text--7

Video--2

\section{Examples}

Examples helped to clarify the text

Especially the examples on research errors

\section{Questions}

There should be more questions to allow time to stop and think about what I have written in my notes

Helpful when we did go through them, but due to time constraints we did not always do the test questions

Very beneficial; they encouraged me to pay attention

\section{Recommendations for improvements}

a. A module on how to critique a research article

b. Written outline of the material (a general outline not necessarily word for word)

c. When the audio voice comes on, there should be a graphic or picture rather than text so that we can pay attention to what is being said and not try to read the screen at the same time

d. More interactive, like a game where you can touch the screen or move the mouse around

e. Need more time for each session so you can do the questions

f. Continuous soft music playing in the background

g. A midterm would have forced me to study the material during the semester instead of waiting until the final

h. More video and audio segments

i. More quiet environment with fewer distractions

j. Can this be put on videotape so we can check it out and view at home? 
Appendix I (continued)

Appendix D. Journal Article

Evaluation of the Effectiveness of Computer Based Instructional (CBI) Courseware

for Teaching Research Methodology

to Undergraduate Students

Victoria G. Castelli, Miriam Saltmarch, and Kathryn Sucher

San Jose State University

Department of Nutrition and Food Science 
Appendix I (continued)

Evaluation of the Effectiveness of Computer Based Instructional (CBI) Courseware for Teaching Research Methodology to Undergraduate Students

\begin{abstract}
The potential effectiveness of computer-based instruction (CBI) as a pedagogical tool has been suggested by numerous studies. Its benefits include logical well-sequenced instruction, a self-paced individualized approach, and the ability to provide immediate feedback to the student. This powerful technology is ideal for teaching the complicated concepts of research methodology. CBI courseware was developed at San Jose State University (SJSU) to teach a one credit, semester-long, undergraduate course in research methodology. The purpose of this study was to evaluate the effectiveness of that courseware. Subjects were nutrition and food science majors at SJSU enrolled during the spring 1994 semester. Students were assigned to a treatment or control group based on ranked random selection according to grade point average. The control group $(n=14)$ received the course material through the traditional lecture and discussion format with the usual classroom teacher. The treatment group ( $n=17$ ) received the same material via the CBI courseware. Analysis of pretest and posttest scores indicated a significant positive difference in achievement in the treatment group over the control group.
\end{abstract}

Introduction 
Appendix I (continued)

It is now widely accepted that computer-based instruction (CBI) is as good as or perhaps better than traditional lecture methods for teaching many subjects (Keane, Norman and Vickers, 1991). CBI is highly visual. It can employ moving video, still images, graphics, icons and color to help stimulate interest and attention (Steinberg, 1983). Among its benefits students liked classes more with CBI, learned with less instructional time, and developed positive attitudes about computers (Kulik \& Kulik, 1987). It has been claimed that students can use their time more efficiently with CBI because it allows them to concentrate on new information and disregard material they already have mastered (Schroeder \& Kent, 1982). The more control students are given over moving through the computer courseware the more they leam as evidenced by higher test scores (Cohen, 1983 and Emerson, 1988). With CBI, students can review material as often as needed and perform self-tests to access their own progress. Furthermore, CBI is nonjudgmental allowing students to make mistakes in privacy and free from embarrassment (Rachal, 1993).

The time and collaboration with programmers required for the development of $\mathrm{CBI}$ obligates curriculum to be reviewed and revised ensuring that the lessons are more thoughtful than their traditional lecture counterparts. CBI instruction is by necessity logical, well-developed and well-sequenced instruction (Kulik \& Kulik, 1987).

The study of research methodology can be daunting for many students. Its intricate definitions and esoteric concepts can cause consternation for even the best students. CBI's logical sequencing, self-pacing and patient repetition make it an ideal medium for teaching the complexities of research methodology. Nutrition research is dynamic and voluminous. Mastery of the concepts of research methodology is essential for the study of nutrition. To date, no programs exists to teach research methodology using $\mathrm{CBI}$ technology. A semester-long, one credit undergraduate course was developed using CBI technology to teach research methodology to nutrition majors at San Jose State 
Appendix I (continued)

University. This study evaluates the effectiveness of $\mathrm{CBI}$ courseware as compared to the traditional lecture and discussion format for teaching research methodology.

Methods

Subject Selection

Subjects were undergraduate students, 32 females and 1 male, $(n=33)$ enrolled in NUFS 195 Research Methodology a one credit course for Nutrition and Food Science majors at San Jose State University during the spring 1994 semester. Nine seniors were granted permission by the department chairperson to simultaneously enroll in NUFS 195 and another department course that met at the same time in order to meet graduation requirements. These nine double-enrolled students were automatically placed in the experimental group. All other students for the experimental group were selected using stratified random sampling and grouped according to their grade point averages. The four grade point average (GPA) groups were: those with GPA 3.5 or greater $(n=6)$, those with GPA greater than 3.0 but less than $3.5(n=12)$, those with GPA greater than 2.5 but less than $3.0(n=9)$, and those with GPA less than $2.5(n=6)$ (Table 1). Students selected for the experimental group who did not wish to participate were given the opportunity to stay in the lecture, control group. Only one student selected this option and was substituted with a student with a similar GPA from the control group.

After four introductory class sessions, the control group participated in the usual lecture and discussion for the course provided by the usual instructor while the experimental group received the remainder of the course material from the CBI teaching modules. A graduate student or faculty member was always present during the $\mathrm{CBI}$ sessions to answer questions or provide technical assistance.

Module Development 
Appendix I (continued)

Intel's digital video interactive technology (DVI) was used to develop the courseware for this class. This technology allows for the integration of moving video, still images, audio, text and graphics into a compressed format. Authology was the authoring program used. $\mathrm{CBI}$ modules were developed directly from the lecture notes from the classroom instructor and textbook for the course. The control group and experimental group students received the same course material.

\section{Testing Methods}

The pretest was administered to all students on the first day that the class met prior to the breakout of the experimental group and before any instruction began. The posttest was administered on the last day the class met and was also given to all students. Both tests were identical and contained fifty multiple choice questions. The test was developed from the lecture notes and textbook material (Rivas, 1993). The pre/posttest was independent of the final exam and was not used to determine students' grades for the course.

The pre/posttests were reviewed for validity with the aid of a discrimination index using choice analysis. The discrimination index measures the degree of differentiation in responses between students comprising the upper and lower twenty-seventh percentiles of all test takers. A discrimination index of -0.5 to +0.5 was considered desirable. Questions with discrimination scores outside of this range were considered invalid (Rivas, 1993). Athough the pre/posttest was administered with eighty questions, after choice analysis was performed, thirty questions were eliminated leaving fifty questions for statistical analysis.

An independent student t-test was performed using the Statistical Package for the Social Science (SPSS/PC, Chicago, II.) software on the overall mean pre/posttest scores of the control and experimental groups. An analysis of GPA subgroups was not conducted due to the small sample size in each subgroup. 
Appendix I (continued)

Experimental group students provided their feedback regarding the CBI courseware through a written survey and selected interviews (Appendix A). Their comments and recommendations will be used to make improvements in the courseware prior to its fielding.

Results

Scores were collected from the control and treatment groups and reviewed prior to conducting any statistical tests. It was observed that in the treatment group two cases showed extreme variability in their scores; the posttest scores were much lower than the pretest scores. Recognizing the potential effect this could possibly have on the requirements of the statistical test, it was decided to eliminate these two particular cases from inclusion in the data prior to analysis using the student $t$ test. Explanation of these two aberrant scores would only be speculative, but might include personal problems, overall academic difficulties, or lack of seriousness in taking the posttest since it did not contribute to the final course grade.

An independent student $t-t e s t(n=31)$ produced a $t$ value of 2.46 at the $p=0.02$ confidence level. Mean posttest scores were higher in the experimental group than the control group across all four GPA subgroups. The most dramatic result was in the group with GPA's less than 2.5 (Table 5). Here the experimental group had mean posttest scores 12.2 points above the control group mean.

\section{Discussion}

Students in the experimental group scored higher on the posttest than students in the control group. These findings are consistent with that of previous research. This trend is more pronounced perhaps because the instructor for the lecture and CBI groups 
Appendix I (continued)

was different. Previous research indicates that when two instructors are used posttest results are more dramatic (Clark, 1985 and Kulik \& Kulik, 1987).

The close grouping of posttest scores among students in the experimental group indicates that the CBI courseware had a universally positive effect on the learning of all students. Additionally, the posttest scores of the students in the experimental group are higher than those in the control group within each GPA subgroup.

While it might be expected that those students in the top GPA group would be successful regardless of instructional method used, the results of the lowest GPA group were unexpected. CBI's positive effects on learning are most powerfully illustrated in the lowest GPA group. These students scored within one point of those in the top GPA group. Without the CBI courseware, these students would have scored comparable to their counterparts in the control group. The CBI courseware enabled them to compete equally with more successful students eliminating the learning barriers which under traditional academic teaching methods negatively effect performance resulting in lower GPA's and lower self-esteem (Rockman, 1993).

Limitations of the Study

Clearly the CBI courseware produced a positive trend in posttest scores and, therefore, a positive effect on the learning of the students in this study. However, due to the small sample size, the results of this study should be interpreted with caution. They do however support previous research in suggesting that $\mathrm{CBI}$ is a feasible alternative to the lecture and discussion format.

The Hawthome effect cannot be overlooked as a possible influence on the higher scores among the computer group on the posttëst. The novelty of exposing students to a new learning tool may have produced sufficient enthusiasm among the computer group students to encourage them to work harder and score higher on the posttest. Close controls were in place in the CBI group to ensure attendance at all sessions. With the 
Appendix I (continued)

exception of one student, all CBI group students attended all CBI sessions and viewed all the modules. Class attendance in the lecture group was not as strictly controlled nor monitored. Furthermore individual study time was not accounted for. These factors may have contributed to the higher posttest scores in the CBI group. The amount of time students spend with new material may contribute to mastery of the material and ultimately to learning.

\section{Recommendations for Further Research}

Additional trials are needed to verify the posttest trends seien in this experiment. More importantly, future research is needed to more specifically identify the characteristics of CBI that led to the trend seen in this study and previous studies with regard to the characteristics and instructional components that are responsible for these results (Keane, Norman and Vickers, 1991 and Gillingham \& Guthrie, 1987). Identifying the specific features of $\mathrm{CBI}$ that promote improvements in leaming would allow these features to be replicated in future CBI courseware and other instructional media. Furthermore, it would settle the debate over the value of CBI as a pedagogical method.

\section{Students' Comments}

Students in the computer group were asked to provide their comments regarding their experience in the form of a written survey that utilized a five point Likert-type scale Additionally, six students were randomly selected and interviewed. In general, students thought the text in the computer modules was thorough and concise. They liked the videotape segments and visuals including the pictures, graphics and icons. Comments concerning the audio aspects were less positive. For example some students enjoyed the background music while others were distracted by it. A few students expressed a desire for time for interaction with other students or an instructor to discuss material that was covered in the computer modules. 
Appendix I (continued)

Students' recommendations for improvement reflect their support for CBI and their positive feelings towards it as an instructional tool. Students wanted more video segments, more interactivity, more self-test questions. Individual interviews conducted with selected students elicited similar comments and served to reinforce and clarify the responses given on the written surveys rather than to reveal new information.

\section{Conclusion}

The purpose of this study was to evaluate the effectiveness of CBI courseware in teaching research methodology to undergraduate students. Analysis of posttest scores indicate that $\mathrm{CBl}$ is an effective tool for this purpose. Furthermore, students expressed a positive attitude toward CBI. They appreciated its completeness and conciseness in covering the course material, and enjoyed its multimedia format. Following the completion of minor improvements in the program based on student's recommendations, copies of this CBI courseware should be made available to other dietetic programs around the country and should be utilized to teach this course for its next offering. 
Appendix I (continued)

Tables

Table 1: Ranked Subject Selection By GPA

\begin{tabular}{|l|l|l|l|}
\hline Group & GPA (1) & $n=33(2)$ & $n=31$ \\
\hline 1 & $>3.5$ & 6 & 6 \\
\hline 2 & $>3.0$ but $<3.5$ & 12 & 12 \\
\hline 3 & $>2.5$ but $<3.0$ & 9 & 8 \\
\hline 4 & $<2.5$ & 6 & 5 \\
\hline
\end{tabular}

NOTE: (1) GPA is grade point average based on a 4.0 scale. (2) $n$ is the number of cases

Table 2: Pretest/Posttest Results ( $\mathrm{n}=31)$

\begin{tabular}{|l|l|l|l|l|}
\hline & \multicolumn{2}{l|}{ Control Group } & \multicolumn{2}{l|}{ Experimental Goup } \\
\hline & Mean & SD (2) & Mean & SD \\
\hline Pretest & 18.0 & 4.1 & 16.9 & 4.8 \\
\hline Posttest & 24.2 & 5.6 & 27.5 & 4.9 \\
\hline Difference Score (1) & 6.2 & 3.7 & 10.6 & 5.7 \\
\hline
\end{tabular}

NOTE (1) Difference score means for the control group and the experimental group are significant at $p=0.02$. (2) SD is standard deviation. 
Appendix I (continued)

Table 3: Pretest Score Results by GPA ( $n=31)$

\begin{tabular}{|l|l|l|l|l|l|}
\hline & \multicolumn{3}{|c|}{ Control Group } & \multicolumn{2}{l|}{ Experimental Group } \\
\hline Group & GPA (1) & Mean & SD (2) & Mean & SD \\
\hline 1 & $>3.5$ & 19.7 & 2.5 & 18.0 & 7.8 \\
\hline 2 & $3.0-3.5$ & 18.5 & 4.0 & 18.0 & 3.2 \\
\hline 3 & $2.5-2.0$ & 20.0 & 1.0 & 14.6 & 6.1 \\
\hline 4 & $<2.5$ & 11.0 & 1.4 & 17.7 & 2.1 \\
\hline
\end{tabular}

NOTE: (1) GPA is grade point average based on a 4.0 scale. (2) SD is standard deviation

Table 4: Posttest Score Results by GPA Group ( $n=31$ )

\begin{tabular}{|l|l|l|l|l|l|l|}
\hline & \multicolumn{3}{|l|}{ Control Group } & \multicolumn{3}{l|}{ Experimental Group } \\
\hline GPA (1) & Mean & SD (2) & $n(3)$ & Mean & SD & $n$ \\
\hline$>3.5$ & 28.7 & 2.3 & 3 & 28.7 & 5.5 & 3 \\
\hline $3.0-3.5$ & 24.3 & 5.3 & 6 & 27.8 & 5.5 & 6 \\
\hline $2.5-3.0$ & 24.7 & 3.5 & 3 & 26.4 & 6.4 & 5 \\
\hline$<2.5$ & 16.5 & 7.8 & 2 & 27.7 & 2.1 & 3 \\
\hline
\end{tabular}

NOTE: (1) GPA is grade point average based on a 4.0 scale. (2) SD is standard deviation.

(3) $n$ is number of cases 